\title{
The Silvicultural and Economic Impact of Professional Forestry Assistance on Timber Harvests on Non-Industrial, Private Forestland in West Virginia
}

\author{
Stuart A. Moss \\ West Virginia University
}

Follow this and additional works at: https://researchrepository.wvu.edu/etd

\section{Recommended Citation \\ Moss, Stuart A., "The Silvicultural and Economic Impact of Professional Forestry Assistance on Timber Harvests on Non-Industrial, Private Forestland in West Virginia" (2011). Graduate Theses, Dissertations, and Problem Reports. 3378.}

https://researchrepository.wvu.edu/etd/3378

This Dissertation is protected by copyright and/or related rights. It has been brought to you by the The Research Repository @ WVU with permission from the rights-holder(s). You are free to use this Dissertation in any way that is permitted by the copyright and related rights legislation that applies to your use. For other uses you must obtain permission from the rights-holder(s) directly, unless additional rights are indicated by a Creative Commons license in the record and/ or on the work itself. This Dissertation has been accepted for inclusion in WVU Graduate Theses, Dissertations, and Problem Reports collection by an authorized administrator of The Research Repository @ WVU.

For more information, please contact researchrepository@mail.wvu.edu. 
The Silvicultural and Economic Impact of Professional Forestry Assistance on Timber Harvests on Non-Industrial, Private Forestland in West Virginia

\author{
Stuart A. Moss
}

Dissertation submitted to the

Davis College of Agriculture, Natural Resources and Design

at West Virginia University

in partial fulfillment of the requirements

for the degree of

\title{
Doctor of Philosophy
}

in

Forest Resources Science

Eric Heitzman, Ph.D., Chair

Kathryn Arano, Ph.D.

John Brooks, Ph.D.

Ray Hicks, Jr., Ph.D.

Thomas Schuler, Ph.D.

Division of Forestry and Natural Resources

Morgantown, West Virginia

2011

Keywords: consulting forester, hardwood management, harvesting practices, highgrading, silviculture, timber quality

Copyright 2011 Stuart A. Moss 


\section{Abstract \\ The Silvicultural and Economic Impact of Professional Forestry Assistance on Timber Harvests on Non-Industrial, Private Forestland in West Virginia}

\section{Stuart A. Moss}

Timber harvests conducted on 90 non-industrial, private forestland properties in West Virginia were investigated to determine the effects that professional foresters have on harvest characteristics and residual stand attributes. Harvests were classified based on the type of forester involved with the harvest: 1) consulting/state service foresters representing landowners, 2) industry foresters (procurement or management) representing forest products firms, and 3) no involvement by a professional forester.

Consulting foresters removed less basal area, sawtimber volume, and timber value from the stand compared to the other two groups. Consulting foresters had less of an impact on quadratic mean diameter and displayed a lower preference for harvesting the more valuable species. Residual stands resulting from consultant harvests were more likely to be fully-stocked, contained higher proportions of basal area in acceptable growing stock and dominant/codominant crown classes, and suffered less damage from logging. There were virtually no differences between industry foresters and non-foresters for any of the harvest or residual stand attributes examined.

Each harvest was given an overall evaluation based on a combination of residual stocking level, proportion of the residual stand in acceptable growing stock, and damage to the residual trees. Nearly one-fourth of the consultant harvests received a "good" evaluation, compared to less than $10 \%$ of industry forester harvests and no harvests which lacked the involvement of a forester. Less than one-fourth of the consultant harvests received a "poor" evaluation, compared to one-half to two-thirds for the other two groups.

Four post-harvest stands representative of "good" and "poor" harvest practices were projected for 20 years into the future using the Forest Vegetation Simulator (FVS) computer growth and yield model. Twenty years after harvest, tracts subjected to "good" harvesting were projected to contain twice the volume of high-quality sawtimber and nearly three times the volume in acceptable growing stock sawtimber compared to tracts subjected to "poor" harvesting. Both "good" tracts contained more than 7,000 board feet per acre in acceptable growing stock, including more than 4,000 board feet per acre in trees 20 " DBH or greater. By contrast, "poor" tracts contained 3,000 board feet per acre or less in acceptable growing stock and contained less than 1,500 board feet per acre in trees 20 " DBH or greater. Due to the lack of a sufficient volume of quality sawtimber in the larger DBH classes on tracts subjected to "poor" harvest practices, it will likely be necessary to subject these tracts to poor harvest practices again in the future, in order to carry out a commercial harvest. 
"Good" harvest practices also had less impact on the species composition of the postharvest stand, with most major species retaining dominance in the residual stand. Significant shifts in species composition occurred on tracts subjected to "poor" harvest practices, with lessdesirable species replacing some of the more desirable species. These effects were persistent throughout the 20-year projection period.

Simulated "high-grade" harvests were performed in FVS for two tracts subjected to "good" harvest practices. This was done to eliminate differences in initial species composition and timber volume and value between tracts. After adjusting stumpage prices to account for differences in tree quality, average $\mathrm{DBH}$, and harvesting costs, subjecting tracts to "good" harvest practices resulted in three to five times the timber value per acre after 20 years, compared to subjecting these same tracts to "high-grading". Despite this, present value (total of initial harvest value and discounted future timber value) was higher for the "high-grade" scenarios at real discount rates greater than $3 \%$.

"Poor" harvest practices resulted in real internal rates of return (IRR) of 5\% and 7\%, whereas "good" harvest practices resulted in real IRRs of about 4\%. Assuming accelerated growth rates for the "good" tracts, resulting from a higher proportion of dominant/co-dominant trees, real IRR increased to 5\%. This is competitive with IRRs from practicing "poor" harvest practices, especially if one takes into account the increased exposure to market risk inherent with "poor" harvest practices.

A post-harvest survey of landowners who participated in this study indicated general satisfaction with harvesting outcomes. Landowners who used a consulting forester were more satisfied with the price they received for their timber compared to those who dealt directly with a logger. Landowners who used a consulting forester were more satisfied with the amount of timber harvested and the overall harvest outcome and were more likely to feel that the harvest met their objectives, compared to landowners who worked with industry foresters. Few serious problems were reported by landowners and these mostly dealt with damage to the residual trees, the condition of roads after harvest, and concerns about the future of their forest.

Landowners' satisfaction was only weakly correlated with the actual physical attributes of the harvest and the residual stand, but some trends were noteworthy. When harvests favored the more valuable species, landowners became less satisfied with logger performance and the overall harvest outcome and were less likely to feel that the harvest met their objectives. As damage to residual trees increased, landowners were less satisfied with both logger performance and the condition of the residual stand and were more likely to report problems with damage to the residual stand. As harvest intensity increased, landowners were less satisfied with the amount of timber harvested, logger performance, condition of the residual trees, and overall harvest outcomes. They were also more likely to report problems with damage to residual trees.

Previous investigations into timber harvesting in Appalachia have suggested that professional foresters have little impact on the type of harvest conducted. This study clarifies that research by demonstrating that the type of forester involved has much more influence on how harvests are conducted than whether or not a forester is involved. 


\section{Acknowledgements}

Funding for this project was provided by the West Virginia Division of Forestry, which also generously provided access to information from their Timbering Notification Forms which was instrumental to the completion of this project. The author would like to thank the following members of the field crews for their assistance with this project: Madison Akers, Dave Dyer, Charles Carpenter, and Corey Bonasso. A special thank-you goes to Matthew Parsons who served as Field Crew Chief. Matt's efforts were crucial to getting the field work completed correctly and in a very timely manner. I want to offer my gratitude to Eric Heitzman, Kathryn Arano, John Brooks, Ray Hicks (who came out of retirement!), and Tom Schuler for taking time out of their busy schedules to serve on my committee. It is a largely thankless task, but one that is greatly appreciated. Lastly, I would like to thank the many landowners who graciously agreed to participate in this project and allowed us unrestricted access to their property and provided much-needed information about their property and the timber harvest operations. It is my hope that their participation in this project will benefit other forestland owners, present and future. 


\section{Table of Contents}

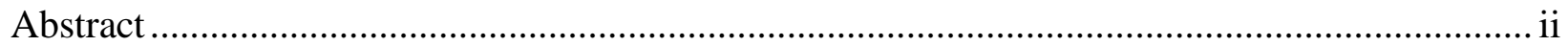

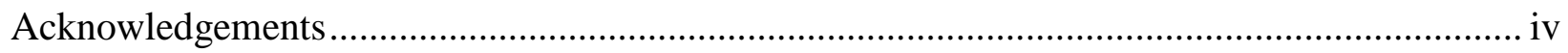

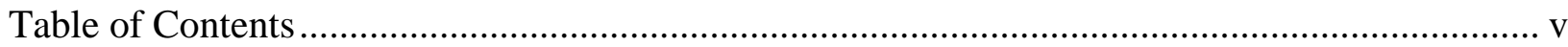

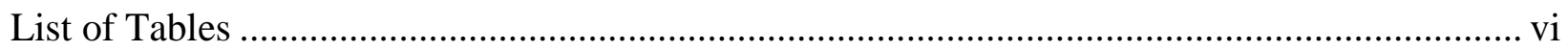

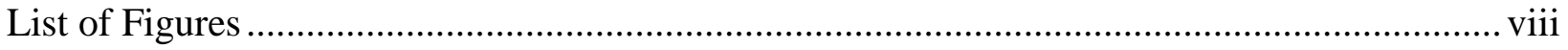

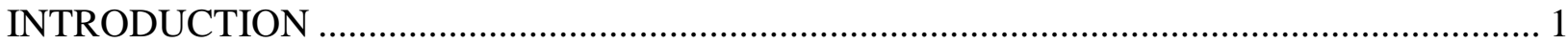

CHAPTER I - The Impact of Forester Type on Harvest and Residual Stand Attributes ............. 9

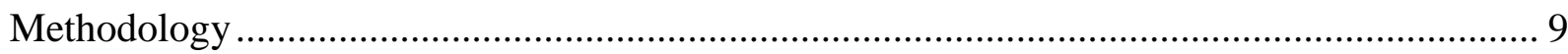

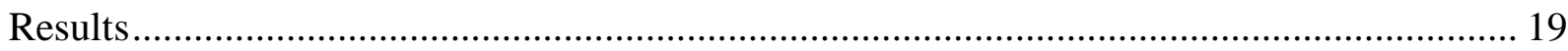

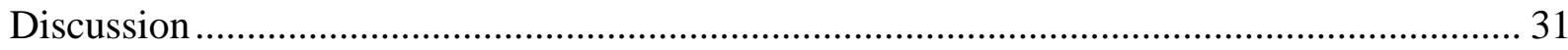

CHAPTER II - The Impact of Timber Harvest Practices on Future Stand Attributes ................ 36

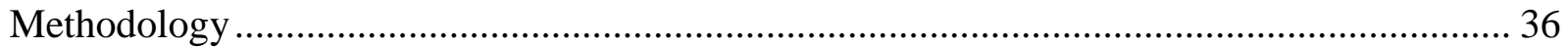

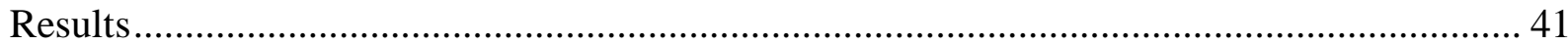

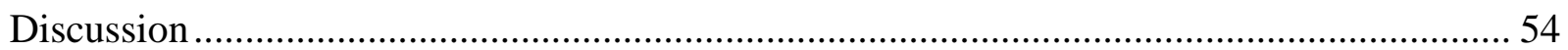

CHAPTER III - The Long-term Economic Impacts of "Good" and "Poor" Harvest Practices ... 60

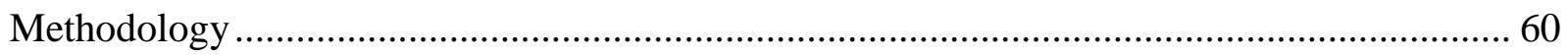

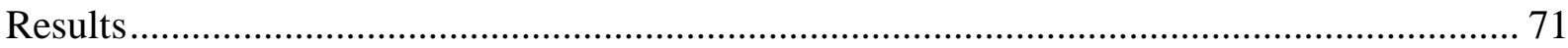

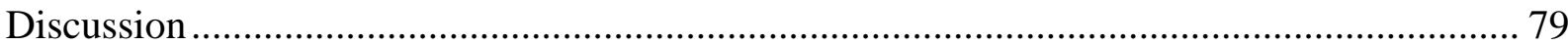

CHAPTER IV - Post-harvest Survey of Participating Landowners ....................................... 85

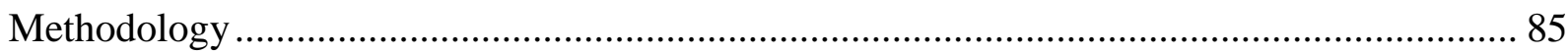

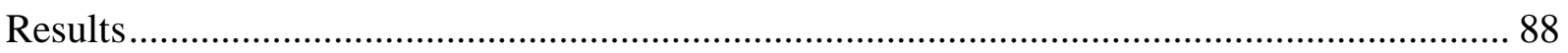

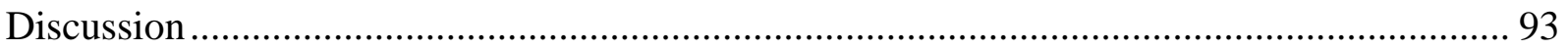

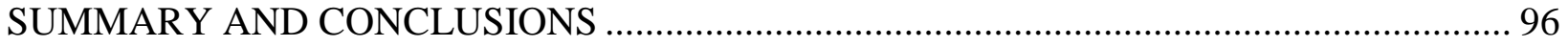

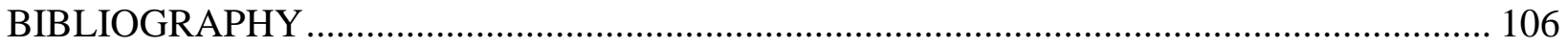

APPENDIX A - Regression Equations to Predict DBH from Stump Diameter....................... 111

APPENDIX B - Indicated Stumpage Prices by Species, Tree Grade and DBH..................... 114

APPENDIX C - Sample Screen for the Central Appalachian Harvesting Analyzer ................. 119

APPENDIX D - Landowner Post-Harvest Survey ....................................................... 121 


\section{List of Tables}

Table 1. Number of properties eligible for inclusion in the study within each former

WVDOF management district.

Table 2. Guidelines for assessing future sawtimber potential (tree quality)...................13

Table 3. Residual tree damage assessment guidelines................................... 13

Table 4. Criteria used to perform an overall harvest evaluation for each property..............18

Table 5. Mean values, by forester type, for various harvest removal attributes................19

Table 6. Mean values, by forester type, for various residual stand attributes...................20

Table 7. Mean values, by forester type, for various quadratic mean diameter parameters........20

Table 8 . Mean values, by forester type, for various stocking level parameters................21

Table 9. Results of multiple regression analysis of the percentage of residual basal area damaged as a function of basal area harvested and forester type $\ldots \ldots \ldots \ldots \ldots \ldots \ldots \ldots \ldots . \ldots \ldots$

Table 10. Percentage of basal area harvested, by species and diameter class, for each

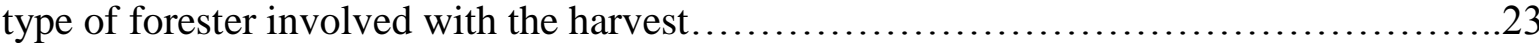

Table 11. Percentage of basal area in acceptable growing stock, percentage of basal area significantly damaged, and percent stocking level for residual stands on Tracts $2 \mathrm{C} 3,2 \mathrm{C} 4$, 4I6, and 4N1 and average values for all tracts rated as "Good" or "Poor"......36

Table 12. Criteria used to select trees for hypothetical "high-grade" harvest of reconstructed

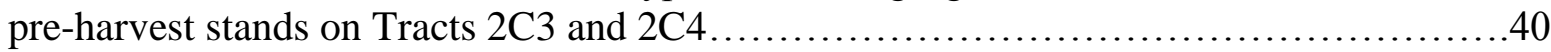

Table 13. Pre-harvest, post-harvest and 10- and 20-year projected whole-stand parameters for Tract 2C3, assuming "good" and "high-grade" harvest scenarios

Table 14. Pre-harvest, post-harvest and 10- and 20-year projected whole-stand parameters for Tract 2C4, assuming "good" and "high-grade" harvest scenarios

Table 15. Pre-harvest, post-harvest and 10- and 20-year projected whole-stand parameters for Tract $4 \mathrm{I} 6$

Table 16. Pre-harvest, post-harvest and 10- and 20-year projected whole-stand parameters for Tract $4 \mathrm{~N} 1$ 
Table 17. Predicted board-foot lumber yield, by grade; total lumber value; lumber value per MBF tree scale; and indicated stumpage price for Forest Service Grade 2 sugar maple trees from 12 " to 24 " DBH that contain 32 merchantable feet per tree...

Table 18. Simulated timber harvesting costs and resulting adjustments to timber stumpage prices for Tracts $2 \mathrm{C} 3,2 \mathrm{C} 4,4 \mathrm{I} 6$, and $4 \mathrm{~N} 1$ under various harvesting scenarios over a 20-year projection period.

Table 19. Initial stand, harvested, and projected future timber volumes and value for Tracts $2 \mathrm{C} 3$ and 2C4, under "good" and "high-grade" harvest scenarios, and Tracts 4I6 and $4 \mathrm{~N} 1$

Table 20. Number of survey responses by satisfaction level and type of forester involved in the sale for various questions related to landowner satisfaction

Table 21. Number of survey responses by severity of problem encountered and type of forester involved in the sale for various questions related to problems with the timber sale.

Table 22. Correlations between various survey question responses and physical stand attributes, using Spearman's rank-order correlation.

Table A-1. Linear regression equations to predict DBH from stump diameter for various species in West Virginia. 


\section{List of Figures}

Figure 1. Percentage of harvested properties classified into residual stocking classes by type of forester involved with the harvest.....................................................

Figure 2. Percentage of harvested properties classified into acceptable growing stock classes

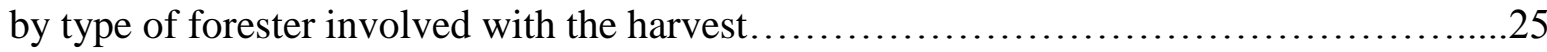

Figure 3. Percentage of harvested properties classified into residual damage classes by type of forester involved with the harvest............................................... 26

Figure 4. Percentage of harvested properties classified into sawtimber basal area removal classes by type of forester involved with the harvest..................................27

Figure 5. Percentage of harvested properties classified into QMD reduction classes by type

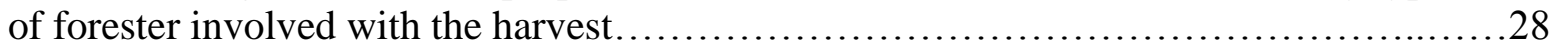

Figure 6. Percentage of harvested properties classified into species preference ratio classes

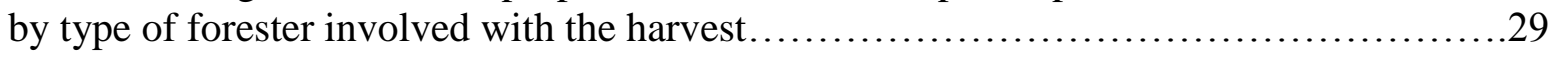

Figure 7. Percentage of harvested properties classified into overall harvest evaluation classes by type of forester involved with the harvest.......................................... 30

Figure 8. Projected 10-year sawtimber volumes, by tree quality, for tracts subjected to "good" harvest practices $(2 \mathrm{C} 3$ and $2 \mathrm{C} 4)$ and tracts subjected to "poor" harvest practices (4I6 and 4N1).

Figure 9. Projected 20-year sawtimber volumes, by tree quality, for tracts subjected to "good" harvest practices and tracts subjected to "poor" harvest practices.

Figure 10. Projected 10-year sawtimber volumes, by diameter class, for tracts subjected to "good" harvest practices and tracts subjected to "poor" harvest practices.

Figure 11. Projected 20-year sawtimber volumes, by diameter class, for tracts subjected to "good" harvest practices and tracts subjected to "poor" harvest practices.

Figure 12. Projected 20-year sawtimber volumes, by tree quality, for Tract $2 \mathrm{C} 3$ under "good" and "high-grade" harvest scenarios.

Figure 13. Projected 20-year sawtimber volumes, by tree quality, for Tract $2 \mathrm{C} 4$ under "good" and "high-grade" harvest scenarios.

Figure 14. Projected 20-year sawtimber volumes, by tree diameter class, for Tract 2C3 under "good" and "high-grade" harvest scenarios. 
Figure 15. Projected 20-year sawtimber volumes, by tree diameter class, for Tract 2C4 under "good" and "high-grade" harvest scenarios..................................50

Figure 16. Projected 20-year sawtimber volumes, by species, for Tract 2C3 under "good"

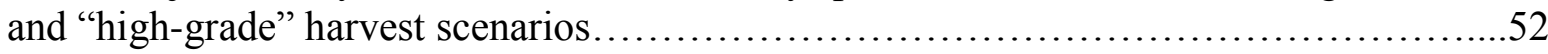

Figure 17. Projected 20-year sawtimber volumes, by species, for Tract 2C4 under "good"

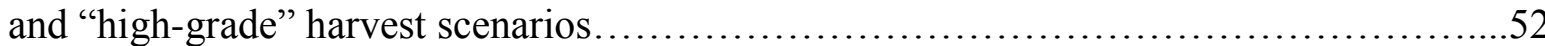

Figure 18. Projected 20-year sawtimber volumes contained in acceptable growing stock trees which are at least 20" DBH, for Tract 2C3 (under good and high-grade scenarios), Tract 2C4 (under good and high-grade scenarios), Tract 4I6, and Tract 4N1...53

Figure 19. Indicated stumpage value by tree DBH and Forest Service tree grade for sugar maple in West Virginia during the summer of 2007.

Figure 20. Present values for Tract 2C3 under "good harvest", "high-grade harvest", and "good harvest with accelerated growth rate" scenarios over a 10-year projection period at real discount rates from $1.0 \%$ to $10.0 \%$

Figure 21. Present values for Tract 2C4 under "good harvest", "high-grade harvest", and "good harvest with accelerated growth rate" scenarios over a 10 -year projection period at real discount rates from $1.0 \%$ to $10.0 \%$

Figure 22. Present values for Tract 2C3 under "good harvest", "high-grade harvest", and "good harvest with accelerated growth rate" scenarios over a 20 -year projection period at real discount rates from $1.0 \%$ to $10.0 \%$. .75

Figure 23. Present values for Tract 2C4 under "good harvest", "high-grade harvest", and "good harvest with accelerated growth rate" scenarios over a 20 -year projection period at real discount rates from $1.0 \%$ to $10.0 \%$.

Figure 24. Net present values for Tracts 2C3, 2C4, 4I6, and 4N1 over a 20-year projection period at real discount rates from $1.0 \%$ to $10.0 \%$, assuming no growth rate adjustments for "good" tracts

Figure 25. Net present values for Tracts $2 \mathrm{C} 3,2 \mathrm{C} 4,4 \mathrm{I} 6$, and $4 \mathrm{~N} 1$ over a 20 -year projection period at real discount rates from $1.0 \%$ to $10.0 \%$, assuming accelerated growth rates for "good" tracts (2C3 and 2C4).

Figure A-1. Linear regression equations to predict DBH from stump diameter for northern red oak for each of the six WVDOF districts in West Virginia.

Figure A-2. Linear regression equations to predict DBH from stump diameter for yellowpoplar for each of the six WVDOF districts in West Virginia. 
Figure A-3. Linear regression equations to predict DBH from stump diameter for sugar maple for each of the six WVDOF districts in West Virginia...

Figure B-1. Indicated stumpage value by tree DBH and Forest Service tree grade for red maple in West Virginia during the summer of 2007

Figure B-2. Indicated stumpage value by tree DBH and Forest Service tree grade for black

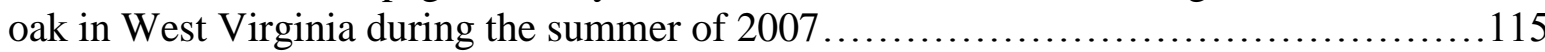

Figure B-3. Indicated stumpage value by tree DBH and Forest Service tree grade for black

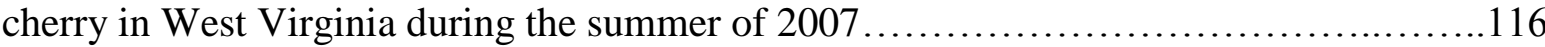

Figure B-4. Indicated stumpage value by tree DBH and Forest Service tree grade for white

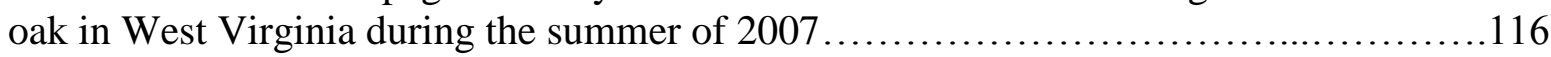

Figure B-5. Indicated stumpage value by tree DBH and Forest Service tree grade for yellow-poplar in West Virginia during the summer of 2007.

Figure B-6. Indicated stumpage value by tree DBH and Forest Service tree grade for northern red oak in West Virginia during the summer of 2007

Figure B-7. Indicated stumpage value by tree DBH and Forest Service tree grade for chestnut oak in West Virginia during the summer of 2007

Figure B-8. Indicated stumpage value by tree DBH and Forest Service tree grade for miscellaneous hardwoods in West Virginia during the summer of 2007 


\section{INTRODUCTION}

Approximately $87 \%$ of West Virginia's forestland and standing timber volume is owned by the private sector, which includes the forest products industry (owners who also own woodutilizing manufacturing facilities), institutional owners/investors (timberland investment management organizations, real estate investment trusts, non-forest products corporations, etc.), and non-industrial private forestland owners (NIPFs) (Widmann et al. 2010). This latter group, the so-called "family forests", comprises 7.4 million acres, or $60 \%$ of the forests within the state. These 260,000 landowners have various reasons for owning forestland, including recreation, wildlife management, timber production, inheritance, pride of ownership, and a desire to live in a rural environment. Timber production is not a primary ownership objective for many West Virginia timberland owners (Fraser and Magill 2000; Joshi 2007), a sentiment echoed in other eastern states (Hodge and Southard 1992; Olson 1979). In the most recent survey of West Virginia NIPFs, only 10\% listed timber production as "very important" or "important" reasons for owning forestland (Widmann et al. 2010). However, these landowners owned nearly onethird of the state's forests.

For many NIPF landowners, non-commodity forest values may exceed the value of income received from timber production. As our eastern forests undergo inter-generational ownership transfers, the primacy of non-timber forest amenities appears to be increasing (Hodges and Cubbage 1990). This is noteworthy, since 20\% of the state's forestland owners are "new" owners, having owned their forestland for less than 10 years (Widmann et al. 2010). This trend shows no sign of slowing, since $95 \%$ of the state's NIPFs are at least 45 years old and onefifth are over age 65. Increasingly, our eastern hardwood forests are becoming a place to live and recreate, and are no longer seen as a "factory" for the production of raw materials for wood products manufacturing facilities. Recent research efforts and government assistance programs have both shifted focus from how NIPFs influence timber supply to addressing the enhancement of a wide array of forest amenities on NIPF lands (Egan 1997).

Nevertheless, a survey conducted in 1999-2000 indicated that 44\% of the state's NIPFs had harvested timber from their land at some time in the past (Fraser and Magill 2000). For 
certain segments of the NIPF ownership, timber production remains primary to the landowner, even if non-timber uses are also important. Nearly two-thirds of West Virginia's American Tree Farm System (ATFS) members felt that forests should be used primarily for timber production and more than $80 \%$ felt that forest landowners should be encouraged to harvest timber (Egan et al. 1997). ATFS members' attitudes regarding timber production are important, as the average West Virginia Tree Farm contains 330 acres. Additionally, 68\% of the state's ATFS members had harvested timber from their property at least once and nearly one-third had harvested timber two or more times. Although it is tempting to characterize the typical NIPF as being interested in aesthetics and wildlife and indifferent to timber production, there still exists an NIPF segment that is interested in, and active in, timber production. This segment is important to timber production in the state, since they own significant acreage.

Although most NIPFs consider privacy, aesthetics, recreation, biodiversity, and place of residence as their primary reasons for ownership, one must keep in mind that $70 \%$ of the state's forestland owners own 20 acres or less (Widmann et al. 2010). Thus, it should come as no surprise that timber production is not primary for a majority of landowners, as this size of ownership does not possess the economies of scale suitable for timber production. However, over $70 \%$ of the state's forestland is contained in parcels 50 acres or larger, with nearly half in parcels 100 acres or larger. Although the number of landowners who own large acreage is small (fewer than 10\% own 100 acres or more), they still control a significant portion of the forest resource. It is also likely that these landowners are much more interested in timber production, relative to the general NIPF population, as noted with the survey of the state's Tree Farmers.

Because NIPFs control such a large portion of the resource, their management, or lack thereof, is crucial to the future timber supply, the provision and enhancement of non-timber forest resources, and protection of the environment. Since these landowners are rarely professional foresters themselves, the long-term fate of our eastern forests lies largely in the hands of non-professionals. Logically, it would seem important to provide professional and technical assistance to this important landowner segment if we are to properly manage our forest for its many important amenities. Because timber harvesting can have a very dramatic and long- 
lasting impact on the forest, it stands to reason that professional involvement in timber harvesting is crucial to addressing forest management concerns.

Foresters have long argued that involvement by a professional forester in the timber sale process can benefit landowners in several ways. Foresters can use their knowledge of silviculture and other facets of the profession to best meet landowners' objectives for their forests. Second, a foresters' knowledge of timber values, markets, and the timber sale process should result in higher sale prices compared to landowners who sell without professional assistance. Since foresters are intimately familiar with Best Management Practices and other aspects of environmental protection, harvests supervised by professional foresters should be less likely to significantly degrade water and soil quality. Finally, a forester is likely to leave a "better" residual stand after harvesting that will yield increased future benefits, financial and otherwise, for the landowner.

Despite the apparent validity of these widely-held views, there is scant evidence to support these claims in the Appalachian region. Rather grim assessments of harvesting practices among NIPF landowners in New York, Pennsylvania, and West Virginia indicate that many landowners cut their largest, most valuable trees and leave the less valuable trees after harvest, regardless of whether or not a forester is involved with the harvest (Fajvan et al. 1998; Pell 1998; Nyland 1992; Nyland 2001). This type of practice - harvesting without regard to silviculture - is exactly the type of practice that is supposedly avoided when professional foresters are involved in harvest planning.

By contrast, evidence from the southern pine region suggests that involvement by foresters in timber harvesting results in less timber being removed, more standing volume after harvest, and a higher price received by the landowner for their timber, compared to harvests handled without benefit of professional assistance (Cubbage et al. 1985; Cubbage et al. 1988; Bullard and Moulton 1989; Munn 1996). However, significant differences exist between the southern pine region and the Appalachian hardwood region, both in terms of forest characteristics and the dominant harvesting practices, and it is unwise to extrapolate these results to the Appalachian region. The greater complexity of hardwood forests, combined with the 
preponderance of partial cutting in the Appalachian region relative to the southern pine region, increases the potential for foresters working with eastern hardwood forests to impact harvest practices and characteristics of the residual stand. However, no empirical evidence exists to suggest that this is, indeed, the case.

A study by Egan et al. (1998) found that $71 \%$ of the timber harvests on NIPF lands in West Virginia were performed without the involvement of a professional forester. This trend appears evident throughout the eastern hardwood region (Nyland 1992). Such findings support the belief among many in the forestry community that poor forest practices are employed on a great many acres in the state. Poor harvesting practices not only affect future stand attributes, such as stocking level, species composition and timber quality, but can have environmental consequences as well, such as lower compliance with Best Management Practices and increased soil damage (Egan 1993).

There are numerous possible reasons for the proliferation of poor harvest practices on NIPF lands. Many landowners lack knowledge about the ecological and economic consequences of harvesting practices and are unaware of professional assistance that is available, and so are in a poor position to make informed management and harvesting decisions. Jones et al. (1995) concluded that "without adequate knowledge or help from a forester ... even those (landowners) who embrace a land ethic can, and often do, make timber harvesting decisions that damage the site and residual stand." Other landowners are strongly motivated by financial considerations or have ownership objectives unrelated to the forest per se (e.g. farming or future development).

An important factor favoring high-grading is the short-term financial benefits that accrue to timber buyers who harvest only the best timber from a site. Since the decision about how the harvest is to be implemented is often left up to the timber buyer, rather than the landowner or a consulting forester assisting the landowner, it stands to reason that a majority of buyers would recommend harvest practices that yield the greatest financial gain for themselves.

These financial benefits may extend to the landowner, as well. Reed et al. (1986) examined financial returns from eight harvesting practices in northern hardwood stands ranging 
from severe diameter-limit cuts to light improvement cuts. They concluded that 5", 12" and 16" diameter-limit harvests were the most financially rewarding in the short-run, with 16 " diameterlimit cuts providing the best combination of financial returns and regular income from timber harvesting. However, the authors cautioned that such intensive harvesting, especially the 5" and 12" diameter-limit harvests, may not be as financially attractive over the long-term, since subsequent timber harvests may not be possible for 20 to 40 years after harvesting. However, landowners may be unaware of the long-term financial consequences of harvesting practices or may be so focused on short-term gains that long-term consequences become irrelevant.

In a case study of six NIPF landowners in Pennsylvania, Brubaker et al. (2006) found that landowners were surprisingly adept at estimating the current value of their standing timber. However, they displayed much less skill at estimating future timber value and did not demonstrate a basic understanding of the factors that affect future timber value. When presented with information about the true value of their timber (e.g. they discovered that their timber was worth more than they had anticipated), landowners expressed an increased interest in harvesting their timber and/or increasing the intensity of the harvest, such as considering a 12" diameterlimit harvest rather than a 16" diameter-limit harvest. Unfortunately, the realization that their timber was more valuable than originally thought did not increase landowners' interest in managing their forest or growing more timber. This provides strong evidence that landowners are more focused on short-term, rather than long-term, financial considerations when making decisions about their forest.

The end result of high-grading and other non-silvicultural harvest practices is a shift in species composition and a significant reduction in timber quality. Although silvicultural harvest practices, such as single-tree selection, often result in a long-term shift in species composition towards more shade tolerant species (Schuler and Gillespie 2000; Smith and Miller 1987), the impact on species composition is magnified by poor harvest practices that favor removing the more desirable species. In timber stands harvested in eastern Kentucky between 1990 and 2000, nearly $80 \%$ of the basal area in northern red oak and yellow-poplar trees 16 " DBH and larger was removed (Luppold and Bumgardner 2009). By contrast, harvesting removed less than half of the basal area in chestnut oak 16" DBH and larger, only about one-third of the red maple 16" 
DBH and larger, and virtually none of the beech 16" DBH and larger. For virtually all species, the percentage of basal area removed in trees 12 "-15" DBH was less than half the percentage of basal area removed in trees 16" DBH and larger. In West Virginia, 36\% of the harvests surveyed in 1995 showed basal area reductions of at least 80\% for northern red oak, white oak, yellowpoplar, ash, and black cherry (Fajvan et al. 1998).

As a consequence of species-selective harvesting and partial harvests that favor more shade tolerant species, northern red oak volume in the Appalachian region has increased only slightly more than 5\% over the past two decades, while sugar maple and red maple volumes have increased by $24 \%$ and 35\%, respectively (Luppold and Bumgardner 2009).

One confounding factor not addressed in previous studies of forester involvement in harvesting is whether or not the forester represents the landowner (i.e. a private consulting forester or state service forester) or represents the buyer (i.e. a procurement or management forester employed by a forest products firm). The relationship between the forester and landowner could significantly influence how the forester conducts the harvest. Since the interests of consulting/service foresters are more closely aligned with those of the landowner, vis-à-vis a forester working for the buyer, it stands to reason that a consulting/service forester might conduct the sale and impact the residual stand in a much different manner than a forester working for the purchaser, whose interests may run contrary to the landowner. However, there have been no studies in the Appalachian hardwood region to test this hypothesis.

If economic returns are still an important part of private forest decision-making, as suggested by Pelkki and Gracey (1998), determining the impact that professional forestry assistance has on the total economic returns from timber harvesting is an important measure of the effectiveness of the profession to meet landowner needs.

This project was designed to compare partial timber harvests conducted by three groups: 1) consulting/state service foresters, 2) industry/procurement foresters, and 3) non-foresters, utilizing the cooperation of 90 landowners throughout the state who had timber harvested from their property during a two-year period (2005 and 2006). Post-harvest inventories of these 
properties (30 for each forester type) were conducted to measure attributes of the residual trees (e.g. species, size, value, quality, amount of logging damage); estimate the species, volume and value of timber harvested; and assess the characteristics of the harvest (e.g. percentage of basal area, volume and value removed; change in quadratic mean diameter and stocking level). Growth projections of the residual stands were made for 10 and 20 years after harvesting to assess the long-term impacts of harvesting on species composition, timber volume and quality, and tree size distribution. Utilizing stumpage prices that reflect the effects of tree quality and DBH on value, financial analyses were performed to assess the long-term economic impacts of various harvesting practices.

This project was restricted to evaluating the impact professional foresters have on partial timber harvests. Since virtually all merchantable timber is removed during a clearcut harvest, it is unlikely foresters would exert much influence on either the trees that are harvested or the residual stand composition. In addition, our analysis of timber harvest notifications provided by the Division of Forestry indicates that over $90 \%$ of the timber harvests in West Virginia are some form of partial harvest, so foresters' impact on these types of harvests is most relevant.

Additionally, this study evaluated landowners' level of satisfaction with the timber harvests conducted on their properties and their perceptions of problems encountered during and immediately after harvesting. Landowner satisfaction was then correlated to various physical attributes of the harvest and residual stand to determine how well landowner perception matched physical reality.

Results of this research can be used to educate landowners of the usefulness of professional forest management during the timber sale process, using substantial and quantifiable numbers. Conversely, should these findings suggest that professional forest management has an insignificant impact on timber harvesting and forest management in the state, this will identify a serious shortcoming in the services provided by the profession and will hopefully provide stimulation to address these issues. Finally, this study provides important information on the sustainability of Appalachian hardwood forests owned by the NIPF sector and the influence, or lack thereof, of professional forestry assistance on sustainability. 
This project consists of four parts: 1) the impact of consulting/service foresters, industry foresters, and non-foresters on the physical characteristics of timber harvests and residual stand attributes; 2) the contrasting impacts of harvest practices on future stand attributes; 3) the longterm financial consequences to the landowner of various harvest practices; and 4) a post-harvest survey of landowners who participated in the study to assess their level of satisfaction with the harvest and identify their concerns regarding the harvest and the future of their forest. Each part is presented in a separate chapter. 


\section{CHAPTER I}

\section{The Impact of Forester Type on Harvest and Residual Stand Attributes}

The first phase of the project was to access the characteristics of timber harvests conducted by the three forester types through investigations and field measurements of recently harvested sites. This data was also used to access the physical attributes of the post-harvest stands.

\section{Methodology}

\section{Sample Selection}

Excel spreadsheets containing information on all timber harvests conducted in West Virginia during 2005 and 2006 were provided by the West Virginia Division of Forestry (WVDOF) in early 2007. These spreadsheets contained information on the type of timber harvest, sale acreage, landowner's name and address, and location of the property (county and latitude/longitude coordinate). Using this information, the lists were pared to include only partial harvests (no clearcuts) of at least 20 acres in size on properties owned by non-industrial, private, forestland (NIPF) owners. The NIPF classification excludes forestland owned by all government agencies, forest products manufacturing firms and other industrial owners (e.g. coal companies, railroads, etc.). The NIPF classification does include non-industrial forestland investment entities, such as real estate investment trusts (REITs) and timberland investment management organizations (TIMOs). This list was further pared to eliminate duplicate sales on a single property, resulting in a list of 2,498 NIPF landowners who had made partial harvest timber sales on their properties during 2005 and 2006.

In March 2007, every landowner on the timber harvest list was contacted by mail to: 1) verify that a timber harvest occurred on their land, 2) determine what type of forester, if any, was involved in the sale, and 3) request their willingness to participate in the study by allowing us to 
inspect and collect inventory data from their property. Within three months, 273 landowners (11\%) had responded in the affirmative to items 1 and 3 and had agreed to participate in the study.

Eligible properties were divided into six groups according to the former WVDOF management districts in which the properties lie (Table 1). This was done to ensure that samples were well-distributed throughout the entire state.

Table 2. Number of properties eligible for inclusion in the study within each former WVDOF management district.

\begin{tabular}{|c|c|}
\hline WVDOF District & Number of Eligible Properties \\
\hline \hline 1 & 68 \\
\hline 2 & 30 \\
\hline 3 & 72 \\
\hline 4 & 21 \\
\hline 5 & 34 \\
\hline 6 & 45 \\
\hline Total & $270 *$ \\
\hline
\end{tabular}

* - three respondents sold property in two or more districts

During the spring and early summer of 2007, we visited each WVDOF District office to obtain copies of the Timbering Operation Notification Forms for each eligible sale. This was necessary to obtain maps of the properties and to verify information provided by the landowners.

Within each district, we randomly selected: 1) five properties for which the landowner indicated they had used a consulting/state service forester to assist with the sale, 2) five properties for which the landowner indicated that only an industry/procurement forester was involved in the sale, and 3) five properties for which the landowner indicated that no professional forester was involved. For some districts, there were an insufficient number of eligible properties for certain forester classifications (e.g. there were only two landowners in District 4 who used a consulting forester to assist with the sale). In these cases, additional properties for 
that forester type were selected from adjoining districts to ensure that a total of 30 properties were selected for each forester type.

After initial selection of the properties, both information provided by the landowner and information provided on the Timbering Operation Notification Forms were scrutinized to ensure that the forester classification provided by the landowner was correct. The following criteria were used to classify each sale according to the type of professional involved:

- “Consulting Forester" - an individual or firm that provides forest management consulting services to the public, for a fee. Such individuals must be Registered Professional Foresters (or Forest Technicians) in West Virginia and must not be employed by forest products companies nor engage in the buying and selling of timber or timberland for themselves or on behalf of their employer. Foresters employed by forest products companies that also provide consulting services and foresters involved with industrial landowner assistance programs were specifically excluded from this classification.

- "State Service Forester" - an individual employed by the WVDOF who is also a Registered Professional Forester (or Forest Technician) in West Virginia.

- "Industry/Procurement Forester" - any Registered Professional Forester (or Forest Technician) not classified as a "Consulting Forester" or "State Service Forester".

- "Non-forester" - all individuals who do not meet any of the above criteria.

"Registered Professional Forester" and "Registered Forest Technician" status was verified using the $42^{\text {nd }}$ Annual Report and Roster of Members published by the West Virginia State Board of Registration for Foresters.

In short, professional foresters whose involvement in the sale clearly indicated that they fully represented the seller (landowner) were classified as "consultant/service forester". Professional foresters whose involvement indicated that they fully or partially represented the 
buyer were classified as "industry forester". All individuals who were not Registered Professional Foresters / Forest Technicians were classified as "non-forester", regardless of whether their interests were aligned with the seller or buyer.

Our review of the information provided by the landowners indicated some confusion on the part of the landowners. For example, some foresters identified by landowners as "consulting foresters" were, in fact, procurement foresters representing the timber buyer. Some individuals identified by landowners as "industry foresters" were not professional foresters, but merely employees of a harvesting contractor. In these cases, the sales were re-classified according to the criteria listed above, rather than the landowner's perception, and new properties were randomly selected to ensure an equal sample size of 30 properties for each forester type. If it was impossible to determine the proper forester classification for a sale with near certainty, the sale was excluded from consideration.

\section{Field Measurements}

Field work was performed during the summer and fall of 2007 by three two-person crews. Circular one-tenth acre inventory plots were established throughout each selected property on a systematic grid. Sampling intensity was one plot per harvested acre, with a minimum of 20 plots and a maximum of 30 plots on each property. Sampling was confined to areas which had been recently harvested. Tree species, stem diameter at 4.5 feet above groundline $(\mathrm{DBH})$ and canopy position (dominant/co-dominant, intermediate or suppressed) were measured for all living residual trees $\geq 4.6$ inches DBH. In addition, each tree was evaluated for future sawtimber potential, as outlined in Table 2. An attempt was made to estimate the potential future U.S. Forest Service tree grade for each tree, based on the number and severity of defects within the butt log (Miller et al. 1986). Due to the lack of standardized criteria for veneer grades, no attempt was made to assess residual trees for future veneer potential. 
Table 2. Guidelines for assessing future sawtimber potential (tree quality).

\begin{tabular}{|c|c|}
\hline Tree Quality & Description \\
\hline \hline 1 & Above-average quality; potential for high-grade sawtimber \\
\hline 2 & Average quality; potential for average-quality sawtimber \\
\hline 3 & Below-average quality; low potential for sawtimber \\
\hline 4 & Poor quality; no potential for sawtimber \\
\hline 5 & Cull / non-merchantable \\
\hline
\end{tabular}

When present, damage to residual trees was quantified as noted in Table 3.

Table 3. Residual tree damage assessment guidelines.

\begin{tabular}{|c|c|c|}
\hline \multirow{2}{*}{ Type of Damage } & Severity Code & Description \\
\hline \hline \multirow{3}{*}{ Stem wound in contact with ground } & 1 & Area exposed $<100$ sq. in. \\
\cline { 2 - 3 } & 2 & Area exposed is $100-500$ sq. in. \\
\cline { 2 - 3 } & 3 & Area exposed $>500$ sq. in. \\
\hline \multirow{2}{*}{$\begin{array}{c}\text { Stem wound on butt log (not in contact } \\
\text { with ground) }\end{array}$} & 1 & Area exposed $<100$ sq. in. \\
\cline { 2 - 3 } & 2 & Area exposed is $100-500$ sq. in. \\
\cline { 2 - 3 } Stem wound above butt log & 3 & Area exposed $>500$ sq. in. \\
\cline { 2 - 3 } & 1 & Area exposed $<100$ sq. in. \\
\cline { 2 - 3 } & 2 & Area exposed is $100-500$ sq. in. \\
\hline \multirow{3}{*}{ Crown broken or missing } & 3 & Area exposed $>500$ sq. in. \\
\cline { 2 - 3 } & 1 & $<25 \%$ of crown removed \\
\cline { 2 - 3 } & 2 & $25-50 \%$ of crown removed \\
\hline \multirow{3}{*}{ Main stem leaning or broken } & 3 & $>50 \%$ of crown removed \\
\cline { 2 - 3 } & 2 & Tree leaning $<22.5^{\circ}$ \\
\cline { 2 - 3 } & 3 & Tree leaning $\geq 22.5^{\circ}$ \\
\hline
\end{tabular}

Species, stump height and stump diameter (average of two measurements) were recorded for every recently-harvested stump $\geq 6$ " in average diameter located within the one-tenth acre sample plots (severely rotted stumps that appeared to have resulted from prior harvests were ignored). On 39 properties, trees to be harvested had been designated as such with tree-marking paint (29 of 30 consulting forester sales, 8 of 30 industry forester sales and 2 of 30 non-forester sales). On these sites, marked trees that were left un-harvested by the logger were considered to be "harvested" and their DBH was measured directly, rather than being estimated from stump diameter. This was done to ensure that the project evaluated forester performance (how the 
forester intended to harvest the site) rather than logger performance (how the site was actually harvested). The incidence of un-harvested marked trees was extremely low (65 trees out of $5,934$ stumps + marked residuals, or just over $1 \%)$.

In all, 2,346 plots were placed on 90 properties in 21 counties. A total of 21,648 residual trees and 5,934 stumps (including marked residual trees) were measured. Based on our field measurements, all properties examined in this study appeared to have been well-stocked with merchantable sawtimber prior to harvesting. No evidence was found of harvest activity prior to the most recent harvest on any subject property.

\section{Data Analysis}

Stump diameters and DBH measurements from the residual trees were used to develop species-specific linear regression equations to predict DBH from stump diameter. Initially, regressions were done separately for each district. However, the equations for the various districts were nearly identical for the first three species examined (northern red oak, yellowpoplar and sugar maple), so state-wide equations were developed for each species (Figures A-1 through A-3 in Appendix A). Coefficients of determination $\left(\mathrm{R}^{2}\right)$ for the regression equations were above 0.92 for all species. These equations were used to predict the DBHs of harvested trees on the sample plots, using the measured stump diameters from the harvested trees (Table A1 in Appendix A).

Merchantable stem volumes for residual and harvested trees were predicted from DBH (for residual trees) or predicted DBH (for harvested trees) using equations from Wiant (1989). Cubic-foot volumes were calculated for all trees with a DBH (or predicted DBH) $\geq 4.6$ ". International $1 / 4$ " Scale board-foot volumes were calculated for all trees with a DBH (or predicted $\mathrm{DBH}) \geq 11.6 "$

Stumpage value was calculated for all trees with a DBH (or predicted DBH) $\geq 11.6$ " using stumpage prices ( $\$$ thousand board feet, International 1/4" Scale) reported by the West Virginia University Appalachian Hardwood Center (AHC) for 2007 (statewide average of the 
four quarterly reporting periods). For stumpage value calculations, species were grouped into the following AHC pricing categories: northern red oak, white oak, mixed oak (all oaks except northern red and white), black cherry, yellow-poplar (including cucumbertree), hard maple (sugar and black maple), soft maple (red and silver maple), ash (all species), hickory (all species), black walnut and other species (all species not otherwise categorized).

The following attributes were calculated for each sample plot. Initial values were calculated by summing the values for residual trees and harvested trees (estimated from stumps):

- Initial and harvested trees per acre $(\geq 4.6 ” \mathrm{DBH})$

- Initial and harvested basal area per acre ( $\geq 4.6 " \mathrm{DBH})$

- Initial and harvested sawtimber basal area per acre $(\geq 11.6 " \mathrm{DBH})$

- Initial and harvested cubic-foot volume per acre $(\geq 4.6 ” \mathrm{DBH})$

- Initial and harvested board-foot volume per acre ( $\geq 11.6 ” \mathrm{DBH})$

- Initial and harvested sawtimber value per acre $(\geq 11.6 " \mathrm{DBH})$

- Initial and harvested average sawtimber value per thousand board feet $(\geq 11.6$ " DBH)

- Basal area of residual trees in each canopy position (dominant/co-dominant, intermediate or suppressed)

- Basal area of residual trees with damage to stem or crown

- Basal area of residual trees with severe damage (severity code 3) to stem or crown

- Basal area of residual trees in each tree quality class (1 - 5)

- Initial and residual quadratic mean diameter

The above stand attributes were used to calculate the following ratios:

- Percentage of trees harvested

- Percentage of basal area harvested

- Percentage of sawtimber basal area harvested

- Percentage of sawtimber value harvested 
- Species preference ratio (harvested value per $\mathrm{MBF} \div$ initial value per $\mathrm{MBF}$ )

- Percentage of residual basal area in dominant or co-dominant canopy positions

- Percentage of residual basal area damaged

- Percentage of residual basal area severely damaged

- Percentage of residual basal area in highest quality trees (tree quality 1)

- Percentage of residual basal area in acceptable growing stock (tree quality 1 or 2)

- Percentage of residual basal area in worst quality trees (tree quality 4 or 5)

- Change in quadratic mean diameter

- Percentage change in quadratic mean diameter

The following attributes were calculated for each property using the averages from the sample plots on that property and utilizing stocking charts for upland central hardwoods (Gingrich 1967):

- Initial and residual stocking percent

- Initial and residual stocking classification (over-stocked, fully-stocked, under-stocked, severely under-stocked)

- Percentage change in stocking percent

Analysis of variance (ANOVA) was performed to determine the effect of forester type (consultant, industry, or none) on each of the attributes and ratios previously listed $(\alpha=0.10)$. The Tukey-Kramer multiple-comparison test was performed on treatment means to determine statistically-significant treatment differences $(\alpha=0.10)$.

In addition, multiple regression analysis was performed to determine the combined effect of forester type and basal area harvested on damage to residual trees. It is possible that residual tree damage could be related to harvest intensity and, if so, differences in residual tree damage between forester types could be caused by solely by differences in the basal area harvested 
between the forester types, and not due to any other effect related to forester type, such as effectiveness of harvest supervision.

Properties were grouped into classes based on various harvest removal and residual stand attributes. For example, each property was assigned to the appropriate residual damage class based on the percentage of the residual basal area damaged, either: 1) $\leq 10 \%$ damaged, 2) $11-$ $15 \%$ damaged, or 3$) \geq 16 \%$ damaged. The number of properties falling into each class was summed for each forester type. Pearson's chi-square goodness-of-fit test was performed to determine if differences in observed frequencies between the forester types were statistically significant.

Finally, an overall harvest evaluation was performed for each property based on three residual stand attributes: 1) stocking classification, 2) percentage of residual basal area classified as acceptable growing stock (\% BA in AGS), and 3) percentage of residual basal area damaged (\% BA Damaged). These criteria were judged by professional foresters to be the three most useful silvicultural attributes for assessing harvesting impacts on a site (Egan and Jones 1997). Together, these three factors significantly affect the quality of the residual stand and the likelihood that the stand will produce quality timber in the next $15-20$ years.

Properties were evaluated for each of the above attributes based on criteria outlined in Table 4. Each attribute was rated as "Good", "Fair" or "Poor" based on these criteria and points were assigned to each property based on these evaluations. These three scores were summed and properties with a total score of 5 or 6 points received an overall evaluation of "Good". Properties with a total score of 3 or 4 points received an overall evaluation of "Fair", while those with 2 or fewer total points received an overall evaluation of "poor". No residual stands were overstocked, so no evaluation criterion was necessary for overstocked conditions. 
Table 4. Criteria used to perform an overall harvest evaluation for each property.

\begin{tabular}{|c|c|c|c|}
\hline Attribute & $\begin{array}{c}\text { Good } \\
\text { (2 points) }\end{array}$ & $\begin{array}{c}\text { Evaluation } \\
\text { Fair } \\
(1 \text { point }) \\
\end{array}$ & $\begin{array}{c}\text { Poor } \\
\text { (0 points }) \\
\end{array}$ \\
\hline Stocking Classification & Fully Stocked & Understocked & $\begin{array}{c}\text { Severely } \\
\text { Understocked }\end{array}$ \\
\hline$\%$ BA in AGS & $\geq 61 \%$ & $41-60 \%$ & $\leq 40 \%$ \\
\hline$\%$ BA Damaged & $\leq 10 \%$ & $11-15 \%$ & $\geq 16 \%$ \\
\hline Overall Evaluation & $5-6$ points & 3 - 4 points & $0-2$ points \\
\hline
\end{tabular}

For example, a property that was fully-stocked with $52 \%$ of the residual basal area classified as acceptable growing stock and $20 \%$ of the residual basal area damaged would receive a stocking classification rating of "Good" ( 2 points), an acceptable growing stock rating of "Fair" (1 point) and a damage rating of "poor" (0 points). A total of 3 points would be assigned to this property and its overall evaluation would be "Fair".

The number of properties falling into each overall evaluation class was summed for each forester type. Pearson's chi-square goodness-of-fit test was performed to determine if differences in observed frequencies between the forester types were statistically significant. 


\section{Results}

Consulting foresters removed smaller proportions of trees, basal area, sawtimber volume, and sawtimber value than either industry foresters or loggers working without direction from a professional forester (Table 5). There were no significant differences between industry foresters and non-foresters for any of the harvest removal attributes examined in this study.

Table 5. Mean values, by forester type, for various harvest removal attributes. Means within a row followed by the same letter are not significantly different $(\alpha=0.10)$.

\begin{tabular}{|lrrr|}
\hline Attribute & $\begin{array}{r}\text {---onsultant } \\
\text { Con }\end{array}$ & $\begin{array}{r}\text { Forester Type } \\
\text { Industry }\end{array}$ & \multicolumn{1}{c|}{ None } \\
\hline \hline$\%$ of Trees $\geq 5 "$ DBH Harvested & $22.1 \%$ a & $25.0 \% \mathrm{~b}$ & $24.7 \% \mathrm{~b}$ \\
$\%$ of Stand Basal Area Harvested & $43.4 \% \mathrm{a}$ & $48.9 \% \mathrm{~b}$ & $48.9 \% \mathrm{~b}$ \\
$\%$ of Sawtimber Basal Area Harvested & $57.7 \% \mathrm{a}$ & $67.8 \% \mathrm{~b}$ & $68.8 \% \mathrm{~b}$ \\
$\%$ of Stand Value Harvested & $57.5 \% \mathrm{a}$ & $68.0 \% \mathrm{~b}$ & $69.2 \% \mathrm{~b}$ \\
$\%$ of Sawtimber Volume Harvested & $60.1 \% \mathrm{a}$ & $70.5 \% \mathrm{~b}$ & $71.2 \% \mathrm{~b}$ \\
$\%$ of Sawtimber Value Harvested & $58.9 \% \mathrm{a}$ & $70.2 \% \mathrm{~b}$ & $71.2 \% \mathrm{~b}$ \\
Initial Sawtimber Value $(\$ / M B F)$ & $\$ 187.49 \mathrm{a}$ & $\$ 188.34 \mathrm{a}$ & $\$ 190.98 \mathrm{a}$ \\
Harvested Sawtimber Value $(\$ / \mathrm{MBF})$ & $\$ 183.61 \mathrm{a}$ & $\$ 190.52 \mathrm{a}$ & $\$ 192.81 \mathrm{a}$ \\
Species Preference Ratio & $0.98 \mathrm{a}$ & $1.00 \mathrm{~b}$ & $1.01 \mathrm{~b}$ \\
\hline
\end{tabular}

The species preference ratio (harvest value per $\mathrm{MBF} \div$ initial value per $\mathrm{MBF}$ ) indicates whether the harvested species were, on average, more valuable (ratio > 1), less valuable (ratio < 1 ), or of equal value (ratio $=1$ ) compared to the initial species composition. The species preference ratio for sales handled by consulting foresters is 0.98 , indicating that harvested species were slightly less valuable than the overall species composition (Table 5). The species preference ratios for sales handled by industry foresters and non-foresters were 1.00 and 1.01, respectively, indicating that harvested species were as valuable as or slightly more valuable than, the average species in the stand.

Properties harvested under the direction of consulting foresters contained higher proportions of dominant/co-dominant trees and acceptable growing stock than properties harvested under the direction of industry foresters or non-foresters (Table 6). 
Table 6. Mean values, by forester type, for various residual stand attributes. Means within a row followed by the same letter are not significantly different $(\alpha=0.10)$.

\begin{tabular}{|lrrr|}
\hline Attribute & $\begin{array}{r}\text { Consultant } \\
\text { \% Basal Area Codominant or Dominant }\end{array}$ & $\begin{array}{r}\text { Forester Type } \\
\text { Industry }\end{array}$ & \multicolumn{1}{c|}{ None } \\
\hline \% Basal Area Damaged & $61.7 \% \mathrm{a}$ & $51.9 \% \mathrm{~b}$ & $52.2 \% \mathrm{~b}$ \\
\% Basal Area Severely Damaged & $14.9 \% \mathrm{a}$ & $20.7 \% \mathrm{c}$ & $17.7 \% \mathrm{~b}$ \\
Basal Area of Best Quality Trees (ft $\left.{ }^{2} / \mathrm{ac}.\right)$ & $5.4 \% \mathrm{a}$ & $8.2 \% \mathrm{~b}$ & $6.8 \% \mathrm{~b}$ \\
Basal Area of Acceptable Growing Stock (ft $\left.{ }^{2} / \mathrm{ac}.\right)$ & $12.9 \mathrm{a}$ & $10.5 \mathrm{~b}$ & $8.7 \mathrm{c}$ \\
Basal Area of Worst Quality Trees (ft $\left.{ }^{2} / \mathrm{ac}.\right)$ & $36.6 \mathrm{a}$ & $27.7 \mathrm{~b}$ & $26.6 \mathrm{~b}$ \\
$\%$ Basal Area in Best Quality Trees & $9.3 \mathrm{a}$ & $11.9 \mathrm{~b}$ & $13.7 \mathrm{~b}$ \\
$\%$ Basal Area in Acceptable Growing Stock & $22.7 \% \mathrm{a}$ & $20.6 \% \mathrm{a}$ & $17.1 \% \mathrm{~b}$ \\
$\%$ Basal Area in Worst Quality Trees & $63.0 \% \mathrm{a}$ & $57.0 \% \mathrm{~b}$ & $53.2 \% \mathrm{c}$ \\
\hline
\end{tabular}

Properties harvested under the direction of industry foresters contained larger proportions of damaged trees compared to properties harvested without the involvement of any forester (Table 6). However, properties harvested under the direction of industry foresters also contained a higher proportion of best quality trees and acceptable growing stock and a lower proportion of worst quality trees compared to properties harvested by non-foresters.

Initial quadratic mean diameter (QMD) was smaller for harvests conducted by industry foresters, while post-harvest QMD was larger for harvests overseen by consulting foresters (Table 7). Timber harvests conducted by consulting foresters resulted in smaller absolute and relative reductions in QMD compared to harvests conducted by industry foresters and nonforesters. The residual QMD on industry properties was smaller than the residual QMD on nonforester properties, although at least some of this may be attributed to the smaller average preharvest QMD on these properties.

Table 7. Mean values, by forester type, for various quadratic mean diameter (QMD) parameters. Means within a row followed by the same letter are not significantly different $(\alpha=0.10)$.

\begin{tabular}{|lrrr|}
\hline Attribute & Consultant & $\begin{array}{r}\text { Forester Type } \\
\text { Industry }\end{array}$ & \multicolumn{1}{c|}{ None } \\
\hline \hline Initial QMD & $13.31 \mathrm{a}$ & $12.96 \mathrm{~b}$ & $13.25 \mathrm{a}$ \\
Residual QMD & $11.04 \mathrm{a}$ & $10.22 \mathrm{c}$ & $10.47 \mathrm{~b}$ \\
Change in QMD & $-2.27 \mathrm{a}$ & $-2.73 \mathrm{~b}$ & $-2.78 \mathrm{~b}$ \\
Pct. Change in QMD & $-16.5 \% \mathrm{a}$ & $-20.2 \% \mathrm{~b}$ & $-20.2 \% \mathrm{~b}$ \\
\hline
\end{tabular}


Initial and residual stocking levels were not significantly different between the different forester types (Table 8). However, consulting foresters caused a smaller percentage reduction in average stocking level compared to industry foresters.

Table 8. Mean values, by forester type, for various stocking level parameters. Means within a row followed by the same letter are not significantly different $(\alpha=0.10)$.

\begin{tabular}{|lrrc|}
\hline Attribute & $\begin{array}{c}\text {--------- } \\
\text { Consultant }\end{array}$ & $\begin{array}{r}\text { Forester Type } \\
\text { Industry }\end{array}$ & None \\
\hline \hline Initial Stocking & $85.7 \%$ a & $81.8 \%$ a & $82.2 \%$ a \\
Residual Stocking & $50.3 \%$ a & $43.7 \%$ a & $44.0 \%$ a \\
Pct. Change in Stocking Level & $-41.6 \%$ a & $-47.5 \%$ b & $-46.5 \%$ ab \\
\hline
\end{tabular}

Regression analysis indicates that the amount of basal area harvested and the involvement of either a consulting forester or industry forester are significant factors affecting the percentage of residual basal area damaged during harvesting (Table 9).

Table 9. Results of multiple regression analysis of the percentage of residual basal area damaged as a function of basal area harvested and forester type.

\begin{tabular}{|c|c|c|c|c|c|}
\hline \multicolumn{2}{|c|}{ Regression Statistics } & & & & \\
\hline$R^{2}$ & 0.04907 & & & & \\
\hline Adjusted $\mathrm{R}^{2}$ & 0.04785 & & & & \\
\hline Standard Error & 0.20438 & & & & \\
\hline Observations & 2338 & & & & \\
\hline Term & Coefficient & Std. Error & t Stat & $P$-value & \\
\hline Intercept & 0.11201 & 0.01043 & 10.74408 & 0.00000 & \\
\hline CONSULTANT & -0.02409 & 0.01053 & -2.28731 & 0.02227 & \\
\hline INDUSTRY & 0.02975 & 0.01052 & 2.82780 & 0.00473 & \\
\hline BA_H & 0.00130 & 0.00014 & 9.33065 & 0.00000 & \\
\hline \multicolumn{6}{|c|}{ Analysis of Variance } \\
\hline Source & $d f$ & SS & $M S$ & $F$ & $P$-value \\
\hline Regression & 3 & 5.03055 & 1.67685 & 40.14544 & 0.00000 \\
\hline Residual & 2334 & 97.48981 & 0.04177 & & \\
\hline Total & 2337 & 102.52036 & & & \\
\hline
\end{tabular}


The regression equation to predict the percentage of basal area damaged during harvesting (\%BA_D) is:

\section{$\%$ BA_D $=0.11201+0.00130($ BA_H $)-0.02409($ CONSULTANT $)+0.02975($ INDUSTRY $)$}

where: BA_H $=$ the amount of basal area harvested $\left(\mathrm{ft}^{2} /\right.$ acre $)$

CONSULTANT $=$ a dummy variable indicating the involvement of a consulting forester $(0=$ no consulting forester involved, $1=$ consulting forester involved $)$

INDUSTRY $=$ a dummy variable indicating the involvement of an industry forester $(0=$ no industry forester involved, 1 = industry forester involved).

The coefficient of determination for the equation is extremely low $\left(\mathrm{R}^{2}=0.05\right)$, indicating that the combined effects of forester type and the amount of basal area harvested explain very little of the variation seen in damage to residual stands. Nevertheless, the equation is highly significant, indicating that these factors do affect damage to the residual stand. On average, a landowner who does not utilize a professional forester can expect damage to $11.2 \%$ of the residual basal area, plus an additional $1.3 \%$ for each $10 \mathrm{ft}^{2}$ of basal area harvested. If a consulting forester is utilized, damage will be reduced by $2.4 \%$, on average. If an industry forester handles the sale, expected damage will be nearly 3\% higher, on average. For harvests that remove $40 \mathrm{ft}^{2}$ of basal area per acre, the expected average damage to the residual stand would be $14 \%$ if a consulting forester is involved, $19 \%$ if an industry forester is involved and $16 \%$ if no forester is involved. As harvesting intensity increases to $80 \mathrm{ft}^{2}$ of basal area per acre, expected average damage to the residual stand increases to $19 \%, 25 \%$ and $22 \%$ for the three forester types, respectively.

It should be noted that, due to the very low $\mathrm{R}^{2}$ of the regression analysis, this equation is not at all useful to predict residual damage on an individual property. However, the equation does give important insight into the average amount of damage to be expected for various types of harvests, given the intensity of harvest and the involvement of professional foresters. 
In general, consultants removed a lower proportion of high-value species (e.g. northern red oak and white oak) $\geq 16 " \mathrm{DBH}$, compared to the other two groups (Table 10). Industry foresters and non-foresters removed more than $80 \%$ of the basal area of high-value species 16 " $\mathrm{DBH}$ and larger. This is consistent with trends observed for timber harvesting in general in West Virginia and eastern Kentucky (Fajvan et al. 1998; Luppold and Bumgardner 2009). Consulting foresters tended to remove considerably less basal area from the smaller diameter classes of high-value species.

By contrast, there were few differences in harvesting intensity of moderate-value species (e.g. chestnut oak and red maple) between the forester types. Consultants did not generally display a strong preference for harvesting the larger high-value species trees over moderate-value species trees. However, they tended to remove a larger proportion of smaller moderate-value species compared to the smaller high-value species.

Consulting foresters also removed much higher proportions of low-value species (e.g. American beech and sweet birch) across all merchantable diameter classes. Industry foresters and non-foresters generally avoided harvesting low-value species.

Table 10. Percentage of basal area harvested, by species and diameter class, for each type of forester involved with the harvest.

\begin{tabular}{|c|c|c|c|c|c|c|c|c|c|c|c|c|}
\hline \multirow[b]{3}{*}{ Forester Type } & \multicolumn{4}{|c|}{ High-Value Species } & \multicolumn{4}{|c|}{ Moderate-Value Species } & \multicolumn{4}{|c|}{ Low-Value Species } \\
\hline & \multicolumn{2}{|c|}{ N. Red Oak } & \multicolumn{2}{|c|}{ White Oak } & \multicolumn{2}{|c|}{ Chestnut Oak } & \multicolumn{2}{|c|}{ Red Maple } & \multicolumn{2}{|c|}{ Beech } & \multicolumn{2}{|c|}{ Sweet Birch } \\
\hline & $12-15^{\prime \prime}$ & $16 "+$ & $12-15^{\prime \prime}$ & $16^{\prime \prime}+$ & $12-15^{\prime \prime}$ & $16^{\prime \prime}+$ & $12-15^{\prime \prime}$ & $16^{\prime \prime}+$ & $12-1 \overline{" \prime}$ & $16^{\prime \prime}+$ & $12-15^{\prime \prime}$ & $16^{\prime \prime}+$ \\
\hline Consultant & $12 \%$ & $76 \%$ & $14 \%$ & $66 \%$ & $20 \%$ & $72 \%$ & $17 \%$ & $69 \%$ & $66 \%$ & $64 \%$ & $44 \%$ & $88 \%$ \\
\hline Industry & $29 \%$ & $89 \%$ & $22 \%$ & $89 \%$ & $27 \%$ & $77 \%$ & $17 \%$ & $66 \%$ & $14 \%$ & $29 \%$ & $0 \%$ & * \\
\hline Non-forester & $22 \%$ & $87 \%$ & $10 \%$ & $82 \%$ & $20 \%$ & $63 \%$ & $23 \%$ & $73 \%$ & $13 \%$ & $32 \%$ & $10 \%$ & $0 \%$ \\
\hline
\end{tabular}


Thirty percent of the harvests handled by consultants resulted in residual stands that were fully stocked, compared to $20 \%$ or fewer of the harvests handled by industry foresters or nonforesters (Figure 1). More than half of the harvests handled by industry foresters or non-foresters resulted in severely under-stocked residual stands, compared to only $30 \%$ for harvests done by consulting foresters.

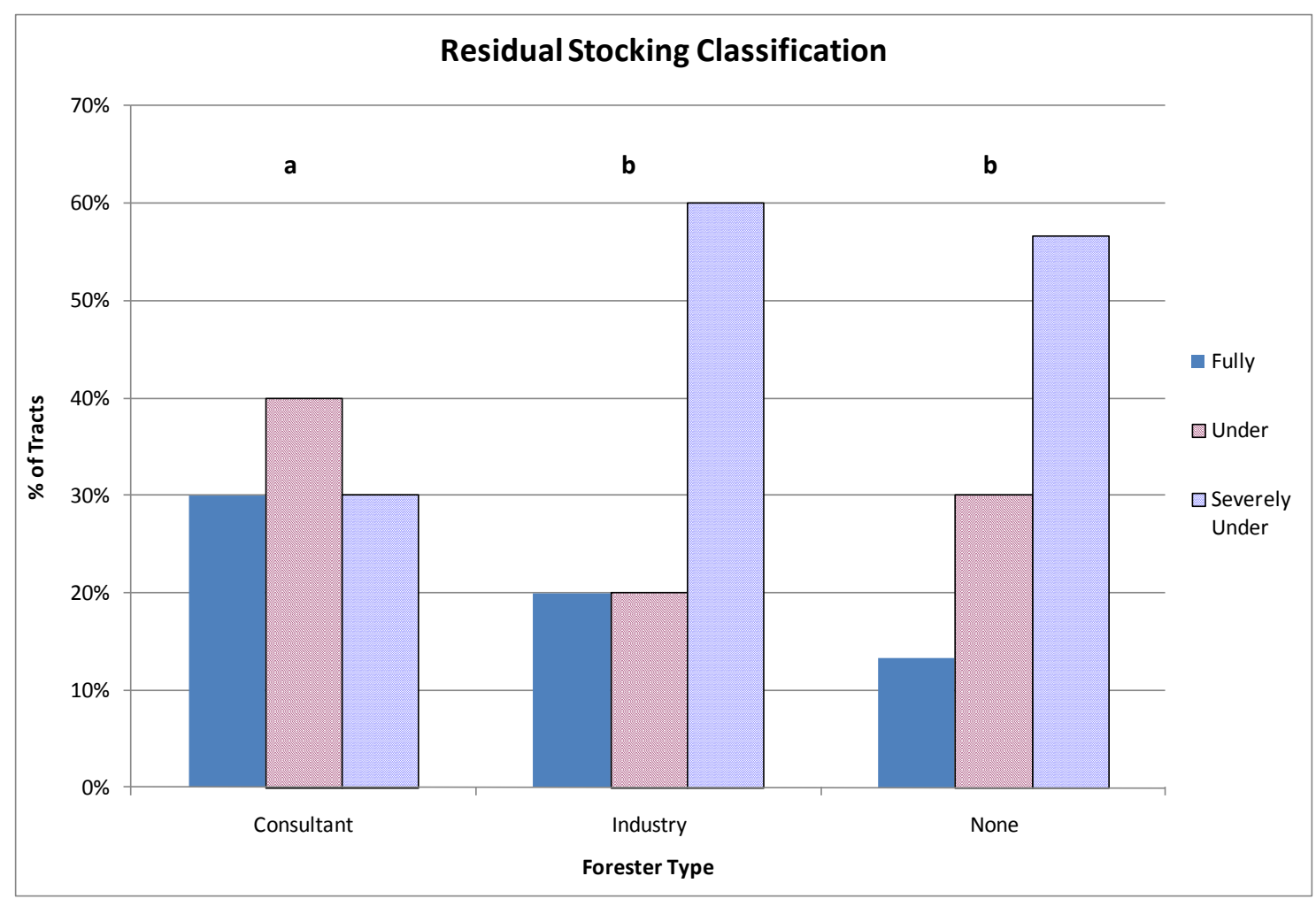

Figure 1. Percentage of harvested properties classified into residual stocking classes by type of forester involved with the harvest. Forester type distributions with the same letter are not significantly different based on Pearson's chi-square goodness-of-fit test $(\alpha=0.10)$. 
Nearly three-fourths of the harvests conducted by consulting foresters resulted in residual stands with more than $60 \%$ of the residual basal area in acceptable growing stock (Figure 2). By contrast, fewer than half of the sales handled by industry foresters or non-foresters had more than $60 \%$ of the residual stand in acceptable growing stock.

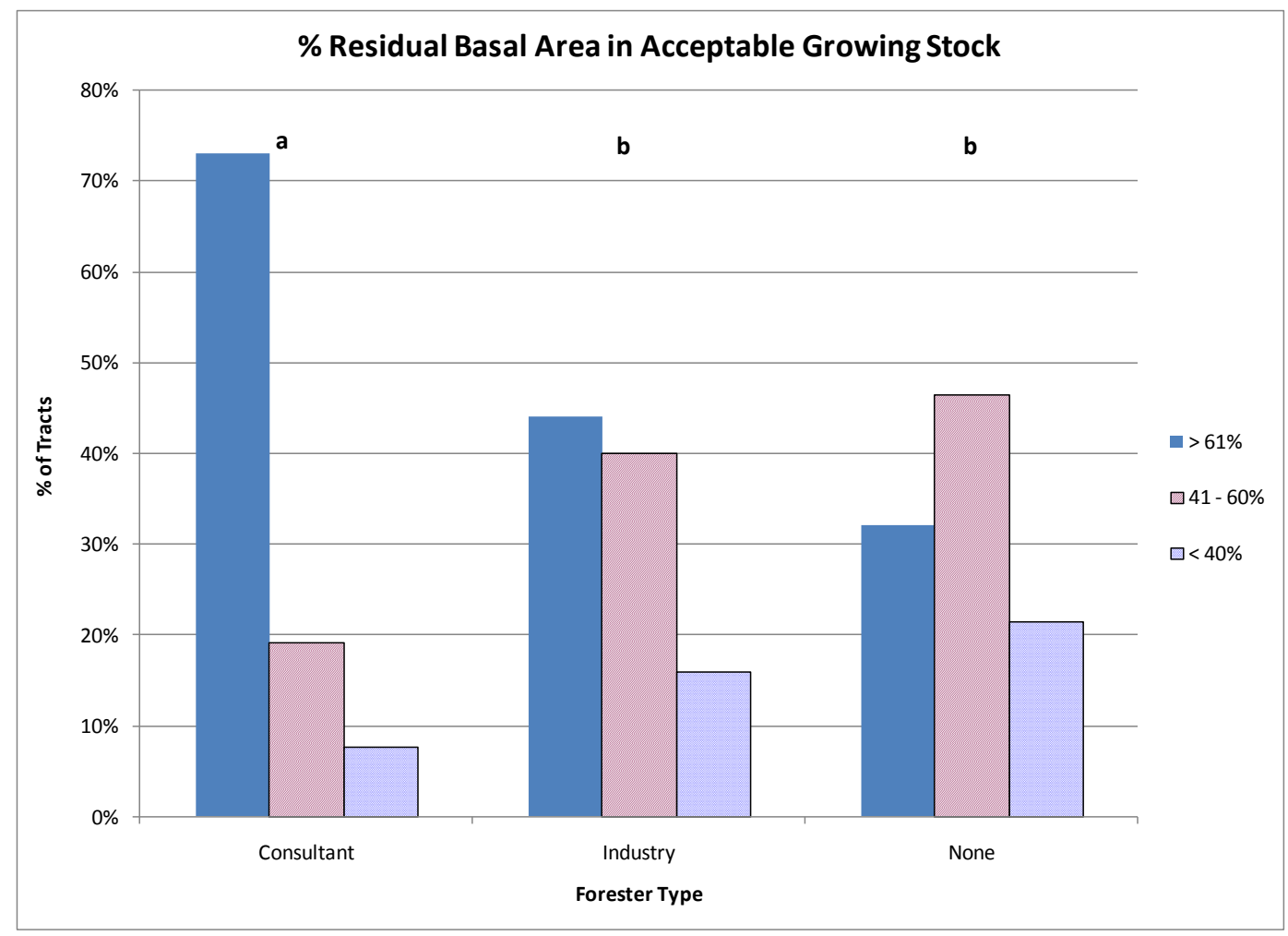

Figure 2. Percentage of harvested properties classified into acceptable growing stock classes by type of forester involved with the harvest. Forester type distributions with the same letter are not significantly different based on Pearson's chi-square goodness-of-fit test $(\alpha=0.10)$ 
One-third of the harvests handled by consultants had no more than $10 \%$ of the residual basal area damaged by logging, while fewer than $20 \%$ of the harvests handled by industry foresters and non-foresters had such low levels of residual damage (Figure 3). Only 30\% of the consultants' harvests resulted in heavily damaged residual stands $(\geq 16 \%$ of the residual basal area damaged), compared to more than half of the industry forester and non-forester harvests.

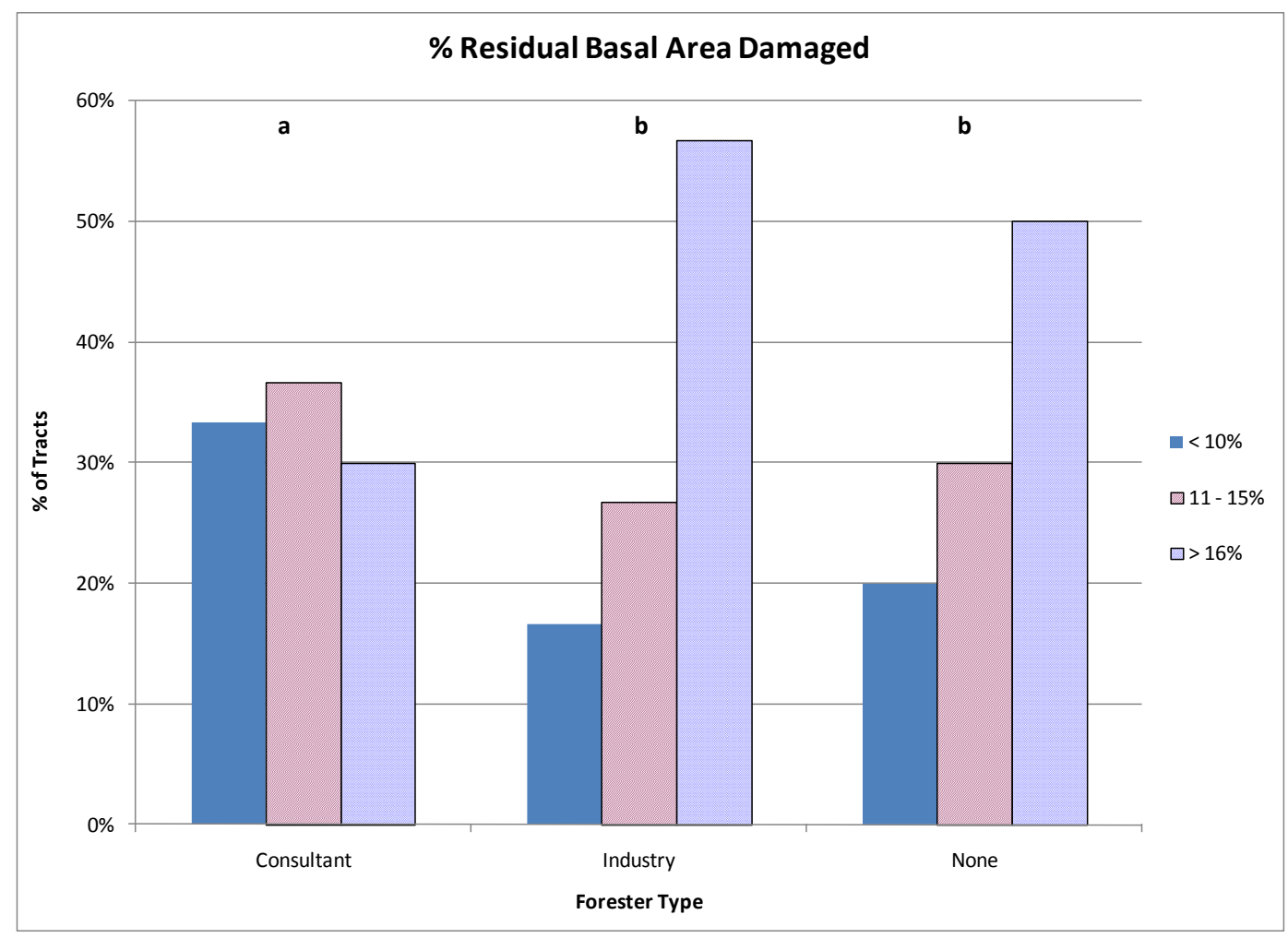

Figure 3. Percentage of harvested properties classified into residual damage classes by type of forester involved with the harvest. Forester type distributions with the same letter are not significantly different based on Pearson's chi-square goodness-of-fit test $(\alpha=0.10)$. 
Only $10 \%$ of the consulting foresters conducted very heavy harvests (more than $70 \%$ of the sawtimber basal area harvested) compared to nearly one-half of the industry foresters and more than one-third of the non-foresters (Figure 4). Nearly two-thirds of the consultant harvests were lower-intensity harvests (no more than $60 \%$ of the sawtimber basal area removed), more than twice the frequency of low-intensity harvests conducted by industry foresters or nonforesters. Industry foresters were also more likely to engage in heavy sawtimber removals than non-foresters.

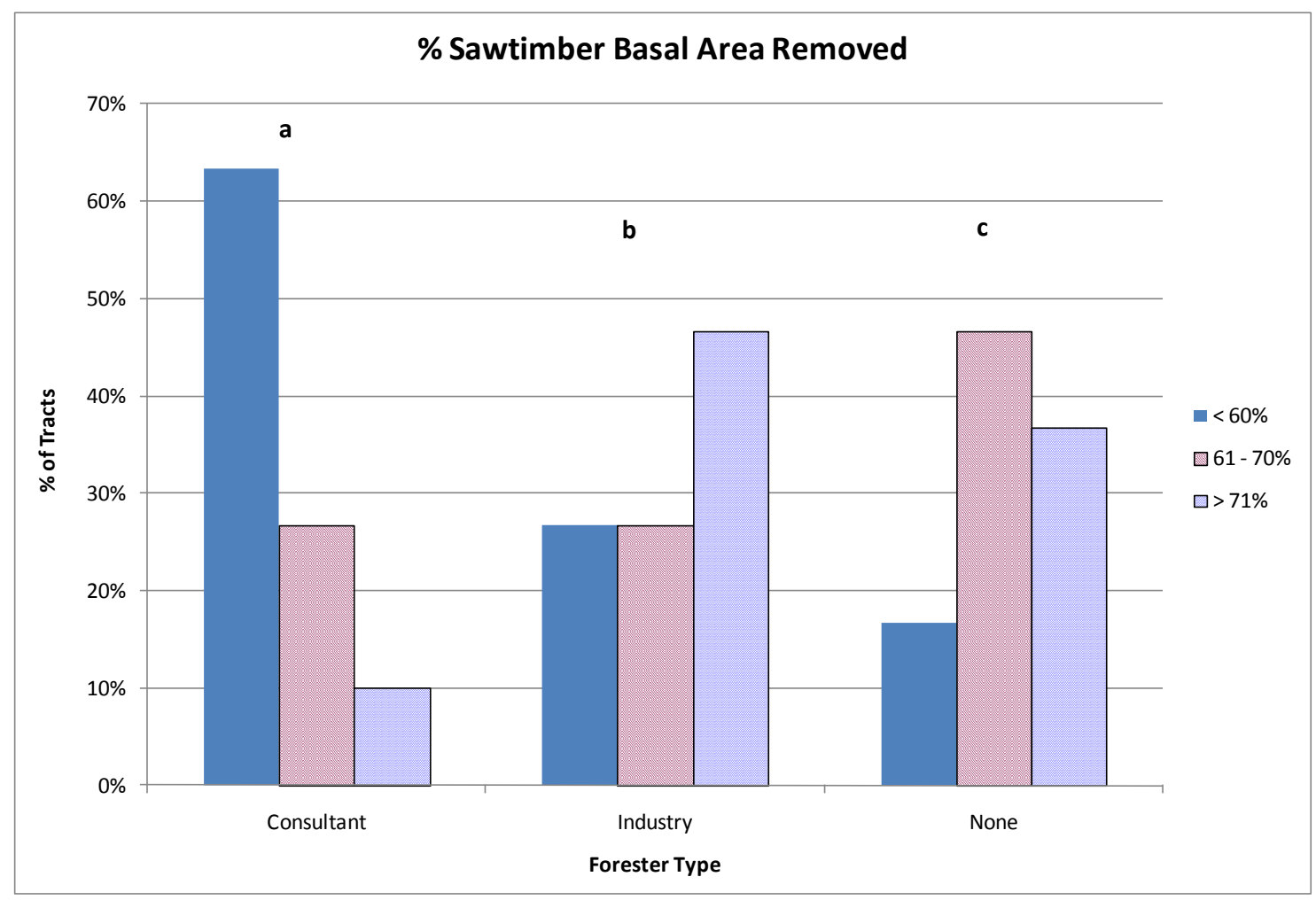

Figure 4. Percentage of harvested properties classified into sawtimber basal area removal classes by type of forester involved with the harvest. Forester type distributions with the same letter are not significantly different based on Pearson's chi-square goodness-of-fit test $(\alpha=0.10)$. 
All harvests resulted in a reduction in quadratic mean diameter (QMD), indicating a universal bias towards harvesting the larger trees. However, one-half of the consulting foresters reduced quadratic mean diameter by $15 \%$ or less, indicating less of a bias towards harvesting only the larger trees (Figure 5). By contrast, fewer than one-fourth of the industry foresters and non-foresters reduced QMD by such a small amount. More than 35\% of the industry foresters and non-foresters reduced QMD by more than $20 \%$, compared to less than $15 \%$ of consulting foresters.

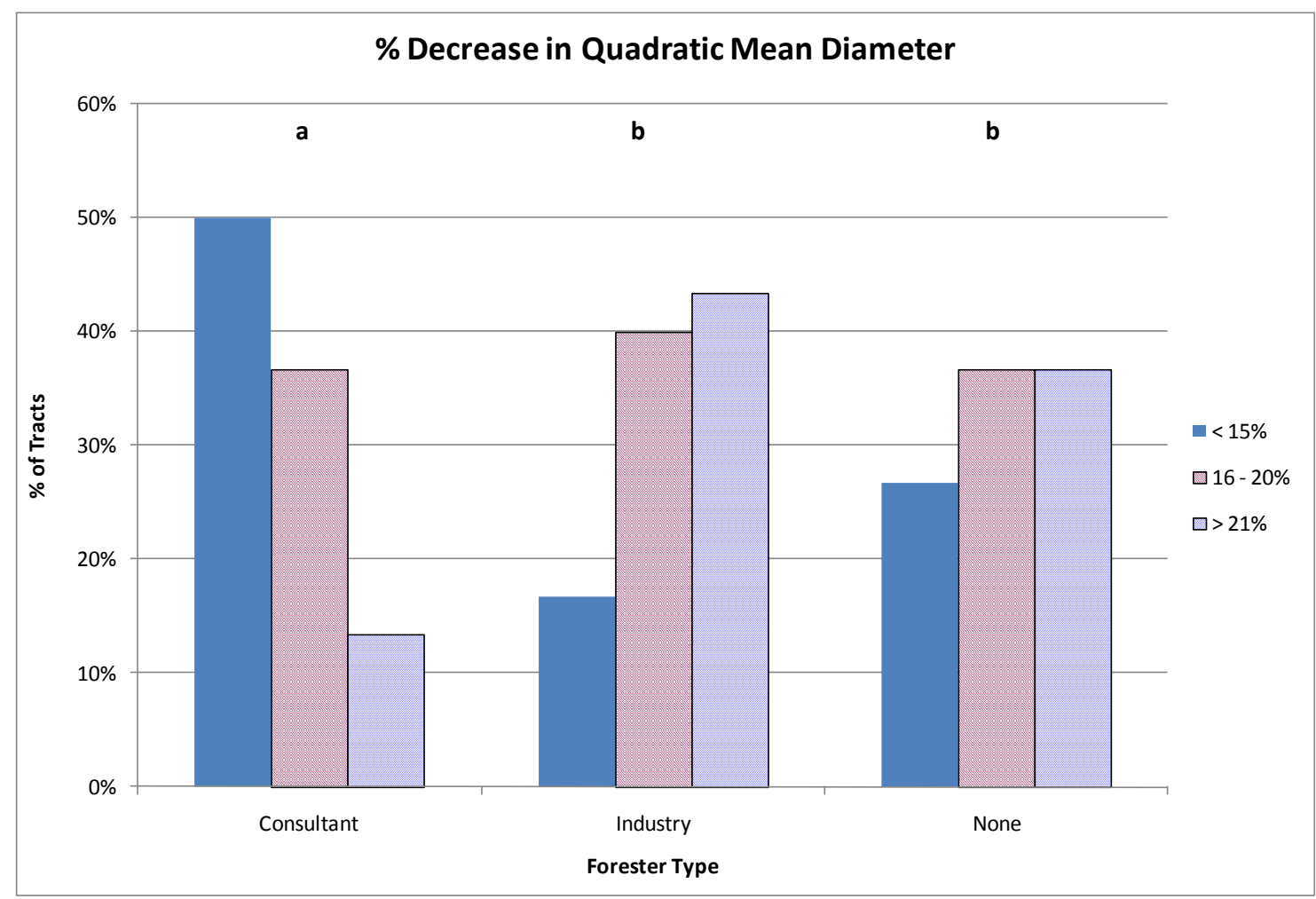

Figure 5. Percentage of harvested properties classified into QMD reduction classes by type of forester involved with the harvest. Forester type distributions with the same letter are not significantly different based on Pearson's chi-square goodness-of-fit test ( $\alpha=0.10)$. 
Only about one-fourth of the consulting foresters displayed a preference for removing the more valuable species during harvest, as indicated by a species preference ratio greater than 1.0 (Figure 6). By contrast, more than half of the industry foresters and non-foresters indicated a bias towards removing the more valuable species during harvesting. In addition, one-third of the consulting foresters attempted to remove at least some of the less valuable species from the stand (species preference ratio $\leq 0.95$ ), compared to fewer than $20 \%$ of the industry foresters and nonforesters.

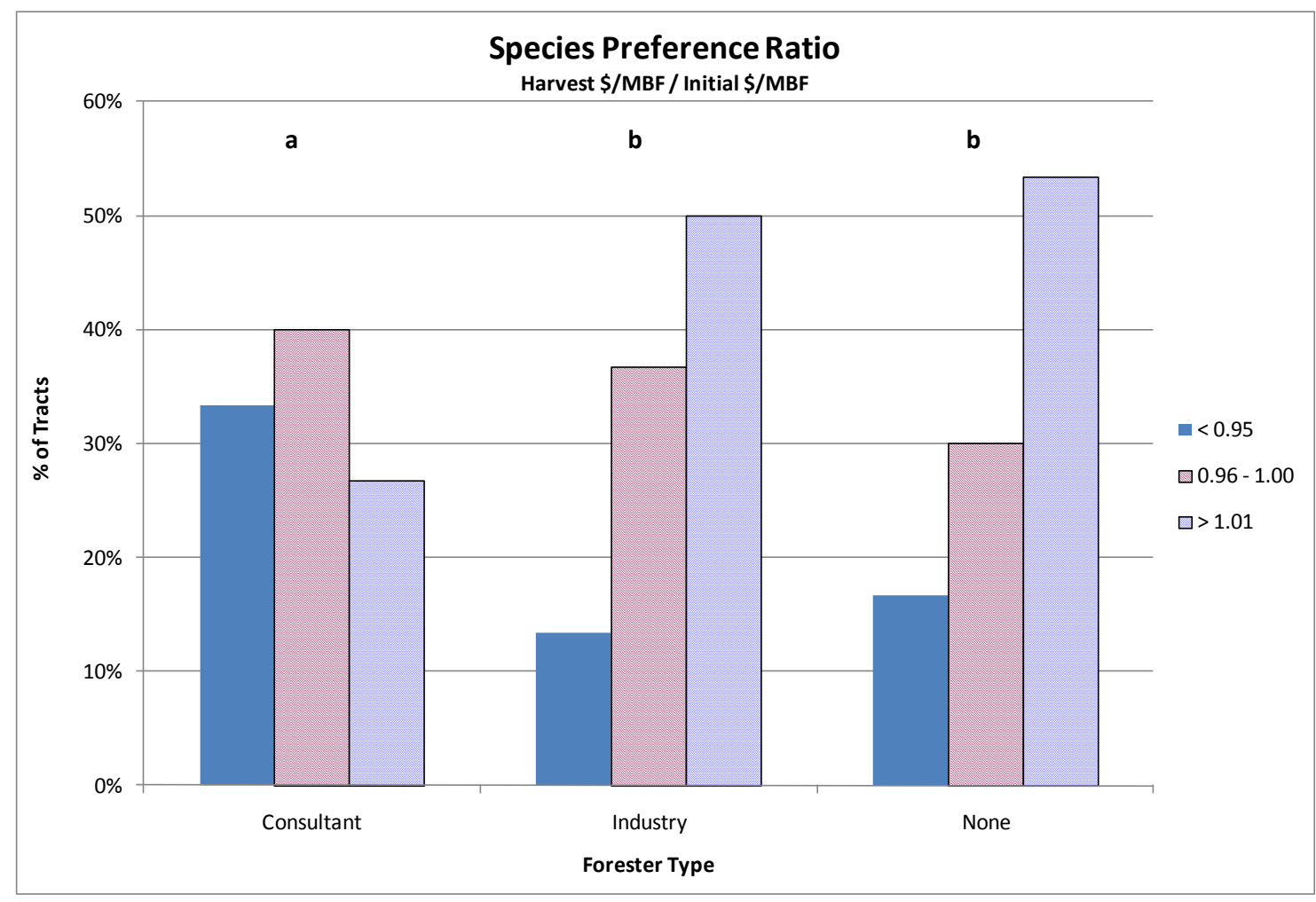

Figure 6. Percentage of harvested properties classified into species preference ratio classes by type of forester involved with the harvest. Forester type distributions with the same letter are not significantly different based on Pearson's chi-square goodness-of-fit test $(\alpha=0.10)$. 
Nearly one-fourth of the harvests conducted by consulting foresters were evaluated as "good" based on evaluations of residual stocking level, acceptable growing stock, and damage to residual trees, as detailed in Table 4 (Figure 7). Fewer than 10\% of the harvests conducted by industry foresters received a "good" evaluation and none of the harvests conducted by nonforesters were rated as "good".

About one-fourth of the harvests conducted by consulting foresters were evaluated as "poor", compared to more than $50 \%$ of non-forester harvests and more than $60 \%$ of the harvests conducted by industry foresters.

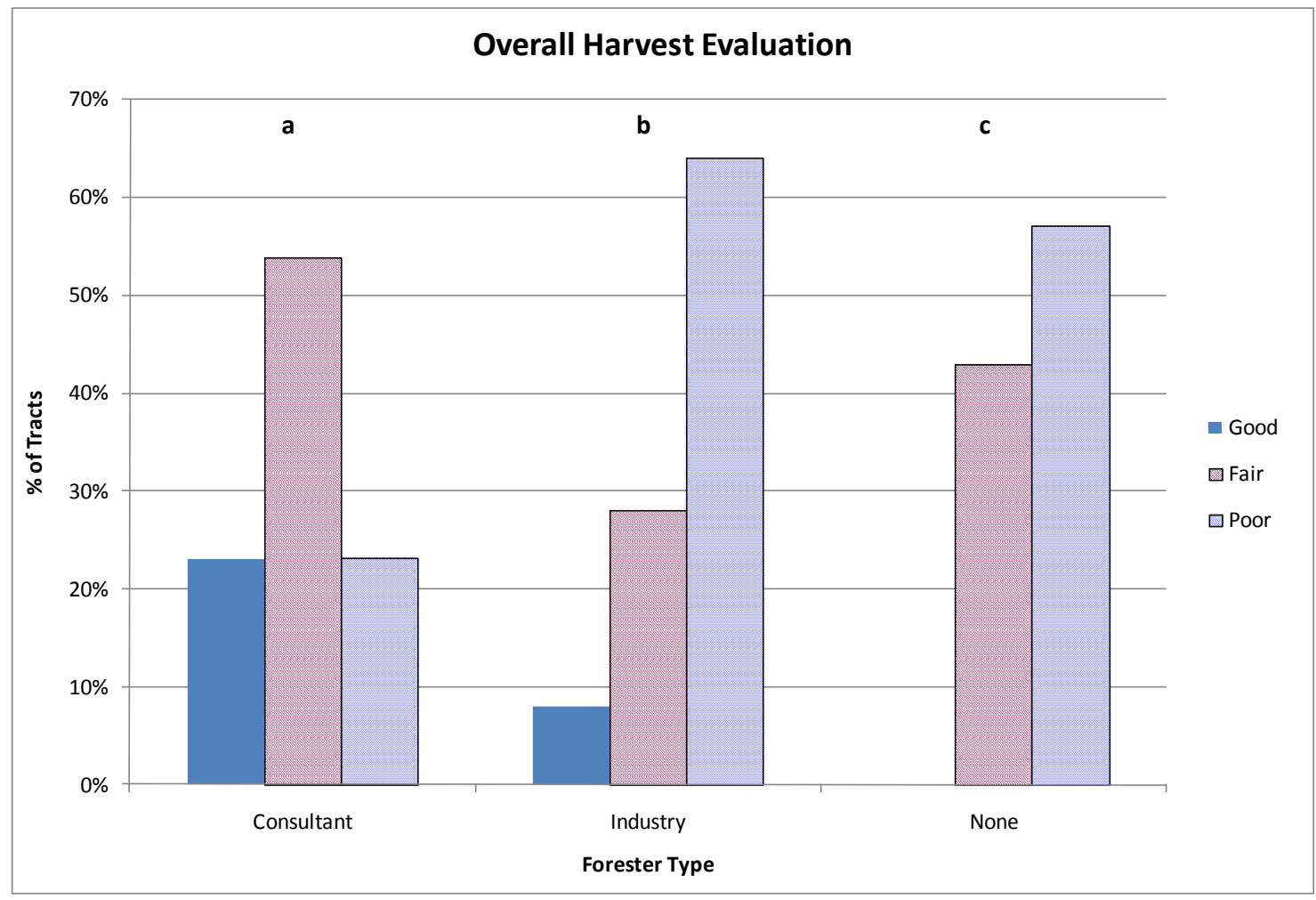

Figure 7. Percentage of harvested properties classified into overall harvest evaluation classes by type of forester involved with the harvest. Forester type distributions with the same letter are not significantly different based on Pearson's chi-square goodness-of-fit test $(\alpha=0.10)$. 


\section{Discussion}

Results from this study suggest that there are significant differences between timber harvests conducted by consulting foresters (including state service foresters) and timber harvests handled by either industry foresters or those conducted without involvement by any professional forester. By contrast, there were very few differences in the attributes we measured between harvests conducted by industry foresters and harvests carried out by non-foresters.

Consulting foresters removed less volume and value from the stand during harvesting compared to the other two groups and displayed a tendency to remove trees that were somewhat smaller in diameter, as evidenced by the smaller reduction in quadratic mean diameter after harvesting. In addition, consultants were less inclined to remove the more valuable species from a stand, particularly in the $12-15$ " diameter classes, which represent future sawtimber growing stock. Industry foresters and non-foresters strongly avoided harvesting low-value species (e.g. beech and sweet birch) while consultants tended to harvest these species heavily. In all but one instance, consulting foresters marked the timber to be harvested, compared to only one-quarter of the harvests conducted by industry foresters and less than $10 \%$ of the harvests conducted by nonforesters. Collectively, these tendencies provide strong evidence that many consulting foresters conducted harvests with the intent to practice silviculture, to at least some extent. In general, such intentions appear to be lacking from most harvests conducted by industry foresters and nonforesters.

Residual stands resulting from harvests managed by consulting foresters were generally in better condition than residual stands resulting from harvests conducted by the other two groups. Stands were more likely to be left in a fully-stocked condition and possess higher proportions of acceptable growing stock and trees in dominant or co-dominant canopy positions when consulting foresters conducted the harvest. In addition, consultant-managed harvests resulted in fewer damaged residual trees and fewer trees of the lowest quality (culls and nonsawtimber quality). Harvests conducted by industry foresters resulted in stands with higher proportions of acceptable growing stock and lower proportions of lowest-quality trees compared to harvests handled by non-foresters, but also resulted in more damage to the residual trees. 
It is impossible to determine the initial quality of the timber examined in this study prior to harvest. Therefore, it is impossible to know for certain if differences in residual timber quality are the result of differences in initial stand conditions or differences in the manner in which the harvests were conducted. However, given the size of this study and the randomness with which properties were selected, there is little reason to believe that significant differences in initial timber quality existed between the various forester types. Regardless of whether or not such differences existed, a number of factors (damage to residual trees, stocking level, percentage of residual trees in dominant / co-dominant canopy positions, reduction in QMD) are not influenced by initial timber quality. Based solely on these factors, there is ample evidence to support a claim that consulting foresters conducted harvests with the intent to practice silviculture, to the extent possible given landowner objectives and market constraints.

Residual damage was correlated with pre-harvest and residual stand density, as was noted by Hassler et al. (1999), but the correlations were very weak $\left(\mathrm{R}^{2}=0.07\right.$ and 0.06 , respectively). More importantly, harvest intensity, as measured by the proportion of basal area harvested, tended to result in more frequent damage to residual trees, as might be expected. However, the effect was quite small, suggesting that other factors such as terrain, logger skill, logger diligence, and the effectiveness of logging supervision are more important in determining damage to the residual stand. Consulting foresters removed less basal area during harvesting than the other forester groups. However, even accounting for this effect on logging damage, harvests conducted by consulting foresters had less residual tree damage than harvests conducted by either industry foresters or non-foresters.

Harvests were given an overall evaluation based on three attributes of the residual stand: 1) residual stocking level, 2) percentage of residual basal area in acceptable growing stock, and 3) percentage of residual basal area damaged during logging. Each attribute was evaluated and scored individually and the overall harvest evaluation was based on the combined score. These three attributes were chosen because they significantly affect the probability that the stand will be productive and yield significant quality sawtimber in the near future $(10-20$ years $)$ and are considered important factors is accessing harvest impacts (Egan and Jones 1997). Of course, 
there are many other factors that determine whether a harvest is "good" or "poor", the most of important of which is whether or not the harvest met the landowner's objectives without unduly degrading soil and water resources. However, this evaluation method is one measure by which to evaluate the probability that a harvest will provide for sustainable timber production. By no means is it the only, nor necessarily even the best, measure of a forester's performance in conducting a harvest.

Based on this evaluation method, nearly one-fourth of the harvests managed by consulting foresters were rated as "good". Although somewhat disappointing, this performance is much better than that achieved by industry foresters (less than $10 \%$ rated as "good") or nonforesters (none rated as "good"). Conversely, more than half of the harvests conducted by both industry foresters and non-foresters were rated as "poor" (failing to provide for short-term sustainability). Fewer than $25 \%$ of consultant-managed harvests were rated as "poor".

Although not specifically investigated in this study, harvest size was related to quality of the harvest. Only $3 \%$ of the harvests less than 50 acres in size received a "good" evaluation, compared to $12 \%$ of the harvests $50-99$ acres in size and $17 \%$ of the harvests 100 acres or larger. Consultants were involved in nearly half of the sales from 50-99 acres and about one-fourth of the sales $<50$ acres and $\geq 100$ acres, so the differences do not appear to be related to involvement by a consultant. A more plausible explanation is that owners of larger properties were more interested in forest management and articulated this desire to the consultant or industry forester.

More than half of the harvests less than 50 acres in size were conducted without the involvement of a professional forester. By contrast, foresters were involved with more than $75 \%$ of the harvests 50 acres or larger, with equal distribution between consulting foresters and industry foresters. It is not clear whether the higher propensity of smaller landowners to work directly with loggers is due to landowner attitudes (they have non-timber objectives and/or don't feel it is worth seeking assistance for such a small acreage) or forester attitudes (less interest in dealing with small properties due to lower economies of scale). It is even possible that loggers seek out smaller timber sales due to having less capital available for purchasing stumpage. 
A cursory examination of the WVDOF Timbering Notification Forms for 2005 indicated that consulting/service foresters were involved in roughly $20 \%$ of the timber harvests in West Virginia, while industry/procurement foresters were involved in about 30\%. Approximately half of the timber harvests in 2005 did not appear to include involvement by any professional forester. Assuming that the findings of this study can be applied state-wide and forester involvement in harvesting typically follows the pattern shown in 2005, this would indicate that only $7 \%$ of the timber harvests in the state would receive a "good" evaluation based on the criteria listed in Table 4. Forty-one percent of the harvests would be considered "Fair" and more than half $(52 \%)$ would be considered "poor". This is consistent with the findings of other researchers who have concluded that most timber harvesting in the Appalachian region consists of high-grading and diameter-limit harvests (Fajvan et al. 1998; Pell 1998; Nyland 1992).

There are a number of possible explanations for the relatively poor ability of professional foresters to carry out silvicultural harvests. First and foremost are landowner objectives. No attempt was made in this study to ascertain the landowners' objectives for their properties or reasons for harvesting timber. It is likely that some landowners were not interested in silviculture, sustainable timber production, or any of the other aspects of forest management that professional foresters can provide. Given this, there are likely to be instances where nonsustainable harvests are carried out by professional foresters, regardless of their personal preferences towards the harvest.

Additionally, economics dictate how timber harvests are conducted to a considerable extent. Inadequate markets for small-diameter trees, poor quality trees and certain low-value species seriously hinder the ability of foresters to remove such trees from a stand during a commercial harvest, for fear of making the sale economically unattractive. "Textbook" silviculture, including practices such as cleaning and thinning from below, are virtually impossible to perform in the context of a commercial harvest, and few landowners appear inclined to subsidize such activities. Thus, foresters are limited to practicing silviculture within the bounds provided by a commercial (i.e. economically-attractive) harvest. 
In spite of these constraints, harvest removal attributes and residual stand characteristics suggest that consulting foresters were more apt to implement silvicultural concepts into their harvests than either industry foresters or non-foresters (landowners and loggers). This study provided scant evidence that industry foresters were any more likely to practice silviculture as part of a timber harvest than non-foresters.

Part of the reason for the greater likelihood of consulting foresters to conduct silvicultural harvests could lie with the landowners. Landowners who are interested in forest management and/or concerned about their forest might be more likely to seek out assistance from consulting foresters and state service foresters compared to those landowners with little or no interest in forest management or sustainability. In other words, industry foresters might be just as motivated to practice silvicultural and sustainable harvesting as consulting foresters, but might be more likely to be working with landowners who are not concerned with such matters. Conversely, consulting foresters might be no more likely to practice sustainable forestry than industry foresters when working with unconcerned landowners or landowners whose objectives for their property do not involve forest management. The reader should be aware of the limitations of this study to address such issues and care should be taken in how these results are interpreted.

Nevertheless, one important conclusion from this study is that only a relatively small fraction (probably less than 10\%) of the timber harvests conducted in the state can be defined as silviculturally-oriented. Overwhelmingly, these harvests were carried out by consulting foresters. Landowners should be made aware of the benefits of engaging consulting foresters and state service foresters to assist with their timber sales, particularly if their ownership objectives involve some aspect of forest management. 


\section{CHAPTER II}

\section{The Impact of Timber Harvest Practices on Future Stand Attributes}

In the second phase of the project, residual stand attributes measured during the first phase of the project were used to project timber volumes by species, sawlog quality, and tree diameter for a twenty-year period.

\section{Methodology}

Residual stand data collected during the field investigations were used to project future stand attributes using the USDA Forest Service's Forest Vegetation Simulator (FVS) Northeast Variant (Dixon 2003). Due to the time involved with entering data, performing the growth projections, and analyzing the results, residual stands from four properties were selected for this analysis: two properties representative of "good" harvest practices and two properties representative of "poor" harvest practices, as defined in Table 4. Table 11 lists the important residual stand attributes of these properties, relative to the average values for residual stands resulting from "good" and "poor" harvest practices.

Table 11. Percentage of basal area in acceptable growing stock (Quality = 1 or2), percentage of basal area significantly damaged (Damage Severity = 2 or 3), and percent stocking level for residual stands on Tracts 2C3, 2C4, 4I6, and 4N1 and average values for all tracts rated as "good" or "poor" (see Table 4).

\begin{tabular}{|l|c|c|c|}
\hline Tract & $\begin{array}{c}\text { \% Acceptable } \\
\text { Growing Stock }\end{array}$ & $\begin{array}{c}\text { \% Significantly } \\
\text { Damaged }\end{array}$ & \% Stocking \\
\hline \hline 2C3 & $73 \%$ & $4 \%$ & $60 \%$ \\
\hline 2C4 & $71 \%$ & $2 \%$ & $60 \%$ \\
\hline Avg. for all "Good" Tracts & $70 \%$ & $6 \%$ & $58 \%$ \\
\hline 4I6 & $46 \%$ & $15 \%$ & $40 \%$ \\
\hline 4N1 & $50 \%$ & $17 \%$ & $40 \%$ \\
\hline Avg. for all "Poor" Tracts & $49 \%$ & $13 \%$ & $37 \%$ \\
\hline
\end{tabular}


Residual stand data entered into FVS included: diameter at breast height (DBH), species, tree quality (Table 2), and damage severity (Table 3). Since FVS does not accept tree quality or grade data directly, tree quality (1-5) was entered into the Prescription Code field.

The impact of damage to the residual trees was included in the model as adjustments to future merchantable volume or mortality, using the Damage Code and Severity fields in FVS. Trees with a bole damage code of 2 (100 - 500 sq. in. of exposed wood) were assumed to suffer a $10 \%$ loss in merchantable volume by the end of the projection period (10 or 20 years), while trees with a bole damage code of 3 (> 500 sq. in. of exposed wood) were assumed to suffer a $15 \%$ loss in merchantable volume by the end of the projection period. Trees with a bole damage code of 1 (< 100 sq. in of exposed wood) were assumed to suffer no loss in merchantable volume. Trees with a crown damage code of 3 (> 50\% of crown removed) or a leaning code of 3 (main stem broken or tree pushing entirely over) were assumed to have died during the projection period (in fact, many were already dead by the time of our field investigation, but were recorded as live trees since they were likely still living immediately after harvest). These assumptions are consistent with research on the impacts of logging damage to hardwood stands (Lamson et al.. 1985; Lamson and Smith 1988; Nyland and Gabriel 1971; Nyland and Gabriel 1972; Ohman 1970; Smith et al.. 1994).

While it is possible that less severe damage to the crown could result in a temporary reduction in the growth rate, no adjustments were made for crown damage codes of 1 or 2 , due to the difficulty of estimating these impacts on growth rate or mortality. Similarly, it is possible that less severe leaning of the residual tree might lead to a reduction in merchantable volume (formation of sweep) or wood quality (formation of reaction wood). However, no adjustments were made for leaning damage codes of 1 or 2 , due the difficulty of estimating these impacts on future merchantable volume or tree quality. As a result, it is possible that the impacts of logging damage on future stand volumes and tree quality have been slightly underestimated. However, since few trees suffered slight-to-moderate crown or leaning damage (damage codes 1 or 2), the bias is likely very small. 
There were significant differences in the proportion of residual basal area in dominant/codominant trees between tracts subjected to "good" and "poor" harvest practices (Table 6). Research has shown that crown class is often the single best predictor of future diameter growth in hardwoods, particularly for the more shade-intolerant species, but also for certain shadetolerant species subject to release (Nyland 2006; Trimble 1969). Low-vigor trees in intermediate and suppressed crown classes often grow slower and are more apt to die (Marquis and Ernst 1991). Thus, it stands to reason that tracts subjected to "good" harvest practices might experience faster growth rates after harvest than tracts subjected to "poor" harvest practices, all other factors being equal. Unfortunately, the models in FVS do not incorporate crown class/canopy position into the calculation of diameter growth. Therefore, no attempt was made to adjust growth rates based on this attribute. However, the financial analyses of harvesting practices, presented in Chapter III, do include an adjustment for possible higher growth rates on "good" tracts.

Growth and mortality equations selected in the model were those appropriate for the Monongahela National Forest (FVS region code 921). These models were adopted from the NETWIGS individual-tree diameter growth model (Teck and Hilt 1991). Merchantable volumes were calculated using the NATCRS equations with International 1/4" board-foot volumes, assuming Mesavage and Girard Form Class 78 and a merchantable top diameter of 8". In order to ensure consistency with growth projections between properties (i.e. eliminate variability in responses due to differing site productivity, stand age, etc. among the four properties) all stands were assumed to be 80 years old (established in 1927) with a northern red oak site index of 75 feet (base age 50 years).

Stand projections were made for 10 and 20 years into the future. This time period was selected because it represents the most likely time frame during which re-entry into the stand for future harvesting would occur. The growth projections support the assumption that a future harvest could occur on the "good" properties within 10 - 20 years after the initial harvest. However, it is improbable that the properties subjected to "poor" harvest practices could support another commercial harvest in 10 years, although a harvest in 20 years seems possible, although not certain. 
For each projection period (10 and 20 years), merchantable sawtimber volume was calculated by species, tree quality and diameter (DBH) class. In order to determine volume by tree quality, each stand was "harvested" at the end of each projection period using the "ThinPRSC" (thin by prescription code) keyword in FVS. This option allows the user to "harvest" all trees with a specific Prescription Code and calculate the volume for those "harvested" trees. By using this keyword to harvest all trees with a Prescription Code of " 1 " (corresponding to a tree quality of 1), it was possible to determine the volume contained in trees with a quality rating of 1 at the end of the projection period. This process was repeated for Prescription Codes 2, 3, and 4 to determine the volume contained in trees with quality ratings of 2,3 , and 4 , respectively. Since a quality rating of 5 indicates a cull, no volume was calculated for these trees.

Conducting analyses on actual tracts provides a realistic evaluation of actual harvest practices encountered throughout the state. However, comparisons between various harvest practices (e.g. between "good" and "poor" harvest practices) are confounded by differences in species composition, initial timber volume, etc. between the tracts investigated. Since this was not a controlled study (e.g. two similar stands subject to two different harvest practices), it was impossible to design the study to account for these differences. To account for these differences, pre-harvest stand reconstructions were made for the two "good" properties (Tracts 2C3 and 2C4) by adding the harvested trees (species and predicted DBH from the stump inventory) to the residual tree data. Since there was no way to estimate quality for the harvested trees, all harvested trees were assumed to have had a tree quality of 2 (average). After reconstruction, the pre-harvest stands were hypothetically "high-graded" by removing certain trees from the database in a simulated harvest. These harvest simulations were done in a manner which mimicked the harvest practices employed on many of the "poor" properties examined in this study (Table 12). 
Table 12. Criteria used to select trees for hypothetical "high-grade" harvest of reconstructed preharvest stands on Tracts $2 C 3$ and $2 C 4$.

\begin{tabular}{|c|c|c|}
\hline Species & Diameter Range & Harvest Criterion \\
\hline \multirow{3}{*}{$\begin{array}{c}\text { Ash spp. } \\
\text { Black cherry } \\
\text { Cucumbertree } \\
\text { Northern red oak } \\
\text { Sugar maple } \\
\text { White oak } \\
\text { Yellow-poplar }\end{array}$} & $\geq 16^{\prime \prime}$ & All trees with tree quality $=1,2$ or 3 \\
\hline & $14-15 "$ & All trees with tree quality $=1$ or 2 \\
\hline & $\leq 13^{\prime \prime}$ & No trees harvested \\
\hline \multirow{2}{*}{$\begin{array}{l}\text { Black oak } \\
\text { Chestnut oak } \\
\text { Red maple } \\
\text { Scarlet oak }\end{array}$} & $\geq 16^{\prime \prime}$ & All trees with tree quality $=1$ or 2 \\
\hline & $<16$ & No trees harvested \\
\hline All other species & All diameters & No trees harvested \\
\hline
\end{tabular}

After the simulated "high-grade" harvest, adjustments were made to the residual stand to simulate the increased logging damage that occurs with typical "poor" harvesting practices. Since the amount of significant (severity code $=2$ or 3 ) logging damage on "poor" tracts was roughly twice that on "good" tracts (Table 11), the amount of logging damage present on each tract was doubled. For example, if a 20 " sugar maple on Tract $2 \mathrm{C} 3$ actually sustained a bole damage rating of 2 (as determined from our field investigation), another 20" sugar maple on this tract was assigned a bole damage rating of 2 for the "high-grade" scenario.

The resulting hypothetical residual stands were projected using FVS as described earlier. This method was employed to provide a clear comparison of "good" harvesting (projection of the actual residual stand) with "high-grading" (projection of the hypothetical high-graded stand) using the same tract, thus eliminating confounding factors - such as differences in initial species composition, volume, and tree quality - that are inherent when comparing two different tracts, each subjected to a different harvest scenario. 


\section{Results}

Tables 12 - 15 present pre-harvest, post-harvest and projected future whole-stand parameters for all trees $\geq 5$ " DBH on Tracts $2 \mathrm{C} 3,2 \mathrm{C} 4,4 \mathrm{I} 6$, and $4 \mathrm{~N} 1$. Data for Tracts $2 \mathrm{C} 3$ and 2C4 (Tables 12 and 13) include post-harvest and projected future parameters for the hypothetical "high-grade" harvest scenarios, in addition to post-harvest and projected future parameters for the tracts as they were actually harvested ("good" harvest scenarios).

Table 13. Pre-harvest, post-harvest and 10- and 20-year projected whole-stand parameters for Tract 2C3, assuming "good" and "high-grade" harvest scenarios.

\begin{tabular}{|ccccccl|}
\hline Tract & $\begin{array}{c}\text { Harvest } \\
\text { Scenario }\end{array}$ & $\begin{array}{c}\text { Years After } \\
\text { Harvest }\end{array}$ & $\begin{array}{c}\text { Trees per } \\
\text { Acre }\end{array}$ & $\begin{array}{c}\text { Basal } \\
\text { Area }\end{array}$ & $\begin{array}{c}\text { Volume } \\
\text { (bd.ft./ac.) }\end{array}$ & Major Species (\% of basal area) \\
\hline \hline 2C3 & Pre-harvest & 0 & 115 & 122 & 13,887 & chestnut oak (39\%); yellow-poplar (11\%); n. red oak (11\%) \\
\hline 2C3 & "Good" & 0 & 97 & 70 & 5,429 & chestnut oak (31\%); hickory (10\%); n. red oak (7\%) \\
2C3 & "Good" & 10 & 95 & 81 & 7,398 & chestnut oak (31\%); hickory $(10 \%) ;$ n. red oak $(7 \%)$ \\
2C3 & "Good" & 20 & 94 & 92 & 9,399 & chestnut oak (30\%); hickory (10\%); n. red oak (8\%) \\
\hline 2C3 & High-Grade & 0 & 85 & 50 & 2,461 & chestnut oak (30\%); hickory (16\%); red maple (8\%) \\
2C3 & High-Grade & 10 & 84 & 62 & 4,156 & chestnut oak (31\%); hickory (16\%); red maple (8\%) \\
2C3 & High-Grade & 20 & 83 & 73 & 5,719 & chestnut oak (30\%); hickory (15\%); red maple (8\%) \\
\hline
\end{tabular}

Table 14. Pre-harvest, post-harvest and 10- and 20-year projected whole-stand parameters for Tract 2C4, assuming "good" and "high-grade" harvest scenarios.

\begin{tabular}{|ccccccl|}
\hline Tract & $\begin{array}{c}\text { Harvest } \\
\text { Scenario }\end{array}$ & $\begin{array}{c}\text { Years After } \\
\text { Harvest }\end{array}$ & $\begin{array}{c}\text { Trees per } \\
\text { Acre }\end{array}$ & $\begin{array}{c}\text { Basal } \\
\text { Area }\end{array}$ & $\begin{array}{c}\text { Volume } \\
\text { (bd.ft./ac.) }\end{array}$ & Major Species (\% of basal area) \\
\hline \hline 2C4 & Pre-harvest & 0 & 127 & 113 & 11,039 & white oak (44\%); n. red oak (12\%); yellow-poplar (10\%) \\
\hline 2C4 & "Good" & 0 & 110 & 76 & 5,784 & white oak (42\%); yellow-poplar (12\%); n. red oak (9\%) \\
2C4 & "Good" & 10 & 109 & 89 & 7,889 & white oak (40\%); yellow-poplar (12\%); n. red oak (9\%) \\
2C4 & "Good" & 20 & 107 & 100 & 9,996 & white oak (40\%); yellow-poplar (13\%); n. red oak (9\%) \\
\hline 2C4 & High-Grade & 0 & 94 & 50 & 2,098 & white oak (36\%); chestnut oak (12\%); red maple (10\%) \\
2C4 & High-Grade & 10 & 93 & 63 & 3,515 & white oak (35\%); chestnut oak (11\%); red maple (10\%) \\
2C4 & High-Grade & 20 & 92 & 75 & 5,249 & white oak (35\%); chestnut oak (11\%); red maple (10\%) \\
\hline
\end{tabular}

Table 15. Pre-harvest, post-harvest and 10- and 20-year projected whole-stand parameters for Tract $4 I 6$.

\begin{tabular}{|cccccl|}
\hline Tract & $\begin{array}{c}\text { Years After } \\
\text { Harvest }\end{array}$ & $\begin{array}{c}\text { Trees per } \\
\text { Acre }\end{array}$ & $\begin{array}{c}\text { Basal } \\
\text { Area }\end{array}$ & $\begin{array}{c}\text { Volume } \\
\text { (bd.ft./ac.) }\end{array}$ & Major Species (\% of basal area) \\
\hline \hline 416 & Pre-harvest & 109 & 112 & 12,450 & yellow-poplar (21\%); n. red oak (17\%); black oak (9\%) \\
\hline 416 & 0 & 81 & 49 & 2,275 & red maple (12\%); beech (12\%); n. red oak (10\%) \\
416 & 10 & 81 & 60 & 3,489 & red maple (13\%); beech (10\%); yellow-poplar (10\%) \\
416 & 20 & 80 & 71 & 4,779 & red maple (13\%); yellow-poplar (11\%); beech (10\%) \\
\hline
\end{tabular}


Table 16. Pre-harvest, post-harvest and 10- and 20-year projected whole-stand parameters for Tract $4 N 1$.

\begin{tabular}{|cccccl|}
\hline Tract & $\begin{array}{c}\text { Years After } \\
\text { Harvest }\end{array}$ & $\begin{array}{c}\text { Trees per } \\
\text { Acre }\end{array}$ & $\begin{array}{c}\text { Basal } \\
\text { Area }\end{array}$ & $\begin{array}{c}\text { Volume } \\
\text { (bd.ft./ac.) }\end{array}$ & Major Species (\% of basal area) \\
\hline \hline 4N1 & Pre-harvest & 122 & 109 & 11,542 & yellow-poplar (23\%); chestnut oak (14\%); white oak (13\%) \\
\hline 4N1 & 0 & 86 & 43 & 1,480 & chestnut oak (21\%); red maple (21\%); white oak (9\%) \\
4N1 & 10 & 85 & 56 & 2,644 & red maple (21\%); chestnut oak (20\%); white oak (10\%) \\
4N1 & 20 & 85 & 68 & 4,302 & red maple (21\%); chestnut oak (19\%); white oak (10\%) \\
\hline
\end{tabular}

Prior to harvesting, the major species on Tract 2C3 were chestnut oak, yellow-poplar, and northern red oak (Table 13). Together, these three species comprised just over $60 \%$ of the total stand basal area. The harvest applied by the consultant on this tract (a "good" harvest) removed $43 \%$ of the stand basal area and $61 \%$ of the sawtimber volume. Post-harvest, the major species on the tract are chestnut oak, hickory, and northern red oak, which collectively comprise nearly $50 \%$ of the total stand basal area. These three species are projected to continue be the major species on the tract throughout the projection period. After 20 years, basal area has returned to $75 \%$ of the pre-harvest level and sawtimber volume is projected to be $68 \%$ of the pre-harvest volume.

The hypothetical "high-grade" harvest on Tract 2C3 removed $59 \%$ of the stand basal area and over $80 \%$ of the sawtimber volume (Table 13). Post-harvest, the major species on the tract are chestnut oak, hickory and red maple, which collectively comprise more than $50 \%$ of stand basal area. These three species are projected to continue to be the major species on the tract throughout the projection period. After 20 years, basal area and sawtimber volume are projected to return to only $60 \%$ and $41 \%$ of their respective pre-harvest levels.

Prior to harvesting, the major species on Tract 2C4 were white oak, northern red oak, and yellow-poplar (Table 14). Together, these three species comprised two-thirds of the total stand basal area. The harvest applied by the consultant on this tract (a "good" harvest) removed 33\% of the stand basal area and $48 \%$ of the sawtimber volume. Post-harvest, the major species on the tract are still white oak, yellow-poplar and northern red oak, which collectively comprise over $60 \%$ of the total stand basal area, although yellow-poplar has become more abundant relative to northern red oak. These three species are projected to continue to be the major species on the 
tract throughout the projection period. After 20 years, basal area has returned to $88 \%$ of the preharvest level and sawtimber volume is projected to be just over $90 \%$ of the pre-harvest volume.

The hypothetical "high-grade" harvest on Tract $2 \mathrm{C} 4$ removed $56 \%$ of the stand basal area and just over $80 \%$ of the sawtimber volume (Table 14). Post-harvest, the major species on the tract are white oak, chestnut oak, and red maple, which collectively comprise more than $50 \%$ of stand basal area. These three species are projected to continue to be major species on the tract throughout the projection period. After 20 years, basal area and sawtimber volume are projected to return to only $66 \%$ and $48 \%$ of their respective pre-harvest levels.

Prior to harvesting, the major species on Tract $4 \mathrm{I} 6$ were yellow-poplar, northern red oak, and black oak (Table 15). Together, these three species comprised nearly half of the total stand basal area. The harvest applied to this tract (with the involvement of an industry forester) removed $56 \%$ of the stand basal area and more than $80 \%$ of the sawtimber volume. Post-harvest, the major species on the tract are red maple, beech, and northern red oak. This represents a stark departure from the pre-harvest species composition. By the end of the projection period, yellowpoplar is projected to replace northern red oak as a major species on the tract. After 20 years, basal area has returned to $63 \%$ of the pre-harvest level and sawtimber volume is projected to be only $38 \%$ of the pre-harvest volume.

Prior to harvesting, the major species on Tract 4N1 were yellow-poplar, chestnut oak, and white oak (Table 16). Together, these three species made up half of the total stand basal area. The harvest applied to this tract (without the involvement of a professional forester) removed $61 \%$ of the stand basal area and $87 \%$ of the sawtimber volume. Post-harvest, the major species on the tract are chestnut oak, red maple, and white oak, which represent a significant change in species composition. These three species remain the major species on the tract throughout the projection period, with chestnut oak becoming somewhat less abundant relative to the other species. After 20 years, basal area has returned to $62 \%$ of the pre-harvest level and sawtimber volume is projected to be only $37 \%$ of the pre-harvest volume. 
Projected 10- and 20-year sawtimber volumes, by tree quality, are presented in Figures 8 and 9. Similar results were obtained for both "good" tracts $(2 \mathrm{C} 3$ and $2 \mathrm{C} 4)$ for both projection periods, suggesting that these results can be generalized for typical properties subjected to "good" harvest practices, as defined in this study. Likewise, similar results were obtained for both "poor" tracts (4I6 and 4N1) for both projection periods, suggesting that these results can be generalized for typical properties subjected to "poor" harvest practices.

After 10 years, "good" tracts contained more than twice the board-foot volume of highest quality trees (Quality =1) and roughly three times the volume in acceptable growing stock (Quality =1 or 2) compared to “poor” tracts (Figure 8).

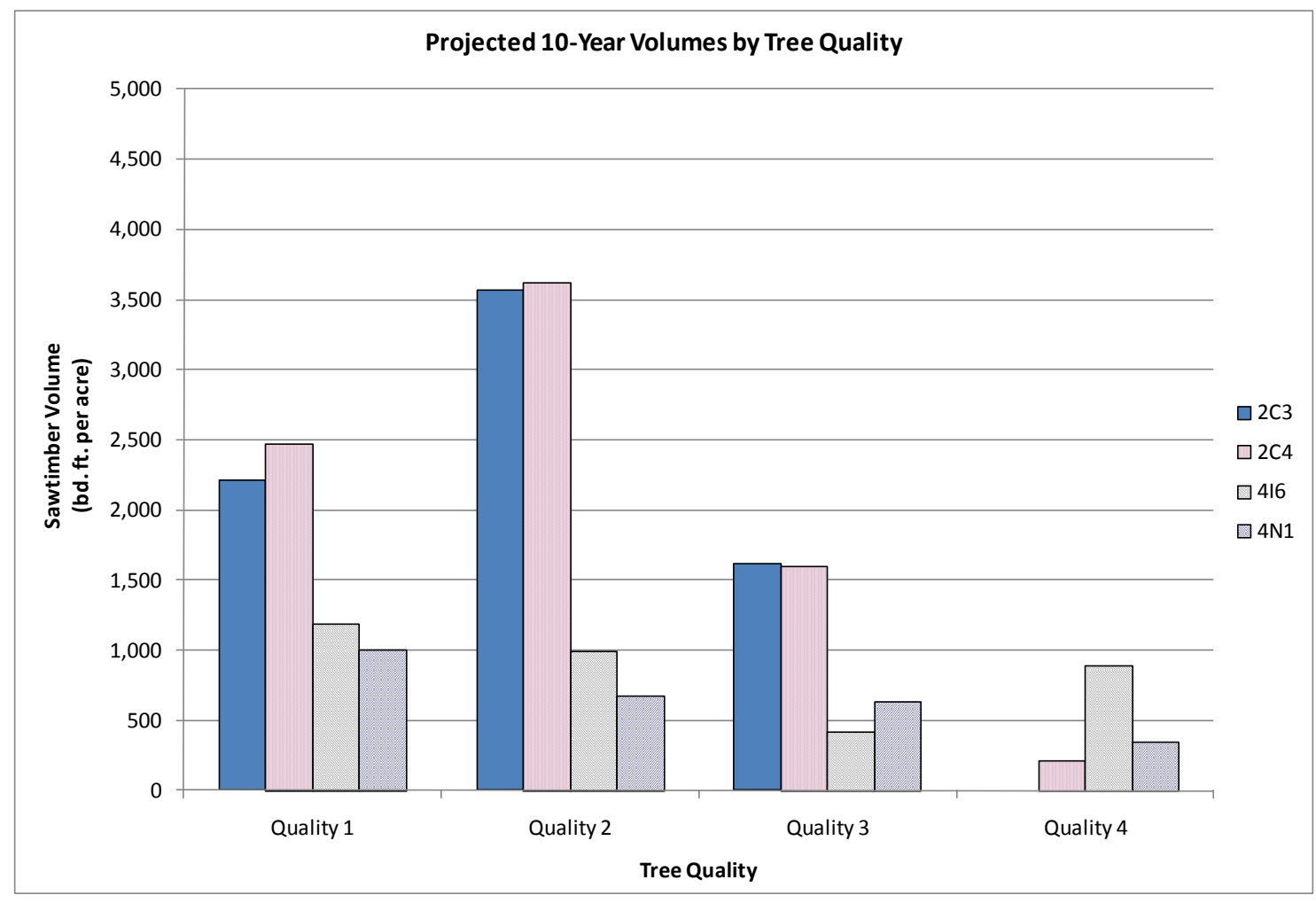

Figure 8. Projected 10-year sawtimber volumes, by tree quality, for tracts subjected to "good" harvest practices (2C3 and 2C4) and tracts subjected to "poor" harvest practices (4I6 and 4N1). 
After 20 years, "good" tracts contained nearly twice the board-foot volume of highest quality trees (Quality =1) and more than twice the volume in acceptable growing stock (Quality $=1$ or 2) compared to "poor" tracts (Figure 9).

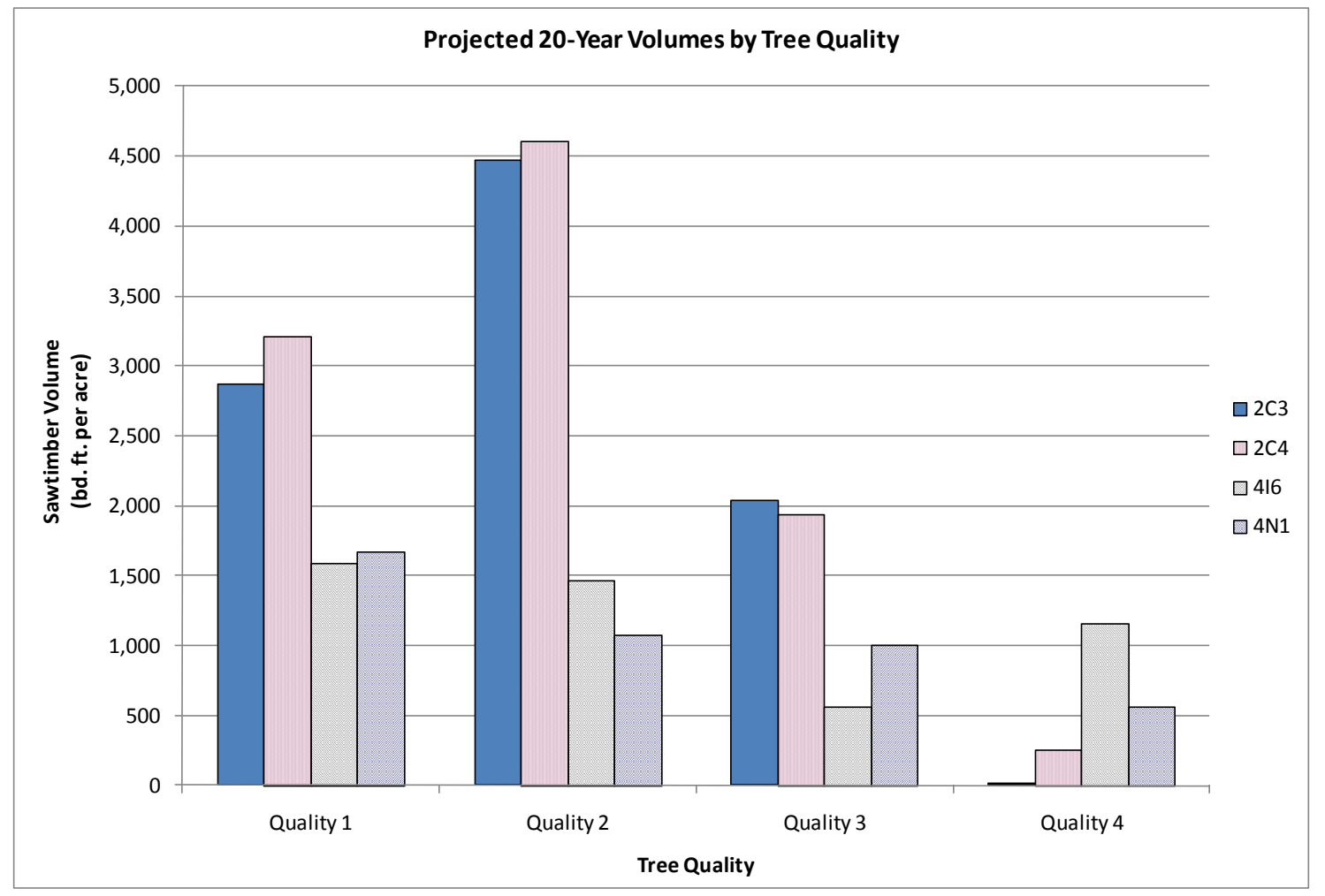

Figure 9. Projected 20-year sawtimber volumes, by tree quality, for tracts subjected to "good" harvest practices (2C3 and 2C4) and tracts subjected to "poor" harvest practices (4I6 and 4N1).

"Good" tracts also contained considerably more volume in poor-quality sawtimber (Quality $=3$ ) as a result of less intensive harvesting and higher residual volumes in all quality classes. However, for both projection periods, more than three-fourths of the board-foot volume in the "good" tracts was contained in acceptable growing stock, compared to less than two-thirds in the "poor" tracts. "Poor" tracts also contained more volume in non-sawtimber quality trees (Quality =4) than the "good" tracts. For "poor" tracts, the volume in non-sawtimber quality trees was nearly as high as the volume in each of the other tree quality classes. 
Tracts subjected to "good" harvest practices contained higher sawtimber volumes in every diameter class after 10 and 20 years, as a result of less intensive harvesting and higher initial residual volumes (Figures 10 and 11). However, the differences between "good" and "poor" tracts were more pronounced in the larger diameter classes, reflecting the trend towards harvesting all large trees with "poor" harvesting practices. After 10 years, "good" tracts contained over 2,500 board feet per acre in trees $\geq 20$ " DBH. By contrast, "poor" tracts contained 500 board feet per acre or less in trees 20 ” DBH or greater.

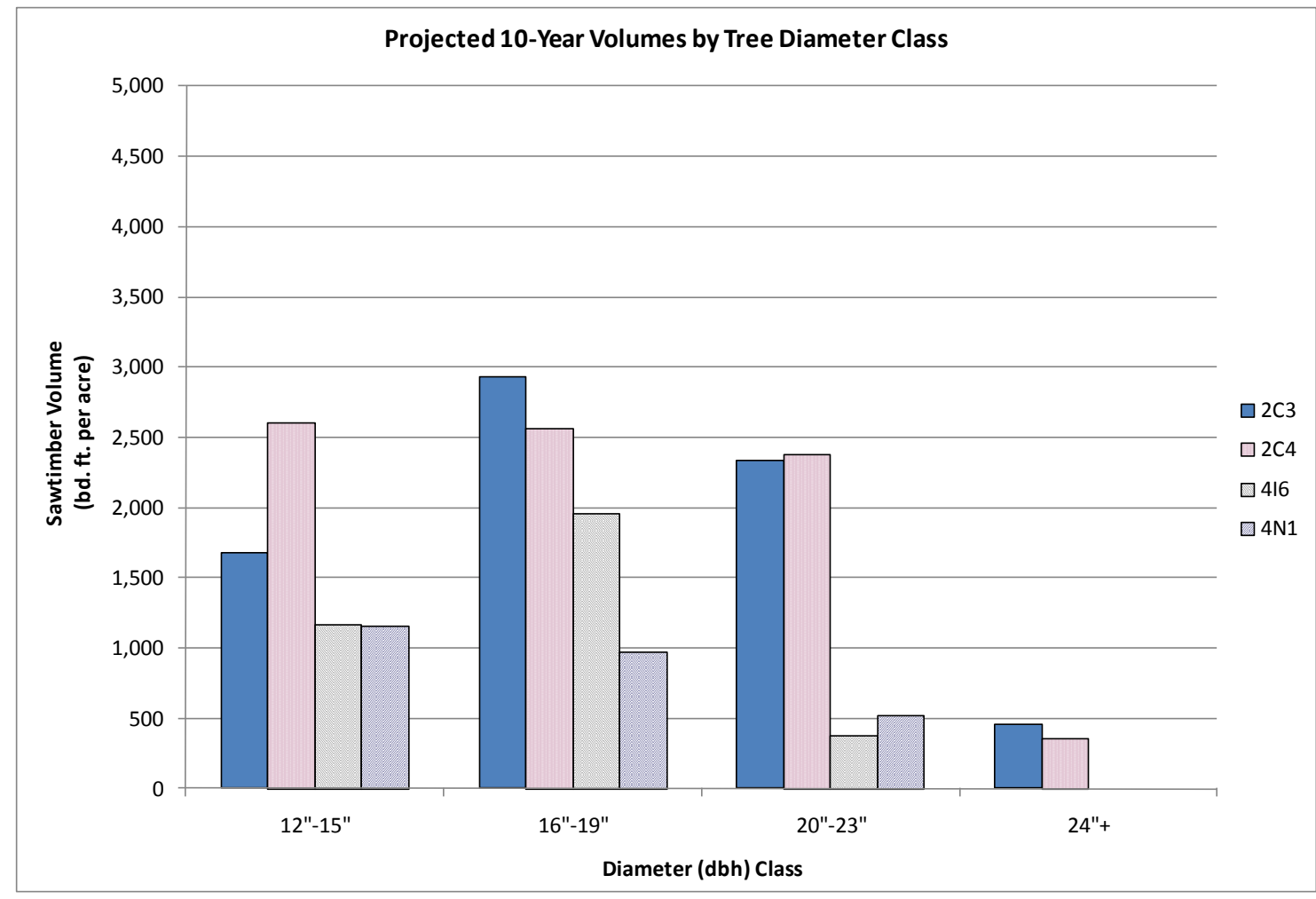

Figure 10. Projected 10-year sawtimber volumes, by diameter class, for tracts subjected to "good" harvest practices (2C3 and 2C4) and tracts subjected to "poor" harvest practices (4I6 and 4N1).

After 20 years, "good" tracts contained over 4,000 board feet per acre in trees $\geq 20$ " $\mathrm{DBH}$, including more than 1,500 board feet per acre in trees 24" DBH or greater. By contrast, "poor" tracts contained less than 1,500 board feet per acre in trees $\geq 20$ " $\mathrm{DBH}$ and virtually no volume in trees $\geq 24$ " DBH (Figure 11). 


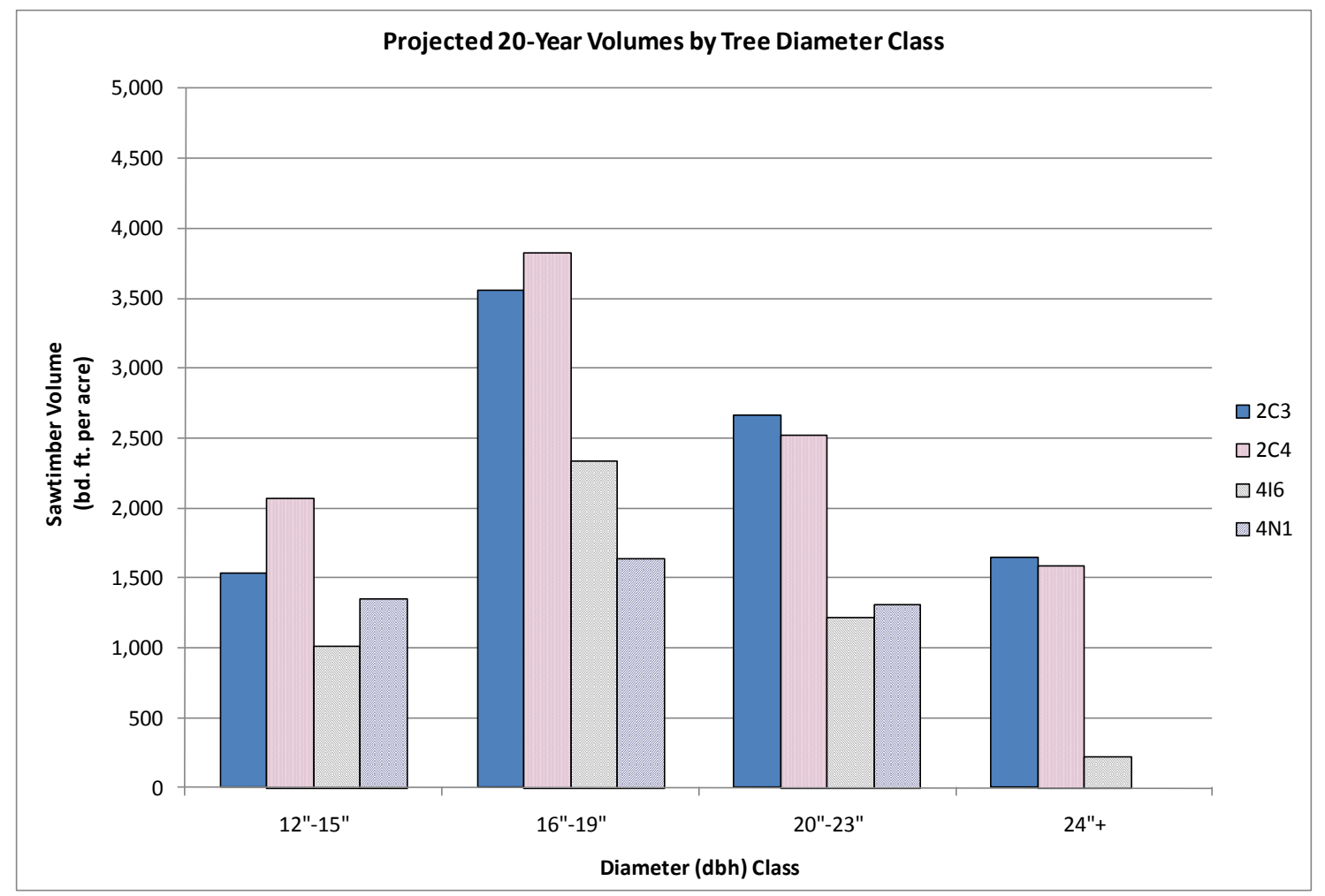

Figure 11. Projected 20-year sawtimber volumes, by diameter class, for tracts subjected to "good" harvest practices (2C3 and 2C4) and tracts subjected to "poor" harvest practices (4I6 and 4N1).

Projections of the "high-grade" simulations on Tracts $2 \mathrm{C} 3$ and $2 \mathrm{C} 4$ were similar to the projections of actual tracts subjected to "poor" harvest practices (Tracts 4I6 and 4N1 in Figure 9), suggesting that the harvest criteria outlined in Table 12 were appropriate for modeling the harvesting practices employed on typical "poor" tracts in this study. Consequently, these projections provided a realistic evaluation of how these two tracts would have responded had they been subjected to "poor" harvest practices instead of the harvest practices that were actually employed by the consulting foresters. In this manner, we can make comparisons of these two harvest practices in the absence of confounding factors - such as species composition, volume and tree quality - that exist when comparing two different tracts, each harvested in a different manner. Since results for the 10-year projections showed the same trends as the 20-year projections, only the results from the 20 -year projections are presented for the "good" versus "high-grade" scenarios. 
After 20 years, "good" harvest practices resulted in nearly twice the total sawtimber board-foot volume compared to the same tracts subjected to "high-grade" harvest practices (Figures 12 and 13 and Tables 12 and 13). More importantly, tracts harvested with "good" practices contained three times as much volume in highest quality trees and more than twice the volume in average quality trees compared to the same tracts subjected to "high-grade" harvest practices. When subjected to "good" harvesting, $78 \%$ of the sawtimber volume on both tracts was contained in acceptable growing stock trees (Quality $=1$ or 2 ) after 20 years. When subjected to "high-grading", only about half of the projected sawtimber volumes on either tract were contained in acceptable growing stock trees.

As a result of less-intensive harvesting under the "good" scenario, both tracts contain more sawtimber volume in all diameter class ranges when subjected to "good" harvesting compared to "high-grading" (Figures 14 and 15). However, the differences were much more pronounced in the larger diameter classes.

When subjected to "good" harvest practices, both tracts were projected to contain five times as much volume in the 20-23" diameter classes after 20 years compared to the same tracts subjected to "high-grading" (Figures 14 and 15). Tract 2C4 also contained five times the volume in trees $\geq 24$ " DBH when subjected to "good" harvesting versus "high-grading" (Figure 15). This difference was much less pronounced on Tract 2C3 (Figure 14), which had more large trees remaining after the simulated "high-grade" harvest. These large trees were either poor-quality or undesirable species (or both) and were therefore not harvested during the "high-grade" harvest simulation. This is consistent with evidence from actual harvesting practices employed on many "poor" tracts inspected during this study.

Even though few trees $<16$ " DBH were harvested during the "high-grade" simulation (see Table 12), this practice still resulted in less volume in trees $\leq 19$ " DBH after 20 years. At least some of this volume reduction is due to increased mortality and volume deductions resulting from the increased logging damage simulated for this scenario. 


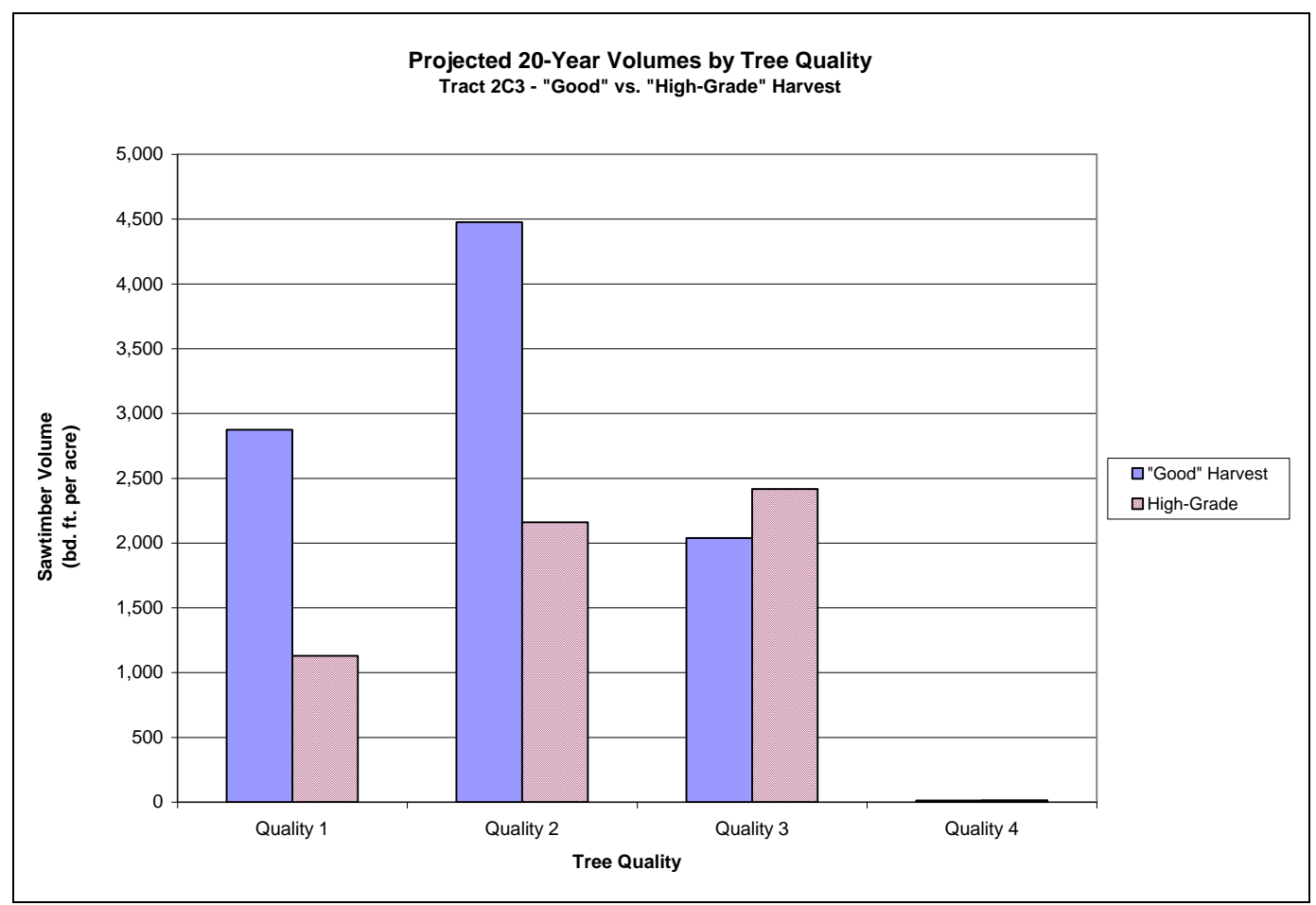

Figure 12. Projected 20-year sawtimber volumes, by tree quality, for Tract 2 C3 under "good" and "high-grade" harvest scenarios.

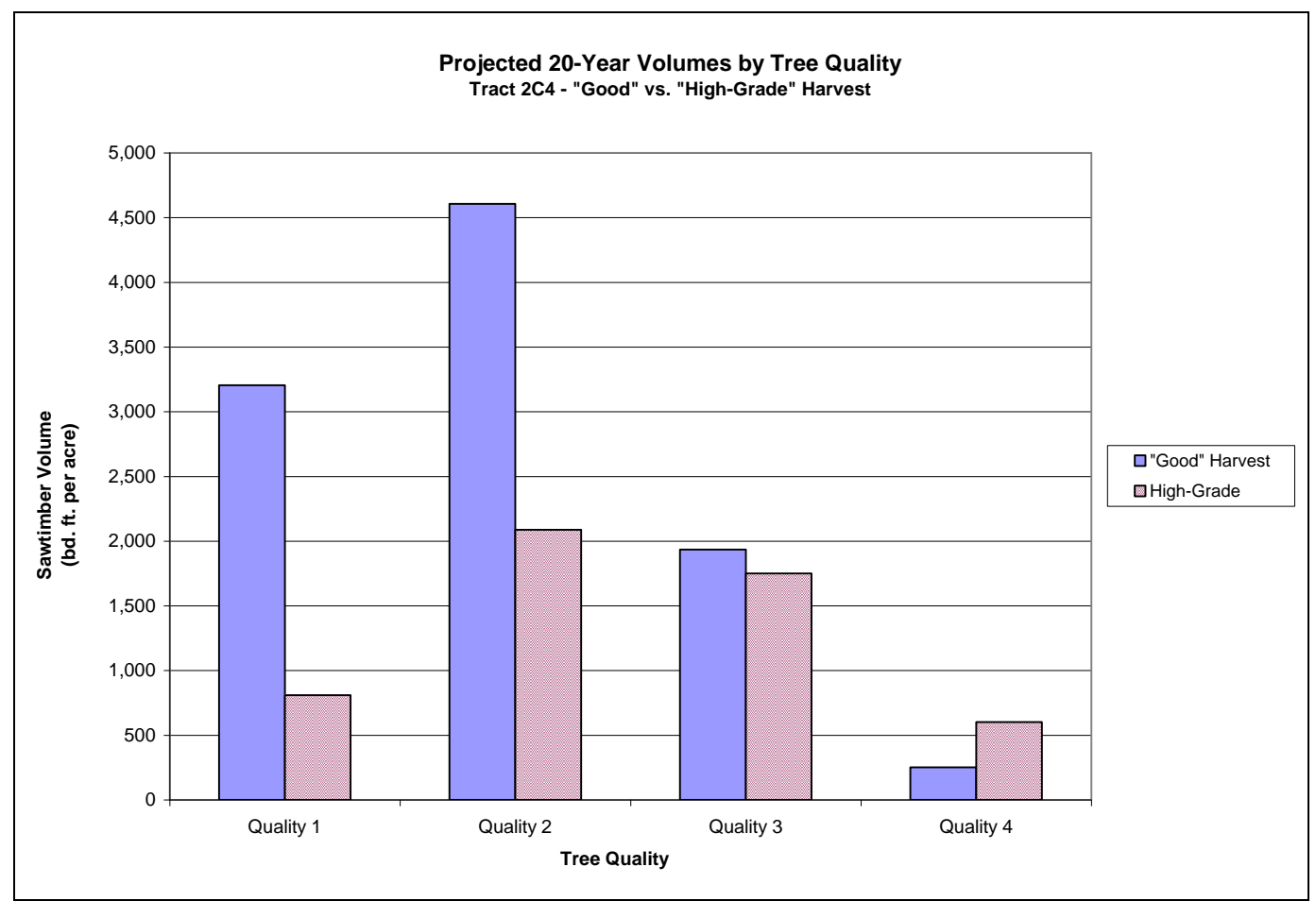

Figure 13. Projected 20-year sawtimber volumes, by tree quality, for Tract 2 C4 under "good" and "high-grade" harvest scenarios. 


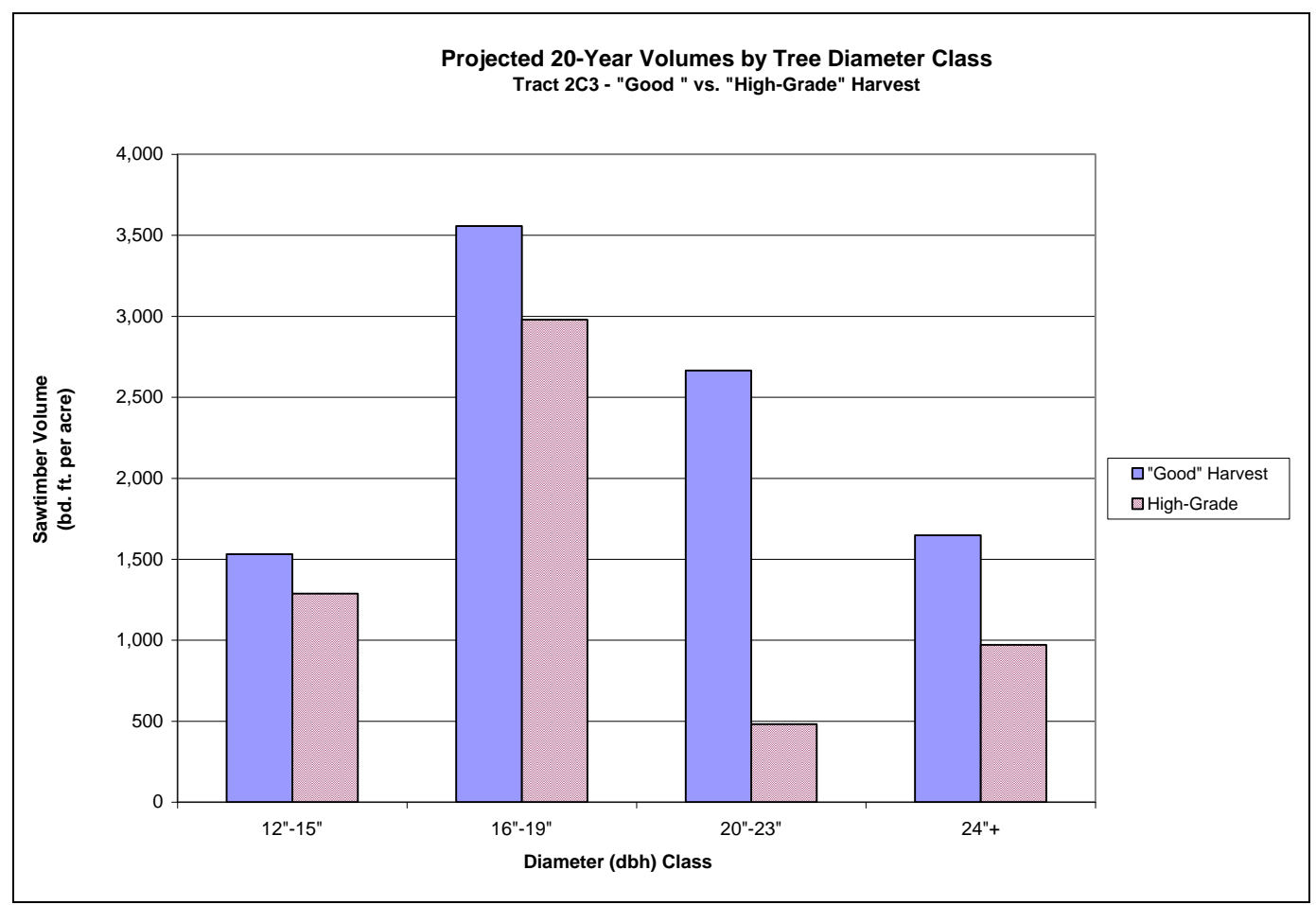

Figure 14. Projected 20-year sawtimber volumes, by tree diameter class, for Tract 2C3 under "good" and "high-grade" harvest scenarios.

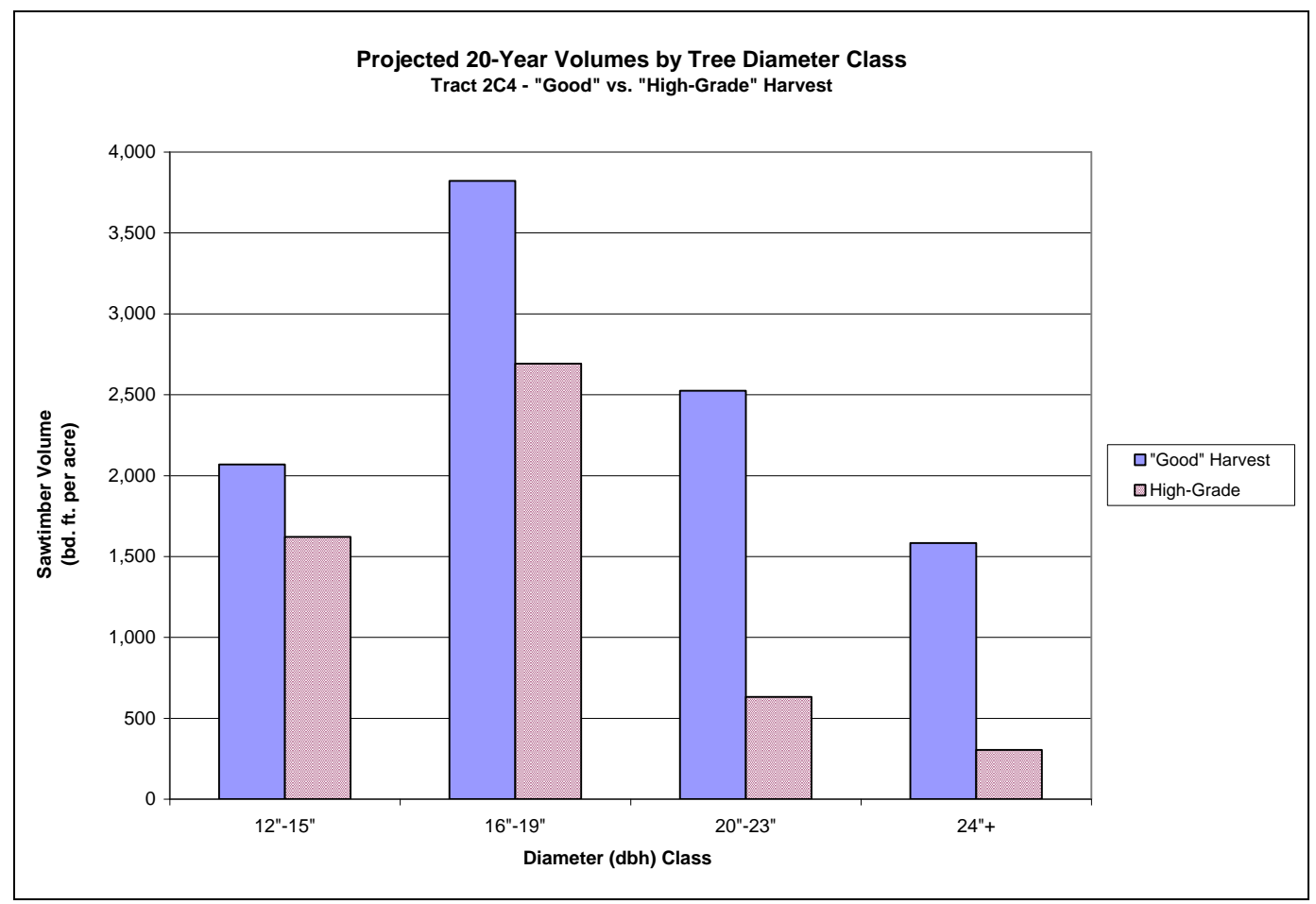

Figure 15. Projected 20-year sawtimber volumes, by tree diameter class, for Tract 2C4 under "good" and "high-grade" harvest scenarios. 
Due to differences in initial species composition, there was little point in comparing projected species composition between the "good" and "poor" tracts examined in this study. However, it was possible to compare projected species

Tract 2C3 contained a high proportion of chestnut oak and miscellaneous hardwood species before and immediately after harvest. As a result, after 20 years chestnut oak and miscellaneous hardwood species still comprise the majority of the sawtimber volume under both harvest practice scenarios (Figure 16). However, when subjected to a "good" harvest, this tract contains more than 750 board feet per acre each of northern red oak, white oak, yellow-poplar and cucumbertree after 20 years. When subjected to "high-grading", this tract contains fewer than 500 board feet per acre of yellow-poplar and fewer than 150 board feet per acre of northern red oak, white oak and cucumbertree after 20 years.

Prior to harvest, the major species on Tract 2C4 were white oak, northern red oak, and yellow-poplar. Twenty years after being subjected to a "good" harvest, these are still the major sawtimber species on the tract, although yellow-poplar has become more prominent relative to northern red oak (Figure 17). By contrast, when subjected to "high-grading", this tract is dominated by white oak, chestnut oak, and miscellaneous hardwood sawtimber after 20 years. White oak sawtimber volume is more than twice as high and yellow-poplar sawtimber volume is six times as high under the "good" scenario compared to the "high-grade" scenario. Twenty years after the "good" harvest, this tract is projected to contain more than 1,000 board feet per acre of northern red oak sawtimber, compared to virtually no red oak sawtimber 20 years after a "high-grade" harvest. 


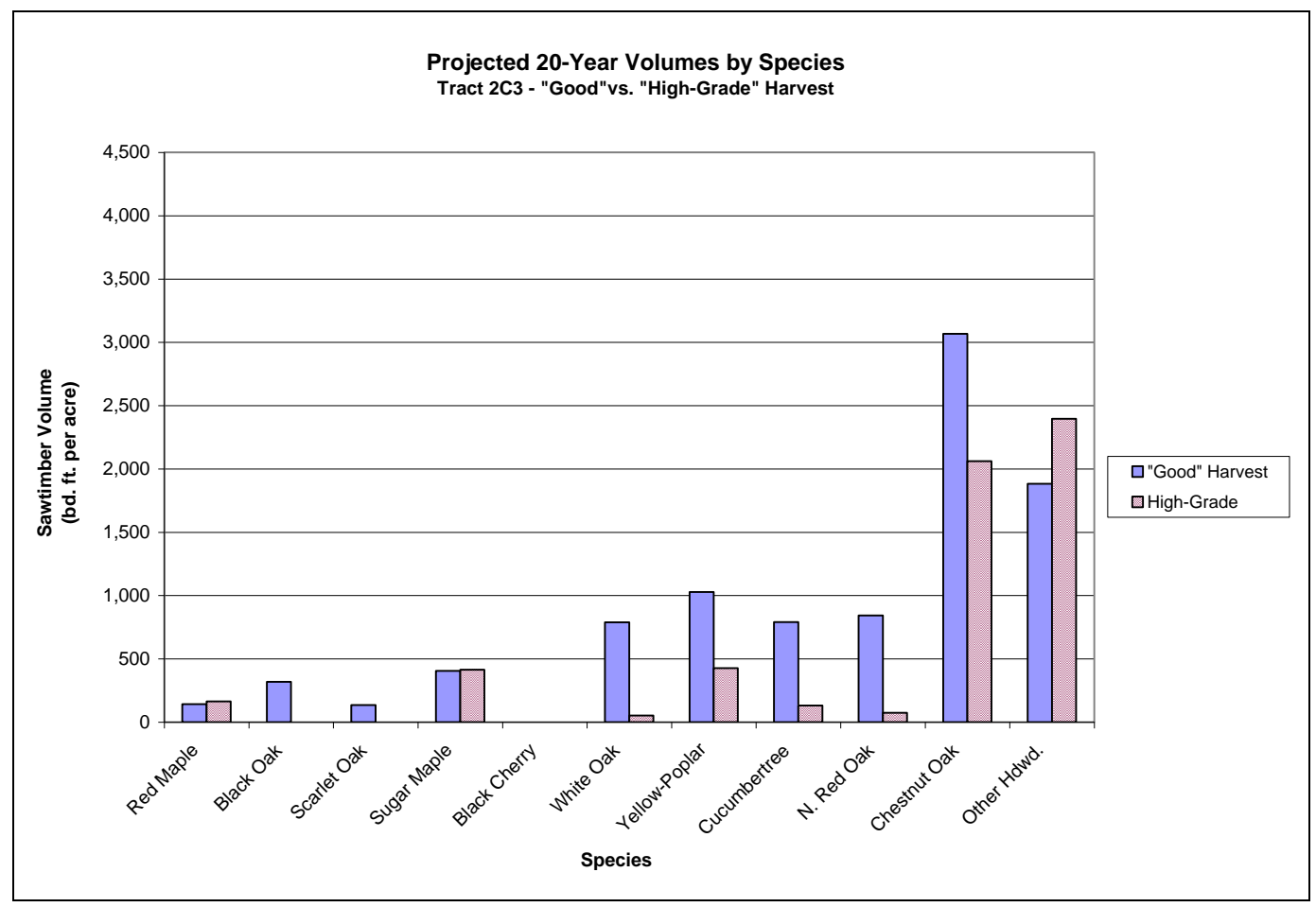

Figure 16. Projected 20-year sawtimber volumes, by species, for Tract $2 C 3$ under "good" and "highgrade" harvest scenarios.

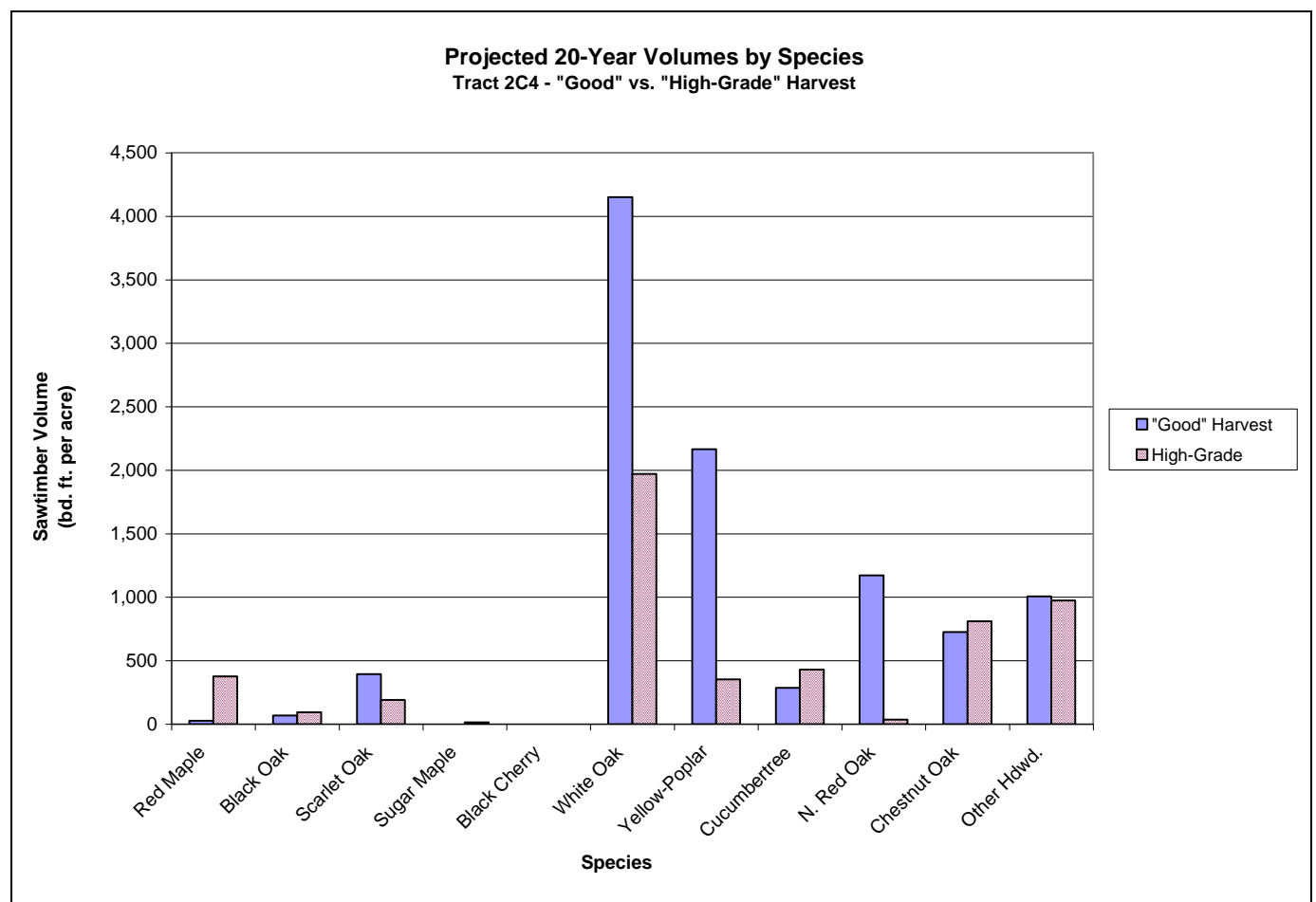

Figure 17. Projected 20-year sawtimber volumes, by species, for Tract 2 C4 under "good" and "highgrade" harvest scenarios. 
In most situations, the most desirable timber for use by typical hardwood sawmills would be characterized as average or better quality trees at least 20 " $\mathrm{DBH}$, as this increases the probability of a tree making a higher grade class (Smith et al. 1979). Figure 18 compares projected 20-year sawtimber volume in acceptable growing stock trees (Quality = 1 and 2) that are at least 20" DBH for Tracts 2C3 and 2C4 under "good" and "high-grade" harvest scenarios and Tracts 4I6 and 4N1 (tracts subjected to "poor" harvest practices).

Twenty years after being subjected to "good" harvest practices, both $2 \mathrm{C} 3$ and $2 \mathrm{C} 4$ are projected to contain over 3,000 board feet per acre of "desirable" timber, ignoring differences in the desirability of various species (Figure 18). By contrast, both tracts are projected to contain less than 500 board feet per acre of "desirable" timber 20 years after being subjected to a "highgrade". Tracts 4I6 and 4N1, both subjected to actual "poor" harvest practices, are projected to contain less than 750 board feet per acre of "desirable" timber in 20 years.

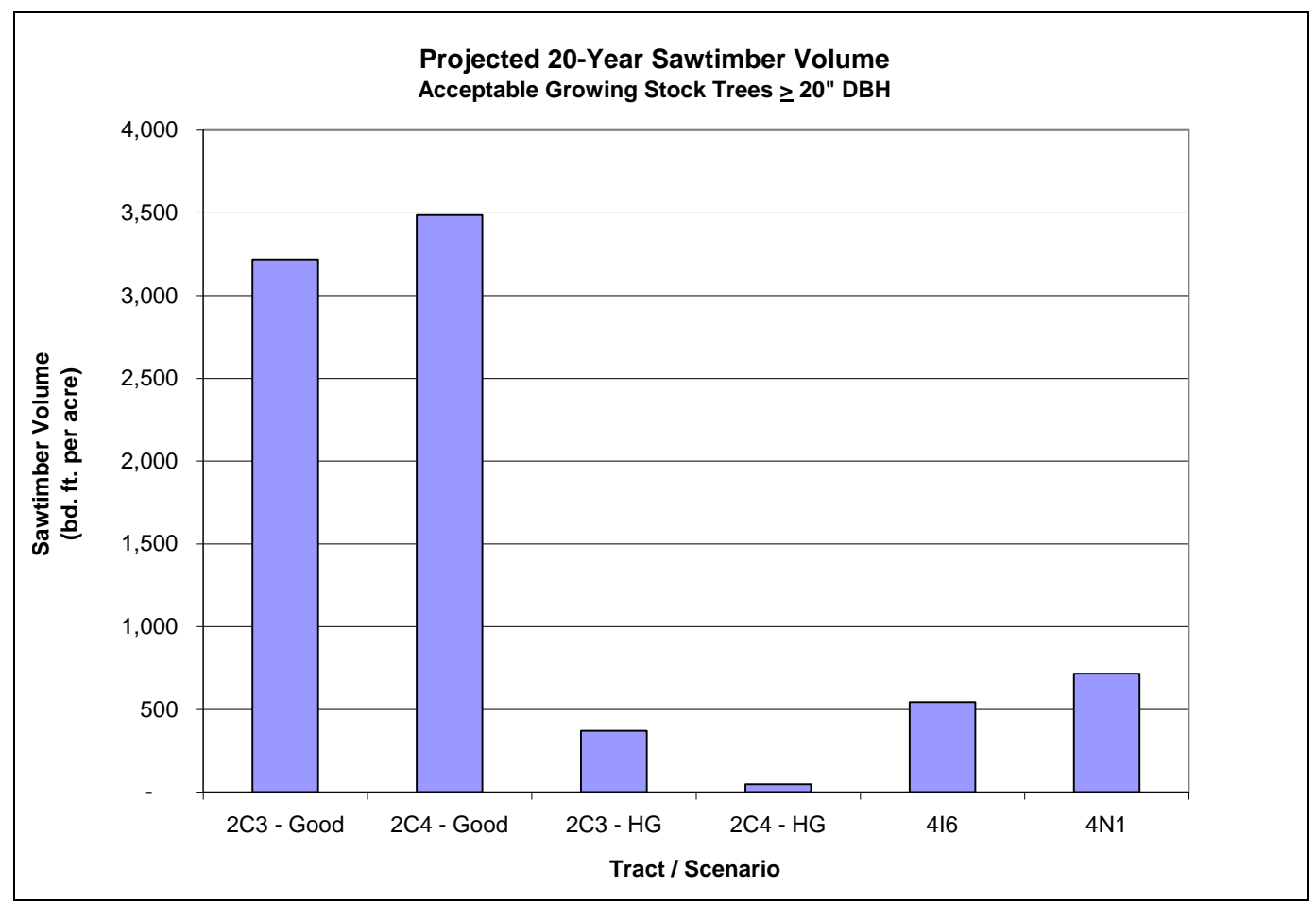

Figure 18. Projected 20-year sawtimber volumes contained in acceptable growing stock trees (Quality $=1$ or 2) which are at least 20" DBH, for Tract 2C3under good and high-grade (HG) scenarios, Tract 2 C4 under good and high-grade scenarios, Tract 4I6, and Tract 4N1. 


\section{Discussion}

The impacts of poor harvesting practices on the timber quality and species composition of residual stands are expected to be readily apparent even 20 years after harvest. While all harvest practices noted in this study have some impact on the species composition of the residual stand, the effects were most pronounced with "poor" harvesting practices. In addition to lower stocking levels, a lower proportion of acceptable growing stock, and a higher incidence of logging damage, "poor" harvest practices also tended to remove a very large proportion of the more desirable (valuable) species. Harvesting on Tract 4I6 changed the species composition from one dominated by yellow-poplar, northern red oak, and black oak to one dominated by red maple, beech, and northern red oak (Table 15). After twenty years, the species composition remains significantly altered from the original composition. Of particular note is the reduction of northern red oak and black oak with a corresponding increase in less desirable red maple and beech.

Likewise, harvesting on Tract 4N1 changed the major species composition from yellowpoplar, chestnut oak, and white oak to one dominated by red maple, chestnut oak and white oak, with red maple replacing the generally more desirable yellow-poplar (Table 16). The relative abundance of chestnut oak increased considerably (from $14 \%$ of stand basal area to $21 \%$ ) as a consequence of very selective harvesting of only the best-quality chestnut oaks. Since chestnut oak generally has fair-to-poor form, it is not surprising that most chestnut oaks would be left unharvested during a "high-grade" harvest.

Harvesting effects on species composition were less pronounced when "good" harvesting practices were employed. Tract 2C3 was dominated by chestnut oak prior to harvesting and, as a result, it remains the dominant species after harvest, although somewhat less abundant relative to other species (Table 13). This is likely due to an effort by the consultant to remove this less desirable species from the stand. As a result of the removal of most commercial yellow-poplar and the infrequent removal of less desirable hickory, hickory replaced yellow-poplar as a major species on the tract after harvesting. However, northern red oak remained a major species on the 
tract, even after fairly intensive harvesting of this desirable species. This is the direct result of the consulting forester leaving most northern red oaks $<20$ " in the stand.

When subjected to a hypothetical "high-grade" harvest, typical of what was employed on tracts that received "poor" harvest evaluations, hickory became even more abundant in the postharvest stand and red maple replaced the more desirable northern red oak as a major species on the tract.

The "good" harvest on Tract 2C4 had minimal impact on post-harvest species composition. Yellow-poplar become somewhat more abundant and northern red oak somewhat less abundant, but both species remained major components of the stand and all three major species retained similar proportions of total stand basal area after harvest (Table 14). By contrast, when subjected to a hypothetical "high-grade", chestnut oak and red maple replaced the more desirable northern red oak and yellow-poplar as major species on the tract. The postharvest white oak component was also decreased due to intensive harvesting of this species.

As expected, these varying impacts on post-harvest species composition have serious ramifications for future sawtimber volumes. Tract $2 \mathrm{C} 3$ contained a large volume of chestnut oak and miscellaneous hardwood sawtimber after harvest. The former is due to the large volume of chestnut oak on the site prior to harvesting and the latter is due to the avoidance of hickory and basswood during harvest (these were the major miscellaneous species remaining after harvest). As a consequence, 20-year sawtimber volume is dominated by chestnut oak and miscellaneous hardwood species (Figure 16). However, the tract is projected to contain over 1,000 board feet per acre of yellow-poplar and over 750 board feet per acre each of northern red oak, white oak, and cucumbertree 20 years after harvest. This would provide ample sawtimber volume in desirable species to make an attractive future timber sale.

Had this tract been subjected to a "high-grade", chestnut oak and miscellaneous hardwoods would also dominate sawtimber volume 20 years after harvest. However, under this scenario the tract would contain fewer than 500 board feet per acre each of yellow-poplar and sugar maple and less than 150 board feet per acre each of northern red oak and white oak. 
This illustrates the potential benefits gained by applying silviculture to timber harvests even on stands dominated by less-desirable species, such as chestnut oak. When high-graded, the future timber harvest on this tract would consist almost entirely of chestnut oak and miscellaneous hardwood species, most of which are commercially undesirable (hickory and basswood). As a consequence, it is questionable whether or not a commercially-viable harvest could occur in this stand 20 years after a high-grade harvest. By contrast, when subjected to a "good" harvest, this stand contains significant volumes of desirable species (northern red oak, white oak, and yellow-poplar) in addition to chestnut oak. Under this scenario, this tract can clearly support a commercial harvest 20 years after the initial harvest conducted by a consulting forester.

Tract 2C4 was dominated by white oak, yellow-poplar and northern red oak sawtimber, both before and after harvesting and all three species will contain significant sawtimber volume 20 years after harvest (Figure 17). White oak and yellow-poplar each contain over 2,000 board feet per acre and northern red oak contains more that 1,000 board feet per acre. By contrast, had the tract been subjected to a "high-grade", 20-year white oak sawtimber volume would be less than half the volume expected after a "good" harvest. In addition, sawtimber volumes of yellowpoplar and northern red oak would be less than 500 board feet per acre each. Next to white oak, chestnut oak and miscellaneous hardwoods would be the most abundant sawtimber species on the tract. While the substantial volume of white oak sawtimber would probably justify a commercial harvest 20 years after the initial high-grade harvest, this will be a much less desirable harvest compared to the one that would occur 20 years after the initial "good" harvest. In fact, the tract would have to be harvested very heavily (either clearcut or severe high-grade) to support a timber harvest in 20 years.

The economics of commercial timber harvesting dictates that at least some emphasis be placed on the harvesting of the more desirable/valuable species. As a consequence, it is expected that timber harvesting will have some impact on future stand composition. Given that, it was somewhat surprising that the "good" harvest practices examined in this study had such a minor impact on post-harvest species composition. This provides evidence that commercial harvests can be conducted in a manner that maintains the presence of the more desirable timber species in 
the future stand. By contrast, "poor" harvest practices can drastically alter species composition and often result in the replacement of desirable species with less desirable/valuable species. These effects persist until at least the next harvest on the site $(20+$ years $)$.

Harvesting impacts on future sawtimber quality are even more substantial than the impacts on species composition. In this study, "good" harvest practices resulted in twice the volume in highest-quality timber and nearly three times the volume in acceptable growing stock timber compared to "poor" harvest practices, after 10 and 20 years (Figures 8 and 9). When coupled with the changes in species composition, this clearly has a significant impact on the value of the future forest and the ability to conduct subsequent commercial timber harvests within a reasonable timeframe (10-20 years).

After twenty years, tracts subjected to "poor" harvest practices contain 3,000 board feet per acre or less of acceptable growing stock timber. As a consequence, virtually all acceptable growing stock trees would need to be harvested to support a commercially-viable harvest. In other words, the tract would have to be subjected to yet another "high-grade". Thus, highgrading becomes a self-perpetuating reality - a high-grade harvest sows the seeds for a future high-grade harvest. By contrast, "good" harvest practices resulted in more than 7,000 board feet per acre in acceptable growing stock trees. Thus, it is possible to conduct a future commercial timber harvest without the need to harvest every acceptable growing stock tree. In addition, the presence of such a substantial volume of quality timber provides opportunities to implement silviculture into the future harvest. By marking significant quality timber, the forester can also mark a reasonable amount of undesirable timber (poor quality or undesirable species) without having a significant negative impact of the overall attractiveness of the sale. On tracts with only a small volume of quality timber, not only must all of the quality timber be harvested to make the sale financially attractive to a buyer, the inclusion of even a small amount of poor-quality timber may reduce the overall sale value to the point that it may be financially unattractive to buyers. Thus, just as poor harvest practices beget future poor harvest practices, good harvest practices open the possibility of continued good harvest practices into the future. This has very important implications regarding sustainability, particularly as it applies to timber quality. 
Similarly, "good" harvest practices in this study resulted in substantially more sawtimber volume in trees $\geq 20$ " DBH (Figures 10 and 11). Larger trees produce higher quality lumber, all else being equal (Hanks 1976), and therefore are potentially more valuable than smaller trees of the same grade and species. In addition, large trees are more efficient to harvest, yielding more volume per man-hour or machine-hour ( $\mathrm{Li}$ et al. 2006). This adds to the stumpage value of larger trees by reducing the harvest cost per MBF.

After 20 years, tracts subjected to "good" harvest practices contained over 4,000 board feet per acre in trees 20 ” DBH and greater, compared to less than 1,500 board feet per acre on tracts subjected to "poor" harvest practices. Some research has suggested that maintaining harvest diameter limits of 20 " or greater can maintain, or even improve, overall sawtimber quality in a stand (Smith et al. 1979). In the case of the "good" tracts, it should be possible to limit future harvesting to these larger diameter classes, plus the removal of smaller trees of poorquality, low vigor, or undesirable species. By contrast, the "poor" tracts contain insufficient volume in these larger diameter classes to support a commercial harvest, even 20 years after the initial harvest. It will be necessary to harvest substantial volume from the smaller diameter classes in order to create a commercially-viable harvest (i.e. a 14" or 16" diameter-limit harvest). Again, poor harvest practices create the need to conduct poor harvests again in the future, with serious implications for the long-term sustainability of quality timber.

Given the negative long-term consequences of poor harvesting practices on timber quality (both grade and species composition), it is noteworthy that these practices are commonly utilized on NIPF properties harvested by industry foresters. Nearly two-thirds of the harvests conducted by industry foresters in this study received "poor" evaluations (Figure 7). This phenomenon is troubling since, in the absence of a consulting forester to advise the landowner, it is the industry forester who often determines the harvest practices to be employed. Thus, professional foresters are often the ones prescribing poor harvest practices in the Appalachian region.

A likely explanation for this behavior is that eastern hardwood forests suffer from "the tragedy of the commons", an economic theory used to explain the exploitation and 
mismanagement of publicly-available resources. Although the majority of eastern forests are privately owned, from the standpoint of buyers procuring timber the resource is publiclyavailable, not private. All buyers have the opportunity to approach timberland owners and negotiate for the purchase of their timber. These same landowners are free to negotiate future sales with other buyers. When considering the harvest practice to be employed on a landowner's property, the procurement forester has the opportunity to practice silviculture, which will entail foregoing some benefit now (harvesting less timber, leaving some quality trees and desirable species, and harvesting some poor-quality timber) in exchange for increased benefits in the future (more desirable species, better quality and larger average tree size). However, there is no guarantee that the procurement forester will be the one to benefit from this investment in silviculture. When it comes time to harvest the stand again and reap the benefits "sown" during the initial harvest, the landowner is free to negotiate with other buyers. The original landowner might not even own the forest by the time a second harvest is warranted and the future owner may have different objectives for the property. It is possible that the landowner could convert the forest to other uses and opt not to engage in any future harvesting, completely eliminating any future benefit that could have been realized from practicing silviculture. In this context, the rational option for the procurement forester is to gain as much benefit from the current harvest as possible, so as to avoid leaving benefits in the forest that will be reaped later by other foresters or lost completely.

Since the benefits of silviculture are likely to be realized by the landowner, it is in the landowner's best interest to practice good harvesting practices, not the timber buyer's. However, without sufficient knowledge about the long-term consequences of harvesting decisions, landowners unassisted by foresters who represent their interests are likely to accept the recommendations of procurement foresters and loggers, who, acting in their own best interests, will likely recommend poor harvest practices. It is noteworthy that $75 \%$ of the "good" harvests encountered in this study were conducted by consulting foresters, presumably working in the best interest of the landowner. 


\section{CHAPTER III}

\section{The Long-term Economic Impacts of "Good" and "Poor" Harvest Practices}

Results from the growth and yield projections from the second phase of the project were used to perform economic analyses comparing "good" and "poor" harvest practices, as defined in the first phase of the project. This data was also used to compare "good" harvest practices actually employed on some properties with hypothetical "high-grade" harvests on those same properties.

\section{Methodology}

Results from the FVS simulations were used to perform long-term financial analyses of the effects of the harvesting practices observed in this study. Financial analyses were performed for Tracts 2C3, 2C4 (both subjected to "good" harvest practices), 4I6, and 4N1 (both subjected to "poor" harvest practices). In addition, Tracts $2 \mathrm{C} 3$ and $2 \mathrm{C} 4$ were analyzed under the hypothetical "high-grade" scenario in addition to the "good" harvest actually implemented.

A comparative financial analysis of various harvesting practices entails combining all income received from timber harvesting over a specified time period plus the residual timber value of the stand at the end of the time period (terminal value). For this study, the analysis time period chosen was 20 years. For many NIPF landowners, this probably represents a typical timeframe for long-range planning. After harvesting, a typical Appalachian hardwood stand should have sufficient volume to sustain a subsequent harvest within 20 years (Miller 1993; Miller and Smith 1991). The effects of the initial harvest on stand characteristics and value should be apparent by the time of the next harvest, i.e. after 20 years. While 20 years might not be considered "long-term" in the context of forest management, it certainly represents "longterm" planning for the typical individual landowner. Since landowners make management and financial decisions based on timeframes relative to them, not those relative to forestry in a broader context, this timeframe was deemed appropriate. 
In order to perform long-term financial analyses, it is necessary to project timber volumes into the future, determine appropriate stumpage prices to apply to those volumes, and apply an appropriate discount rate to future cash flows and timber values. The projection of future timber volumes was presented in Chapter II. Methodologies for determining stumpage prices and discount rates are presented in this chapter.

\section{Determination of Stumpage Prices - Adjustments for Tree Quality and DBH}

Stumpage prices for hardwood sawtimber reflect the expected revenue from the sale of hardwood lumber minus mill production costs, profit, and expenses related to the procurement, harvesting, and transportation of saw logs to the mill. In order to estimate the value per board foot of lumber expected to be sawn from a log, it is necessary to determine the species, quality and size of the log. Obviously, different species and grades of lumber have different desirability in the marketplace, and these varying demands are reflected in the prevailing market prices for lumber. Log diameter and grade have a strong bearing on the grades and value of lumber produced from the log. As a consequence, larger, higher-grade logs are worth more and, subsequently, larger, higher-grade trees are worth more on the stump. A sound analysis of the financial effects of harvesting practices must incorporate not only harvesting effects on the species composition, tree diameters, and timber quality of the future stand, but must apply stumpage prices which incorporate the effects of tree diameter and quality on price, rather than simply relying on species-specific prices.

Stumpage price reporting services, such as the Appalachian Hardwood Center's Timber Market Report (AHC-TMR), report stumpage prices by species only. While these prices are useful for tracking price trends over time, they are of limited use in determining site-specific prices, since they do not account for differences in timber quality, average tree size, and various factors that affect harvesting costs, such as accessibility and operability. In this study, it was critical to account for price differences due to timber quality and tree diameter, since the "good" and "poor" harvest practices examined in this study had such dramatically different effects on these parameters over the 20-year forecast period (Chapter II). 
The effects of tree quality and size on stumpage price were estimated by assuming a positive relationship between lumber and stumpage prices. In a study of this relationship, Luppold et al. (1998) concluded that there is indeed a strong correlation between lumber and stumpage prices over the long-term, even though there is weak correlation over the short-term unless there is a large change in lumber prices. This stands to reason, since the price that buyers can pay for stumpage over the long-term is strongly influenced by the price the mill will receive for the finished lumber, but short-term variations in the availability of, and competition for, stumpage cause fluctuations in stumpage prices not reflected in lumber prices. This study assumed that lumber and stumpage prices are in long-term equilibrium and, as a consequence, lumber prices can be used to derive appropriate stumpage prices.

Hardwood lumber yield data, by species, tree grade, and tree $\mathrm{DBH}$, were obtained from Hanks (1976), while Appalachian regional hardwood lumber prices, by species and grade, were obtained from the Hardwood Market Report (Johnson et al. 2007). These data were combined to calculate expected lumber value, per thousand board feet, for each important timber species, by tree diameter and grade. For example, Table 17 shows predicted lumber grade yields for Forest Service Grade 2 sugar maple trees from 12" to 24" DBH, assuming 32 merchantable feet per tree.

Table 17. Predicted board-foot lumber yield, by grade; total lumber value; lumber value per MBF tree scale; and indicated stumpage price for Forest Service Grade 2 sugar maple trees from 12" to 24” DBH that contain 32 merchantable feet per tree (from Hanks 1976). Lumber prices are for the Appalachian region as of June 2007.

\begin{tabular}{|c|c|c|c|c|c|c|c|c|c|c|c|c|}
\hline \multirow[b]{3}{*}{ DBH } & \multirow{3}{*}{$\begin{array}{c}\text { Tree Volume } \\
\text { bd.ft. }\end{array}$} & \multicolumn{2}{|c|}{ |------------------- } & \multicolumn{3}{|c|}{ Lumber Grade and Price per MBF } & \multicolumn{2}{|c|}{-------------------- } & \multirow{3}{*}{$\begin{array}{l}\text { Total } \\
\text { bd.ft. }\end{array}$} & \multirow{2}{*}{\multicolumn{2}{|c|}{ Lumber Value }} & \multirow{3}{*}{$\begin{array}{c}\text { Indicated } \\
\text { Stumpage } \\
\$ / M B F\end{array}$} \\
\hline & & $\$ 1,265$ & $\$ 1,255$ & $\$ 1,255$ & $\$ 970$ & $\$ 550$ & $\$ 340$ & $\$ 290$ & & & & \\
\hline & & FAS & FAS1F & SEL & $1 \mathrm{C}$ & $2 \mathrm{C}$ & $3 A$ & 3B & & $\$$ & $\$ / \mathrm{MBF}^{1 /}$ & \\
\hline 12 & 100 & 2.7 & 4.9 & 7.6 & 1.7 & 24.9 & 23.4 & 26.9 & 92.0 & $\$ 50.16$ & $\$ 501.60$ & $\$ 78.76$ \\
\hline 13 & 120 & 4.1 & 7.5 & 7.6 & 9.1 & 28.8 & 24.3 & 27.4 & 108.7 & $\$ 65.00$ & $\$ 541.64$ & $\$ 118.81$ \\
\hline 14 & 140 & 5.6 & 10.3 & 7.6 & 17.2 & 32.9 & 25.2 & 27.9 & 126.7 & $\$ 81.02$ & $\$ 578.72$ & $\$ 155.89$ \\
\hline 15 & 160 & 7.3 & 13.3 & 7.6 & 25.9 & 37.3 & 26.2 & 28.5 & 146.1 & $\$ 98.23$ & $\$ 613.96$ & $\$ 191.12$ \\
\hline 16 & 180 & 9.0 & 16.5 & 7.6 & 35.2 & 42.0 & 27.3 & 29.1 & 166.8 & $\$ 116.63$ & $\$ 647.95$ & $\$ 218.00$ \\
\hline 17 & 210 & 10.9 & 19.9 & 7.6 & 45.1 & 47.0 & 28.5 & 29.8 & 188.8 & $\$ 136.22$ & $\$ 648.65$ & $\$ 225.82$ \\
\hline 18 & 240 & 12.8 & 23.6 & 7.6 & 55.5 & 52.3 & 29.7 & 30.5 & 212.1 & $\$ 156.99$ & $\$ 654.12$ & $\$ 231.29$ \\
\hline 19 & 270 & 14.9 & 27.4 & 7.6 & 66.6 & 57.9 & 31.0 & 31.2 & 236.8 & $\$ 178.95$ & $\$ 662.77$ & $\$ 239.94$ \\
\hline 20 & 300 & 17.1 & 31.5 & 7.6 & 78.3 & 63.9 & 32.4 & 32.0 & 262.8 & $\$ 202.09$ & $\$ 673.65$ & $\$ 250.81$ \\
\hline 21 & 330 & 19.4 & 35.7 & 7.6 & 90.6 & 70.1 & 33.9 & 32.9 & 290.2 & $\$ 226.43$ & $\$ 686.14$ & $\$ 263.31$ \\
\hline 22 & 360 & 21.9 & 40.2 & 7.6 & 103.5 & 76.7 & 35.4 & 33.7 & 318.9 & $\$ 251.95$ & $\$ 699.86$ & $\$ 277.02$ \\
\hline 23 & 395 & 24.4 & 44.9 & 7.6 & 116.9 & 83.5 & 37.0 & 34.6 & 348.9 & $\$ 278.66$ & $\$ 705.46$ & $\$ 282.62$ \\
\hline 24 & 430 & 27.0 & 49.7 & 7.6 & 131.0 & 90.6 & 38.6 & 35.6 & 380.3 & $\$ 306.55$ & $\$ 712.91$ & $\$ 290.07$ \\
\hline
\end{tabular}

1/ - Tree scale 
Lumber prices indicated in Table 17 were average prices for the month of June 2007, as reported by the Hardwood Market Report. Multiplying lumber yield by the appropriate price for each grade of lumber yields the total lumber value per tree. For example, a 16" grade 2 sugar maple tree is predicted to yield 9.0 board feet of FAS grade lumber, 16.5 board feet of FAS1F grade lumber, etc., with a total lumber value of $\$ 116.63$ (as of June 2007). Estimated board-foot volume for a 16" two-log tree is 180 board feet, International 1/4" scale, Form Class 78. Therefore, the value of the lumber expected from this tree is $\$ 647.95$ per thousand board feet of tree scale $(\$ 116.63 / 180 * 1,000)$. As expected, lumber value per MBF tree scale increases with increasing DBH, as a result of higher yields of better grades of lumber. A 16" Grade 2 sugar maple tree yields 41\% 1C and better lumber, whereas a 24" Grade 2 sugar maple yields 57\% 1C and better lumber.

This process was repeated for Forest Service Tree Grades 1 and 3 and for the following timber species: red maple, black oak/scarlet oak, sugar maple, black cherry, white oak, yellowpoplar/cucumbertree, northern red oak, and chestnut oak. Since there are no standardized criteria for determining veneer grade, no attempt was made to estimate the potential for future veneer quality for the residual trees. Consequently, there was no need to calculate stumpage prices for veneer-quality trees.

The resulting lumber values per MBF tree scale formed the basis for adjusting stumpage prices obtained from the $A H C-T M R$ to reflect the effects of tree grade and diameter. It was assumed that the stumpage prices in the $A H C$-TMR reflect prices of "average" timber. While any number of definitions of "average" timber might be appropriate, it was assumed that Grade 2 trees from 16" to 24" DBH would constitute "average" timber in most circumstances. For sugar maple, the average lumber value per MBF tree scale for Grade 2 trees from 16" to 24" DBH was $\$ 676.83 / \mathrm{MBF}$. The statewide average price for sugar maple stumpage reported by the $A H C$ $T M R$ for the $2^{\text {nd }}$ and $3^{\text {rd }}$ quarters of 2007 was $\$ 254.00 / \mathrm{MBF}$. The difference between lumber value per $\mathrm{MBF}$ and stumpage price per MBF represents sawmill operating costs, harvest and transportation costs, procurement and transaction costs, market forces arising from localized supply and demand for sugar maple stumpage, and profit for various entities, as well as random variation and market inefficiencies. Collectively, these will be referred to as "conversion cost", 
since they represent all costs associated with converting timber into lumber. Subtracting the sugar maple conversion cost of $\$ 422.83 / \mathrm{MBF}$ from the lumber price per MBF for every combination of tree grade and DBH yields the indicated stumpage prices for various diameters and grades of sugar maple sawtimber trees (Table 17). For example, a 22" DBH Grade 2 sugar maple has an expected lumber value of $\$ 699.86$ per MBF tree scale. Subtracting the conversion cost of $\$ 422.83 / \mathrm{MBF}$ from this value yields an indicated stumpage price of $\$ 277.02 / \mathrm{MBF}$. This process was repeated for the other timber species. Figure 19 summarizes the resulting stumpage prices for sugar maple. Graphs for the other species are contained in Appendix B.

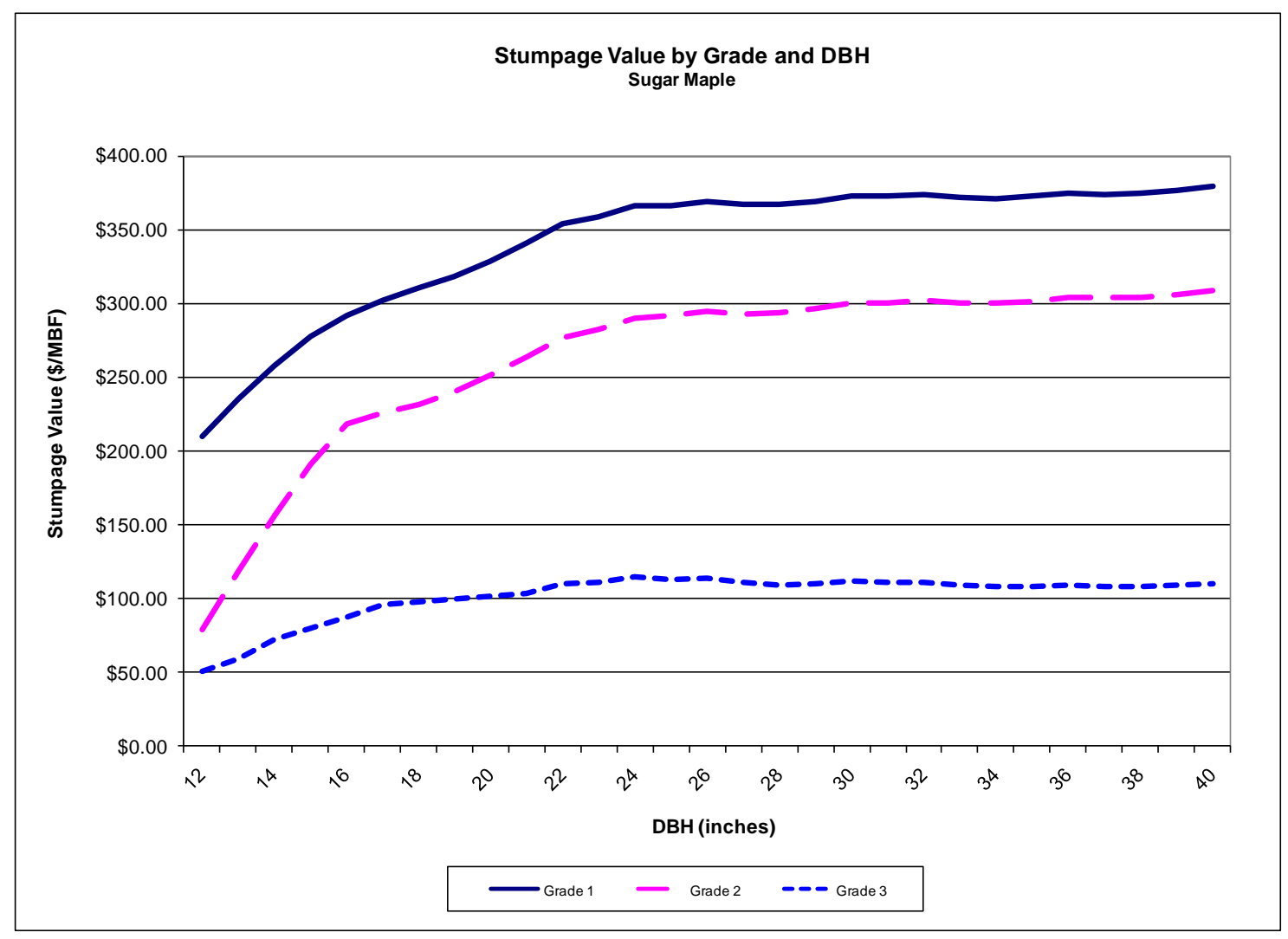

Figure 19. Indicated stumpage value by tree DBH and Forest Service tree grade for sugar maple in West Virginia during the summer of 2007.

Since the analysis by Hanks (1976) contained only the previously listed eight species, all other species were grouped together as miscellaneous hardwood. To make an adjustment to the miscellaneous hardwood stumpage price from the $A H C-T M R$, average lumber value by tree grade and DBH for the eight species were used. Although this clearly does not represent the 
actual lumber values for miscellaneous hardwoods (many of which are low-value species), the purpose of calculating lumber value was to adjust the stumpage price reported by the $A H C-T M R$, and so the method is reasonable.

\section{Determination of Stumpage Prices - Adjustments for Differences in Harvesting Cost}

Per-unit harvesting costs directly impact stumpage prices, since stumpage price is essentially delivered log value minus harvesting, transportation and procurement transaction costs. Although delivered log costs may be very similar within a market region, stumpage prices may vary considerable from site to site due to differences in harvesting cost and distance to purchasing mills. In order to eliminate compounding factors not related to the harvest practices being analyzed, this study assumes that all tracts are similar in most factors that affect harvesting cost (e.g. topography, stream dissection, soil operability, and tract size) and distance to the mill. However, per-unit harvesting cost is affected by harvest volume per acre and average tree size (Cubbage et al. 1989; Egan and Baumgras 2003; Li et al. 2006). Ten and twenty years after harvest, timber volume per acre and average tree size varied greatly between tracts, as a consequence of the harvest practices initially employed. Therefore, it was necessary to adjust stumpage prices for possible differences in harvesting costs.

Harvesting cost was simulated using the Central Appalachian Harvesting Analyzer (CAHA). This model incorporates the important factors that determine harvesting costs for ground-based harvesting systems in the Appalachian region (Wang and LeDoux 2003; Wang et al. 2004; Wang et al. 2007). Stands with significantly different average tree volumes and merchantable trees per acre will incur different harvesting costs since these factors influence felling and skidding efficiency. Although it requires more time to fell a large tree compared to a small tree, the volume harvested is much larger, resulting in a higher volume yield per hour when felling larger trees. Skidding efficiency and cost is greatly influenced by volume per cycle (round trip between the landing and the harvest area). In a stand with large trees, three harvested trees might constitute a full load for the skidder (i.e. approaches hauling capacity). On a site with smaller trees, three trees would contain much less volume and be far below skidder 
capacity. The skidder is left with two choices: 1) return to the landing with three trees, resulting in less volume per cycle, or 2) spend more time collecting a full load (e.g. 4 or 5 trees) in the woods before returning to the landing, resulting in increased cycle times. Either choice results in less volume skidded to the landing per hour and increased harvesting cost per MBF.

The simulated harvesting system utilized on all tracts for all scenarios consisted of a single manual feller using a chainsaw, two cable skidders, and a knuckle-boom loader. Site input variables not affected by the harvesting practices being examined (e.g. moving and setup costs, tract acreage, miles of roads constructed, operator efficiency, etc.) were identical for all tracts and were selected by the investigator to represent typical properties in West Virginia. Operating cost variables (depreciation, maintenance and repair expense, labor expense, etc.) were provided by the developers of the computer model and were deemed typical for a harvesting operation in West Virginia (Wang and Spong 2010). Since the objective was to compare harvesting costs between tracts subjected to various harvest practices, rather than to calculate a highly accurate estimate of harvesting costs, the accuracy of these input variables is unimportant, so long as they are reasonable.

The "good" and "poor" harvesting practices examined in this study had significantly different impacts on future per-acre timber volumes and DBH distributions. To model these effects, stand tables (trees per acre by DBH class and average board-foot volume per tree by DBH class) were entered into the CAHA model for the initial harvests, as well as 10- and 20-year projected stands for Tracts 2C3, 2C4, 4I6, and 4N1. For Tracts 2C3 and 2C4, separate simulations were run for the "good" and "high-grade" harvest scenarios. The CAHA model provided default values for felling time per tree. These values reflect the increased time required to harvest larger diameter trees. Skidding efficiency was simulated by assuming three trees skidded to the landing during each cycle. Therefore, volume per cycle equaled three times the average board-foot volume per tree, with a maximum volume of 600 board feet, to simulate skidder capacity. A sample report from the $C A H A$ simulations, showing values for all input variables, is found in Appendix C. 
Simulated timber harvesting costs using the CAHA are shown in Table 18. The initial (actual) harvests employed on the four tracts resulted in similar estimated harvesting costs, with an average cost of $\$ 101 / \mathrm{MBF}$. This was assumed to represent "average" harvesting costs on typical tracts. Thus, any tract with expected harvesting costs of approximately $\$ 101 / \mathrm{MBF}$ or less would not be subject to any stumpage price adjustment due to excessive harvesting costs.

Ten years after the "good" harvests that were actually employed, Tracts $2 \mathrm{C} 3$ and $2 \mathrm{C} 4$ were projected to contain sufficient volume for a subsequent harvest (Tables 12 and 13). However, the per-acre volumes and average tree sizes (board feet/tree) were less than what was initially harvested, resulting in higher harvesting costs of $\$ 115 / \mathrm{MBF}$ and $\$ 120 / \mathrm{MBF}$, respectively (Table 18). Therefore, per-acre timber values for these tracts were reduced by \$14/MBF and \$19/MBF, respectively, in Year 10.

Table 18. Simulated timber harvesting costs and resulting adjustments to timber stumpage prices $(\$ / M B F)$ for Tracts $2 C 3,2 C 4,4 I 6$, and $4 N 1$ under various harvesting scenarios over a 20-year projection period. All costs and adjustments are $\$ / M B F$.

\begin{tabular}{|ccccc|}
\hline Tract & Scenario & $\begin{array}{c}\text { Harvest } \\
\text { Year }\end{array}$ & $\begin{array}{c}\text { Harvesting } \\
\text { Cost }\end{array}$ & $\begin{array}{c}\text { Stumpage } \\
\text { Adjustment }\end{array}$ \\
\hline \hline 2 C3 & Initial "Good" Harvest & 0 & $\$ 100$ & $\$ 0$ \\
$2 \mathrm{C} 4$ & Initial "Good" Harvest & 0 & $\$ 107$ & $\$ 0$ \\
416 & Initial "Poor" Harvest & 0 & $\$ 98$ & $\$ 0$ \\
$4 \mathrm{~N} 1$ & Initial "Poor" Harvest & 0 & $\$ 98$ & $\$ 0$ \\
& & & & \\
$2 \mathrm{C} 3$ & "Good" Harvest & 10 & $\$ 115$ & $-\$ 14$ \\
$2 \mathrm{C} 3$ & "Good" Harvest & 20 & $\$ 99$ & $\$ 0$ \\
$2 \mathrm{C} 3$ & High-grade Harvest & 10 & $\$ 156$ & $-\$ 55$ \\
$2 \mathrm{C} 3$ & High-grade Harvest & 20 & $\$ 128$ & $-\$ 27$ \\
& & & & \\
$2 \mathrm{C} 4$ & "Good" Harvest & 10 & $\$ 120$ & $-\$ 19$ \\
$2 \mathrm{C} 4$ & "Good" Harvest & 20 & $\$ 101$ & $\$ 0$ \\
2C4 & High-grade Harvest & 10 & $\$ 189$ & $-\$ 88$ \\
2C4 & High-grade Harvest & 20 & $\$ 145$ & $-\$ 44$ \\
& & & & \\
416 & "Poor" Harvest Practice & 10 & $\$ 177$ & $-\$ 76$ \\
416 & "Poor" Harvest Practice & 20 & $\$ 146$ & $-\$ 45$ \\
& & & & \\
$4 \mathrm{~N} 1$ & "Poor" Harvest Practice & 10 & $\$ 219$ & $-\$ 118$ \\
$4 \mathrm{~N} 1$ & "Poor" Harvest Practice & 20 & $\$ 170$ & $-\$ 69$ \\
\hline
\end{tabular}


By contrast, 10-year projected per-acre volumes and average tree sizes on Tracts 4 I6 and $4 \mathrm{~N} 1$ were much smaller than what was initially harvested, resulting in harvesting costs roughly twice the "average" cost. As a result, Year 10 per-acre timber values for these tracts were reduced by $\$ 76 / \mathrm{MBF}$ and $\$ 118 / \mathrm{MBF}$, respectively.

Twenty years after the "good" harvest, Tracts $2 \mathrm{C} 3$ and $2 \mathrm{C} 4$ recovered to stand conditions similar to the pre-harvest stand. As a consequence, estimated harvesting costs at Year 20 were very similar to the harvesting costs estimated for the initial harvest (i.e. "average" cost) and no adjustment was made to stumpage values at Year 20.

Twenty years after the initial harvest, projected per-acre volumes and average tree sizes on Tracts 4I6 and 4N1 were still much less than what was initially harvested, resulting in harvesting costs roughly 50\% higher than "average" cost. As a result, per-acre timber values for these tracts were reduced by $\$ 45 / \mathrm{MBF}$ and $\$ 69 / \mathrm{MBF}$, respectively, at Year 20.

When subjected to simulated "high-grade" harvests, estimated harvesting costs on Tracts 2C3 and 2C4 were similar to Tracts 4I6 and 4N1 (the tracts actually subjected to "poor" harvest practices). This lends further support to the conclusion that the "high-grade" simulations used for Tracts $2 \mathrm{C} 3$ and 2C4 were appropriate for mimicking the "poor" harvest practices observed in this study.

Quality and DBH-specific stumpage prices were applied to the sawtimber volumes harvested from each tract (estimated from stump diameter measurements - see Chapter 1) and future sawtimber volumes projected using FVS (see Chapter 2) for Tracts 2C3 and 2C4 under two scenarios each ("good" and "high-grade" harvests) and Tracts 4I6 and 4N1. Since the quality of the harvested trees was unknown, all harvested trees were assumed to be of average quality (Quality $=2$ ). This produced a less precise estimate of the true value of timber that was harvested, but was unavoidable. Unless there were significant differences in the quality of timber harvested on the tracts subjected to "good" and "poor" harvest practices, the effect on the comparative financial analysis of harvesting practices should be relatively small. 
The resulting per-acre timber values were then adjusted for above-average harvesting costs, when appropriate, as indicated in Table 18. The resulting net per-acre timber values were used in all present value calculations for the financial analyses. Stumpage prices used to calculate future timber values were not adjusted for expected future inflation, and thus represent "real" 2007 prices and assume no real stumpage price appreciation over the 20 -year projection period.

\section{Selection of Discount Rates}

One of the most troublesome aspects of financial analyses is the selection of an appropriate discount rate to apply to future cash flows. The purpose of a discount rate is to reduce (discount) future revenues/benefits to account for: 1) delayed consumption (all else being equal, we would rather enjoy benefits now rather than later) and 2) risk (future revenues/benefits are not certain). Time preference for consumption (placing a discounted value on future benefits because we must wait to receive them) varies among individuals and is affected by many factors. Likewise, individuals have varying levels of risk tolerance/aversion and, therefore, require differing levels of compensation as reward for assuming risk. To further complicate matters, risk is often difficult to quantify, so individuals may have varying perceptions of the riskiness of a particular investment/activity. As a result, selection of a discount rate is a complex issue which can be approached from various angles (Vicary 2006).

Given that NIPF owners are a numerous and diverse group, it is difficult to derive a single discount rate, or even a relatively narrow range of discount rates, that might be appropriate for analyzing forestry practices on NIPF land. Previous research has suggested real discount rates applicable to NIPFs ranging from less than 3\% to well over 10\% (Atmadja and Sills 2009; Bullard et al. 2002; Kronrad and de Steiguer 1983). Among the factors affecting the discount rate used by NIPFs are time period of the investment, acreage owned, and the landowner's annual income. In addition, there is a temporal dimension to discount rates - discount rates deemed reasonable by investors at one point in time may be viewed as unacceptably low or unrealistically high at a later point in time, due to changes in economic conditions, returns 
yielded by alternative investments, and changes in the perceived riskiness of the investment. Determining a discount rate appropriate for a single forestland owner at a given point in time is challenging enough. Determining a discount rate appropriate for a group of forestland owners that would be appropriate at any point in time is virtually impossible.

To address this issue, financial analyses for this study were done utilizing a range of real (inflation-adjusted) discount rates from $1.0 \%$ to $10.0 \%$. The resulting "present value profiles" graphically illustrate present values for various options/scenarios for the range of discount rates analyzed. This allows the reader to ascertain the range of discount rates under which one scenario would be financially superior to another. Each reader is free to select the discount rate they feel is most appropriate and draw their own conclusions as to the attractiveness of each option/scenario, rather than being presented with an analysis showing which option is superior under a single, pre-determined discount rate assumption. In addition, internal rate of return (IRR) can be derived from net present value profiles, since net present value will equal $\$ 0$ at the discount rate that is equal to the IRR.

Although no adjustments were made in the FVS projections to account for possible higher growth rates on tracts subjected to "good" harvest practices, as a result of higher proportions of dominant/co-dominant trees in the residual stands, it was possible to make such adjustments in the financial analyses. This was done by assuming that 10-year projected volumes on "good" tracts would actually be attained in 8 years and 20-year projected volumes on "good" tracts would actually be attained in 16 years. These "accelerated growth" assumptions were incorporated by simply discounting 10- and 20-year timber values on "good" tracts by 8 and 16 years, respectively, while continuing to discount 10- and 20-year timber values on "poor" tracts by 10 and 20 years, respectively. This adjustment effectively changed the post-harvest periodic annual increment (PAI) on Tract 2C3 from 198 board feet/acre/year to 247 board feet/acre/year and increased the PAI on Tract 2C4 from 211 board feet/acre/year to 263 board feet/acre/year. 


\section{Results}

The simulated "high-grade" harvest on Tract 2C3 removed 35\% more volume and 37\% more value than the actual "good" harvest implemented on this tract (Table 19). After 10 years, sawtimber volume is $78 \%$ higher under the "good" harvest scenario. However, due to the larger tree diameters, lower harvesting costs, and greater proportions of acceptable growing stock and valuable timber species, timber value under the "good" scenario is $342 \%$ greater than under the "high-grade" scenario. After 20 years, volume and value are 64\% and 215\% greater, respectively, under the "good" harvest scenario.

Table 19. Initial stand, harvested, and projected future timber volumes and value for Tracts 2 C3 and 2C4, under "good" and "high-grade" harvest scenarios, and Tracts 416 and 4N1. All values are per-acre.

\begin{tabular}{|c|c|c|c|c|c|c|c|c|c|}
\hline \multirow[b]{2}{*}{ Tract } & \multicolumn{2}{|c|}{ Initial Stand } & \multirow[b]{2}{*}{ Harvest Scenario } & \multicolumn{2}{|c|}{ Harvested } & \multicolumn{2}{|c|}{ Year 10 Projected } & \multicolumn{2}{|c|}{ Year 20 Projected } \\
\hline & Volume $^{1 /}$ & Value & & Volume $^{7 /}$ & Value & Volume $^{1 /}$ & Value & Volume $^{1 /}$ & Value \\
\hline \multirow{2}{*}{$2 \mathrm{C} 3$} & \multirow{2}{*}{13,887} & \multirow{2}{*}{$\$ 1,831$} & "Good" & 8,459 & $\overline{\$ 1,274}$ & $7,7,398$ & $\$ 832$ & 99,399 & $\$ \$ 1,192$ \\
\hline & & & High-Grade & 11,426 & $\$ 1,744$ & 4,156 & $\$ 188$ & 5,719 & $\$ 379$ \\
\hline \multirow{2}{*}{$2 \mathrm{C} 4$} & \multirow{2}{*}{11,039} & \multirow{2}{*}{$\$ 1,545$} & "Good" & 5,255 & $\$ 873$ & 7,889 & $\$ 971$ & 9,996 & $\$ 1,410$ \\
\hline & & & High-Grade & 8,941 & $\$ 1,490$ & 3,515 & $\$ 54$ & 5,249 & $\$ 277$ \\
\hline 416 & 12,450 & $\$ 1,892$ & "Poor" & 10,174 & $\$ 1,730$ & 3,489 & $\$ 236$ & 4,779 & $\$ 449$ \\
\hline $4 \mathrm{~N} 1$ & 11,542 & $\$ 1,400$ & "Poor" & 10,062 & $\$ 1,314$ & 2,644 & $\$ 85$ & 4,302 & $\$ 324$ \\
\hline
\end{tabular}

1/ - Board feet, International 1/4" Scale

The simulated "high-grade" harvest on Tract 2C4 removed 70\% more volume and 71\% more value than the actual "good" harvest implemented on this tract (Table 19). After 10 years, sawtimber volume is $124 \%$ higher under the "good" harvest scenario. However, timber value is 18 times greater than the "high-grade" scenario. After 20 years, timber volume is nearly twice as large and timber value is five times higher under the "good" harvest scenario.

Harvest volumes and values and projected future stand volumes and values for Tracts 4I6 and 4N1 were very similar to the "high-grade" scenarios for Tracts 2C3 and 2C4 (Table 19), indicating that the criteria used to simulate "high-grade" harvests was a reasonable method for predicting the biological and financial impacts of "poor" harvesting practices on these two tracts. 
The similarities between the results from $4 \mathrm{I} 6$ and $4 \mathrm{~N} 1$ and between these two tracts and the simulated "high-grade" harvests suggests that these results can be generalized for all tracts examined in this study that were subjected to "poor" harvest practices.

Present value (PV) profiles for Tracts $2 \mathrm{C} 3$ and 2C4 over a 10-year projection period are presented in Figures 20 and 21. For each tract, present value profiles are presented for three scenarios: 1) the "good" harvest that was actually conducted by the consulting foresters, 2) a hypothetical "high-grade" harvest that simulates typical "poor" harvest practices examined in this study, and 3) the "good" harvest with the assumption that the tract will exhibit increased growth (i.e. achieve projected 10 -year volumes in only 8 years).

For Tract 2C3, PV of the "good" scenario was greater than the PV of the "high-grade" scenario at all discount rates less than 3.2\% (Figure 20). The PV of the "good with accelerated growth" scenario was greater than the PV of the "high-grade" scenario at all discount rates less than $4.3 \%$. The accelerated growth assumption increased PV by $\$ 45-65$ per acre at discount rates of $4 \%$ or greater, but the increase was less at lower discount rates.

Similar trends were obtained with Tract $2 \mathrm{C} 4$. The PV of the "good" scenario was greater than the PV of the "high-grade" scenario at all discount rates less than 4.0\% (Figure 21). The PV of the "good with accelerated growth" scenario was greater than the PV of the "high-grade" scenario at all discount rates less than 5.1\%. The accelerated growth assumption increased PV by $\$ 55-80$ per acre at discount rates of $4 \%$ or greater, but the increase was less at lower discount rates.

The present value profiles for both "high-grade" scenarios are rather flat, indicating that $\mathrm{PV}$ is insensitive to discount rate. This is due to the fact that most value is realized during the initial harvest (Year 0) and is therefore not subject to discounting. 


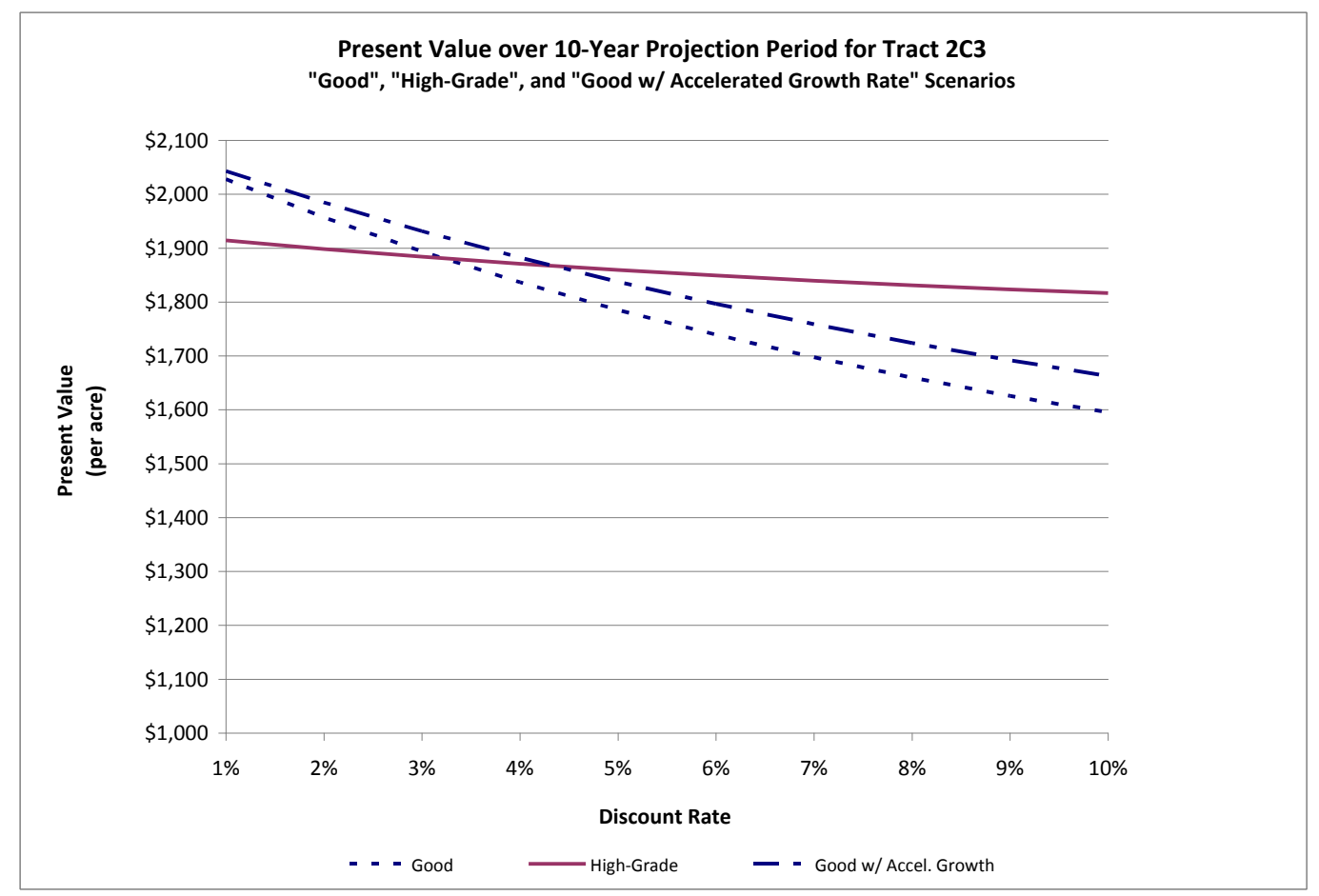

Figure 20. Present values for Tract $2 C 3$ under "good harvest", "high-grade harvest", and "good harvest with accelerated growth rate" scenarios over a 10-year projection period at real discount rates from $1.0 \%$ to $10.0 \%$.

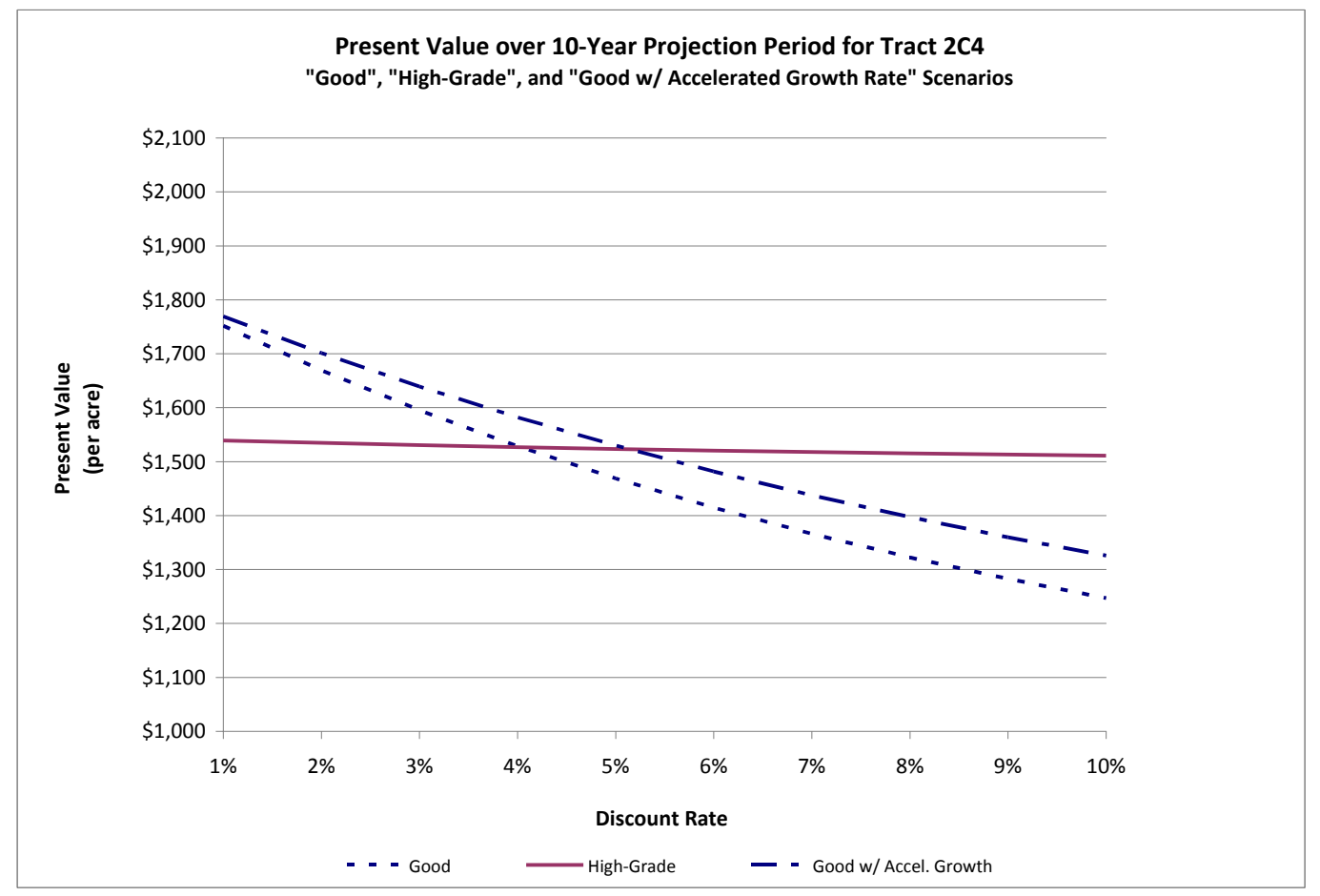

Figure 21. Present values for Tract 2C4 under "good harvest", "high-grade harvest", and "good harvest with accelerated growth rate" scenarios over a 10-year projection period at real discount rates from $1.0 \%$ to $10.0 \%$. 
Present value profiles for Tracts $2 \mathrm{C} 3$ and $2 \mathrm{C} 4$ over a 20 -year projection period are presented in Figures 22 and 23. The accelerated growth scenario assumes that tracts subjected to "good" harvest practices will achieve projected 20 -year volumes in only 16 years.

Trends for the 20-year projections were similar to the 10-year projections. For Tract $2 \mathrm{C} 3$, the PV of the "good" scenario was greater than the PV of the "high-grade" scenario at all discount rates less than $2.8 \%$ (Figure 22). The PV of the "good with accelerated growth" scenario was greater than the PV of the "high-grade" scenario at all discount rates less than $3.9 \%$. The accelerated growth assumption increased PV by $\$ 85-100$ per acre at discount rates of $3 \%$ or greater, but the increase was less at lower discount rates.

For Tract 2C4, the PV of the "good" scenario was greater than the PV of the "highgrade" scenario at all discount rates less than 3.1\% (Figure 23). The PV of the "good with accelerated growth" scenario was greater than the PV of the "high-grade" scenario at all discount rates less than $4.1 \%$. The accelerated growth assumption increased PV by $\$ 100-115$ per acre at discount rates of $3 \%$ or greater, but the increase was less at lower discount rates.

All present value profiles are steeper than the 10-year project period, indicating more sensitivity to discount rate. This is expected, given the greater discounting of future cash flows that occur 20 years into the future compared to cash flows that occur 10 years into the future. The PV profile for Tract $2 \mathrm{C} 4$ is somewhat steeper than the PV profile for Tract $2 \mathrm{C} 3$. Tract $2 \mathrm{C} 3$ was subjected to a more intense initial harvest and, therefore, a higher proportion of total income was received in Year 0 and was not subject to discounting. Conversely, a higher proportion of total income on Tract $2 \mathrm{C} 4$ was realized as terminal timber value at the end of the projection period (Table 19), which is subject to discounting and, therefore, more sensitive to changes in the discount rate. 


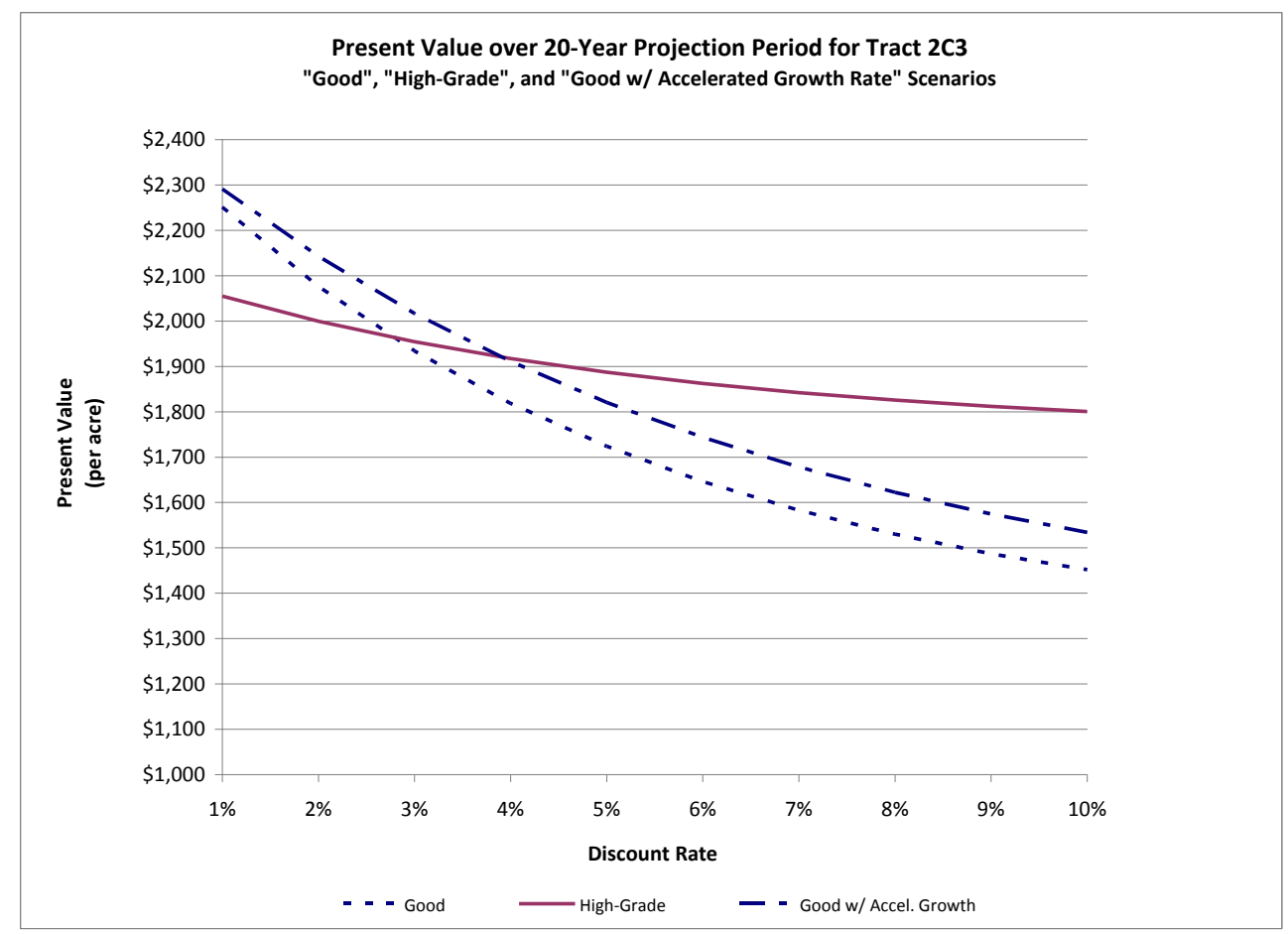

Figure 22. Present values for Tract $2 C 3$ under "good harvest", "high-grade harvest", and "good harvest with accelerated growth rate" scenarios over a 20-year projection period at real discount rates from $1.0 \%$ to $10.0 \%$.

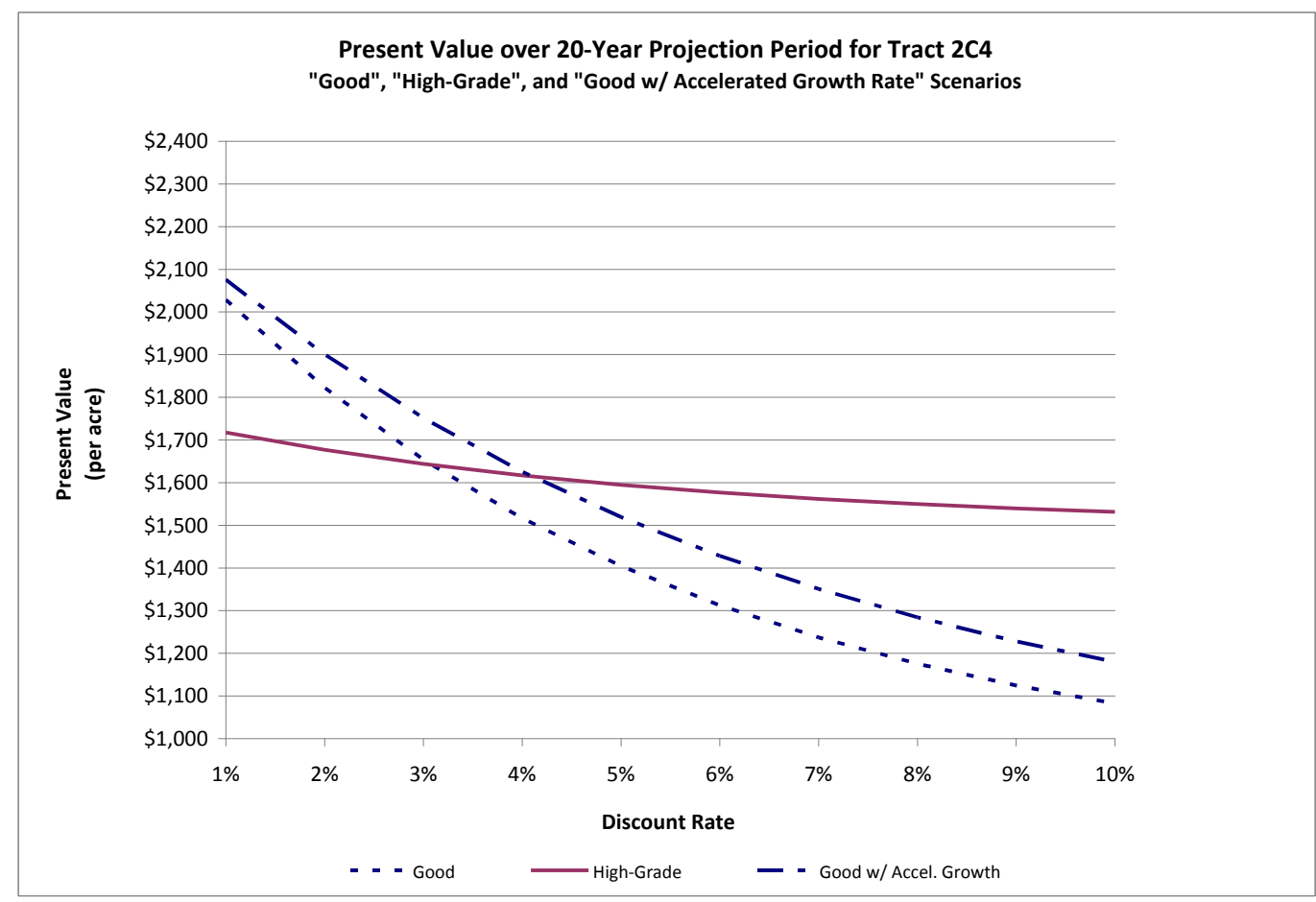

Figure 23. Present values for Tract 2C4 under "good harvest", "high-grade harvest", and "good harvest with accelerated growth rate" scenarios over a 20-year projection period at real discount rates from $1.0 \%$ to $10.0 \%$. 
Since there are significant differences in initial timber value on the various tracts (due to differing volumes, species composition, and timber quality), there is limited insight to be gained by directly comparing present values of the different tracts. In order to adjust for differences in initial timber value, net present value (NPV) was calculated for each tract. In this method, initial timber value is treated as an opportunity cost and is subtracted from harvest income and discounted future timber value. This is financially appropriate, since partial harvesting in Year 0 followed by a second harvest (or disposal of the property) in Year 20 implies forgoing the income that could be received from liquidating the timber (clearcut harvest or property sale) in Year 0. Essentially, calculating NPV in this manner determines the long-term financial gain (or loss) realized by the landowner as a result of various harvesting techniques (in our case "good" or "poor" practices as defined in Chapter 1), assuming the initial timber value represents an investment by the landowner.

Net present value profiles for Tracts 2C3, 2C4, 4I6, and 4N1 over a 20-year projection period are presented in Figures 24 and 25. The accelerated growth rate scenario (Figure 25) assumes that tracts subjected to "good" harvest practices will achieve projected 20-year volumes in only 16 years. Net present value profiles for the 10-year projection showed similar trends, and are omitted for brevity.

For the 20-year projection period, NPV is greater for the tracts subjected to "good" harvest practices (Tracts $2 \mathrm{C} 3$ and 2C4) compared to the tracts subjected to "poor" harvest practices (Tracts 4I6 and 4N1) for all discount rates less than about 3\% (Figure 24). Net present value falls more steeply with increasing discount rate for the two "good" tracts compared to the two "poor" tracts, since a larger proportion of total value is realized at the end of the projection period and is therefore subject to discounting. Trends for the two "good" tracts are very similar, as are the trends for the two "poor" tracts, suggesting that these trends can be generalized for all tracts in this study subjected to "good" and "poor" harvest practices. 


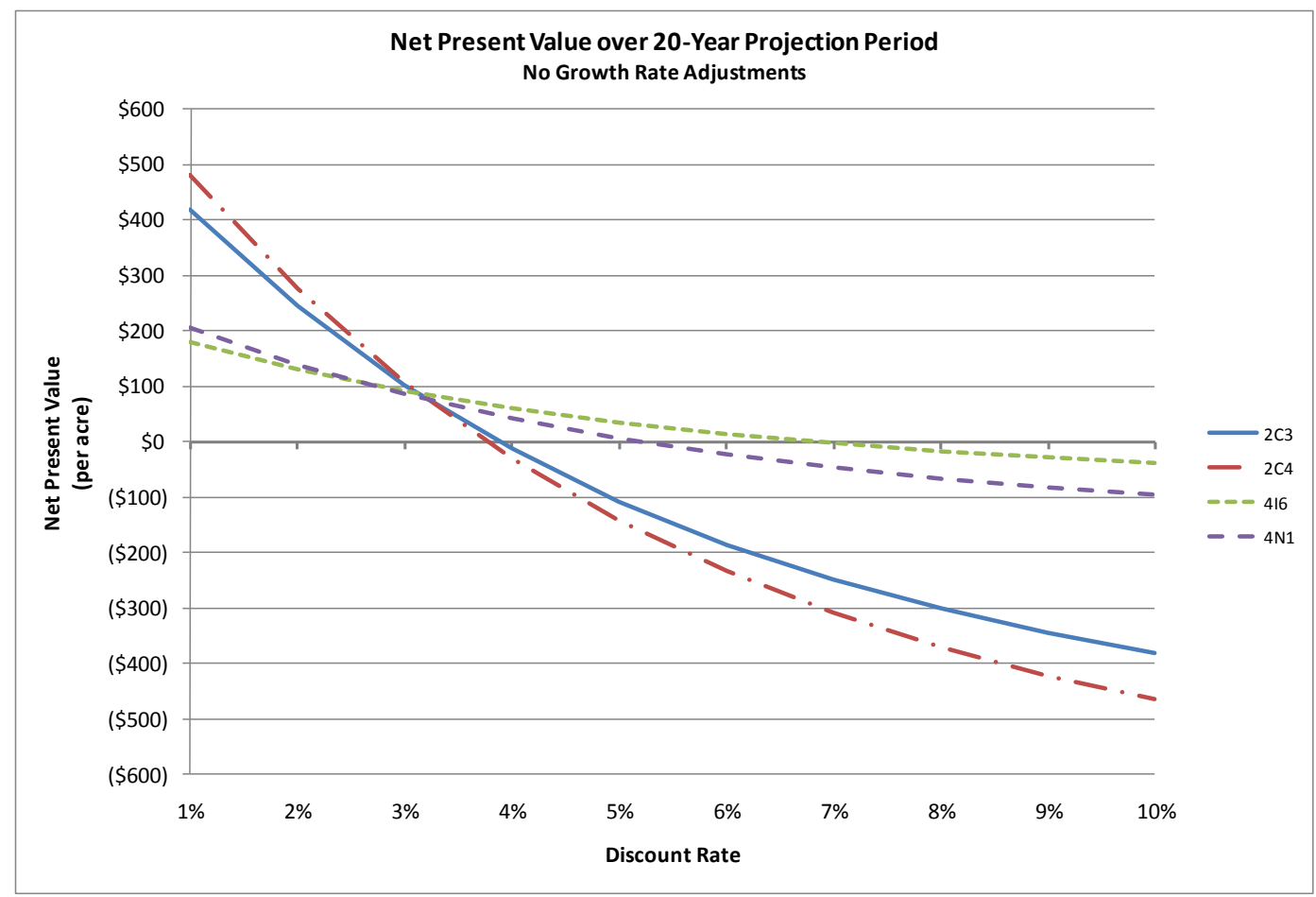

Figure 24. Net present values for Tracts 2C3, 2 C4 ("good" tracts), 4I6, and 4N1 ("poor" tracts) over a 20-year projection period at real discount rates from $1.0 \%$ to $10.0 \%$, assuming no growth rate adjustments for "good" tracts.

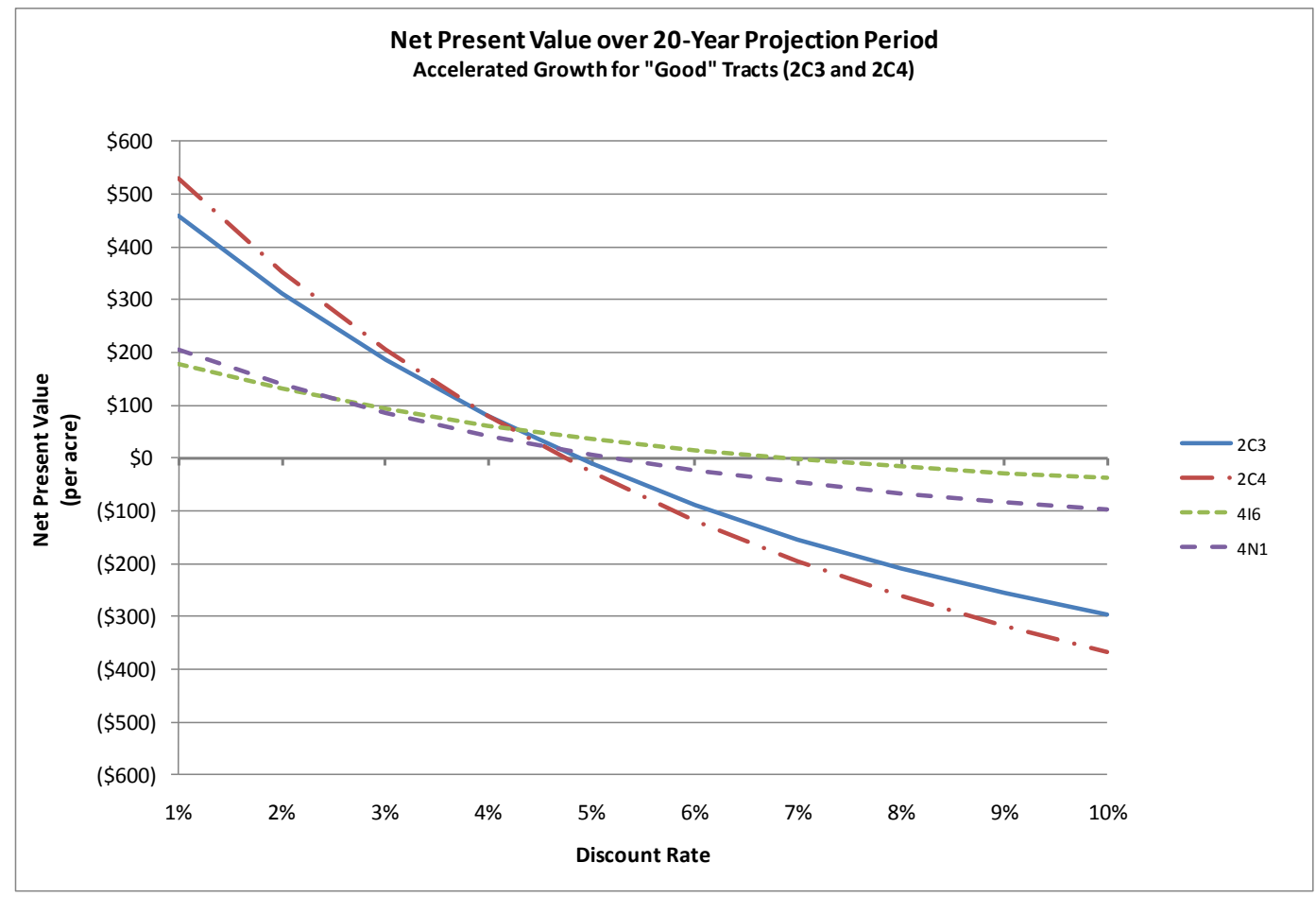

Figure 25. Net present values for Tracts 2C3, 2 C4 ("good" tracts), 4I6, and 4N1 ("poor" tracts) over a 20-year projection period at real discount rates from $1.0 \%$ to $10.0 \%$, assuming accelerated growth rates for "good" tracts (2C3 and 2C4). 
At discount rates below 4\%, NPVs of the "good" tracts are positive, indicating that landowners are better off financially by performing a partial harvest using "good" guidelines versus liquidating their forest. This indicates a real internal rate of return of approximately $4 \%$ for landowners engaging in silvicultural harvests.

Engaging in "poor" harvest practices yielded financial gains for landowners at all discount rates below 5\%, as indicated by the positive NPVs (Figure 24). The real internal rates of return for the two "poor" tracts are 5\% and 7\%.

Assuming accelerated growth for the tracts subjected to "good" harvest practices, NPV is greater for the "good" tracts (Tracts 2C3 and 2C4) compared to the "poor" tracts (Tracts 4I6 and $4 \mathrm{~N} 1$ ) for all discount rates less than approximately $4.5 \%$ (Figure 25). At discount rates below $5 \%$, NPVs of the "good" tracts are positive, indicating that landowners are better off financially by performing a partial harvest using silvicultural guidelines versus liquidating their forest. This indicates a real rate of return of $5 \%$ for landowners engaging in silvicultural harvests.

As noted earlier, the accelerated growth assumption increased the NPV of the "good" tracts by $\$ 85-100$ per acre at discount rates of $3 \%$ or greater. The increase was less at lower discount rates. 


\section{Discussion}

The analysis of the effects of tree grade and DBH on lumber value and, subsequently, stumpage price, clearly indicated that tree quality and size are important considerations when determining standing timber value (Figure 19 and Appendix B). "Good" harvest practices yielded greater sawtimber volumes than "poor" harvest practices 10 and 20 years after the initial harvest. However, the effects on timber value were much greater than the effects on sawtimber volume, due to the significant differences in species composition, average tree size, and timber quality. In addition, future per-unit harvesting costs were higher on tracts subjected to "poor" harvest practices, as a result of the lower felling and skidding efficiencies incurred on tracts with a lower per-acre volume and a smaller average tree volume. This further reduced future stumpage values on these tracts.

Despite their negative impacts on species composition, sawtimber volume, timber quality, and harvesting cost of the future stand, "poor" harvest practices were deemed to be financially attractive to landowners. Although "good" harvest practices yielded 20-year timber values two to five times higher than "poor" practices, the much higher initial harvest income generated by "poor" harvesting resulted in higher net present values at all real discount rates greater than about 3\%. Landowners engaging in "poor" harvesting were projected to realize real internal rates of return (IRR) of $5 \%$ to $7 \%$, compared to $4 \%$ for landowners who performed "good" harvests. If "good" harvest practices result in higher timber growth rates, the real IRR for "good" harvest practices increases to 5\%. These findings are consistent with other research in this area which suggests that silvicultural harvests can yield real returns of $4 \%$ to $6 \%$ (McCauley and Trimble 1972; Reed at al 1986).

The failure of "good" harvest practices to outperform "poor" harvest practices in financial terms, despite being clearly superior from a silvicultural standpoint, is a result of: 1) the relatively long time period between harvests, which is itself a function of timber growth rates, 2) applicable discount rates, and 3) the inadequate premium paid for higher quality and/or larger diameter timber. 
At periodic annual increments of 200 - 250 board feet/acre/year, a second harvest will not be feasible for 10 - 15 years in most cases. Although this seems a short time period relative to the long-term nature of forestry, this represents very significant discounting of future values at any reasonably high discount rate (i.e. $3 \%$ real or greater). To the extent that forest management can affect growth rates, this issue can be addressed somewhat. In this study, assuming a higher periodic annual increment - as a result of a high proportion of dominant/co-dominant trees in the residual stand - increased the real IRR of "good" harvest practices from 4\% to 5\%. In general, however, timber growth rates in the Appalachian hardwood region will necessitate relatively long-periods between harvests and, subsequently, relatively high discounting of any benefits obtained from silvicultural practices, including harvesting practices.

The applicable discount rate is largely a function of time preference for consumption and the perceived risk of the investment. As such, its determination is made by the market and is not subject to manipulation or management. Simply put, we must accept the discount rates deemed appropriate by the market. If they are high, we must accept the consequence that future values will be highly discounted. If future values occur well into the future, as is the case with forestry, these values may be discounted so highly that they become almost irrelevant.

In order to overcome the limitations imposed by relatively long discounting periods (i.e. 10-15 years between harvests) and relatively high discount rates (i.e. generally $>3 \%$ real), it is necessary to realize significant premiums for higher quality and/or larger diameter timber in order to justify silvicultural harvesting from a financial standpoint. Although this study utilized stumpage prices that accounted for timber quality and tree diameter (as well as harvesting cost), these premiums were generally insufficient to compensate for discounting (a function of time and discount rate) unless fairly low discount rates were assumed. It is impossible to determine if these adjustments reflect premiums actually paid by the market, since actual stumpage price data is relatively scarce and is generally reported only by species, with no adjustments for grade or $\mathrm{DBH}$. If actual premiums for quality and tree size are larger than those assumed in this study, that would improve the financial performance of "good" harvest practices vis-à-vis "poor" harvesting practices. 
However, it is uncertain whether or not landowners actually realize any premium for timber that is of superior quality or larger-than-average diameter. Many (most?) timber transactions in the Appalachian region are the result of negotiation between the landowner and buyer, usually either a procurement forester working for a mill or a logger. Given their lack of experience in selling timber and inadequate knowledge regarding timber markets, timber quality, and the effects of tree size on timber value and harvesting cost, it is reasonable to assume that landowners are in a poor position to negotiate well with experienced timber buyers. Thus, there is little incentive for buyers to provide additional compensation to landowners who posses superior timber. In order to realize premiums for timber quality and size - if they even exist sellers must market their timber in a manner that maximizes competition between buyers. In this situation, savvy buyers will recognize the higher value present in quality timber stands and will offer higher prices accordingly, in order to out-compete other buyers. Without this, it is unlikely that sellers realize any premium for quality timber. In order for good harvest practices to financially benefit landowners, there must be a sufficiently large premium for quality timber and landowners must sell their timber in a manner that captures this premium. Both requirements are paramount. Unfortunately, there is scant evidence that either of these conditions is prevalent in the state, especially the latter. For landowners with a tendency to negotiate directly with buyers, there is no incentive to practice good harvesting, since they are unlikely to capture the future financial gains of doing so. This provides further incentive to engage in high-grading.

The issue of how large a discount rate is appropriate for NIPFs remains a nagging question. Derived nominal discount rates for Mississippi NIPFs ranged from $8.0 \%$ for forestry investments lasting 5 years, to $13.1 \%$ for investments lasting 25 years (Bullard et al. 2002). This would suggest real discount rates of approximately 5\% to 8\%, assuming 3\% annual inflation. However, these estimates were made during a robust economy and booming stock market (2000). At that time, landowners indicated that acceptable returns on very low-risk investments would be $5.5 \%$ to $6.5 \%$ (bank savings accounts and certificates of deposit, respectively). Given that these instruments currently yield $0.5 \%$ or less, it is likely that these same landowners today would find real timberland investment returns of much less than $5 \%$ to be highly desirable. 
A 2004 study in North Carolina and Virginia estimated a real, risk-free discount rate of 2.6\% for "limited resource" NIPFs (Atmadja and Sills 2009). "Limited resource" NIPFs were characterized as forestland owners who operate under significant financial, social, natural and human capital constraints. Research indicates that landowners with these characteristics have lower hurdle (discount) rates than NIPFs in general. In addition, a risk adjustment would be required to convert a risk-free rate to a rate appropriate for a risky investment, such as timberland. Still this study suggests that the appropriate real discount rate for NIPFs might be significantly lower than $5 \%$ to $8 \%$.

In some instances, however, landowners display behavior that suggests a much higher discount rate might be appropriate. When Pennsylvania landowners learned the true value of their timber, many were more inclined to harvest timber immediately and harvest more intensely, and showed no increased interest in growing timber or planning for future harvests (Brubaker et al. 2006). This implies a discount rate high enough to make future income largely irrelevant and focus landowner interest on immediate gains at the expense of possible future gains.

Despite the limitations imposed by not knowing an appropriate discount rate for financial analyses, "good" harvest practices are potentially financially competitive with "poor" harvest practices over a range of likely discount rates, so long as we assume increased growth rates on "good" tracts. At a real discount rate of 5\%, per-acre NPVs for Tracts $2 \mathrm{C} 3$ and $2 \mathrm{C} 4$ were negative $\$ 11$ and negative $\$ 27$, respectively, versus $\$ 36$ and $\$ 7$ for Tracts $4 \mathrm{I} 6$ and $4 \mathrm{~N} 1$. At a real discount rate of 3\%, per-acre NPVs for Tracts 2C3 and 2C4 were \$186 and \$206, respectively, versus $\$ 93$ and $\$ 86$ for Tracts $4 \mathrm{I} 6$ and $4 \mathrm{~N} 1$. Without the benefit of increased growth, however, "good" harvest practices had NPVs clearly inferior to "poor" harvest practices at all real discount rates above $3.5 \%$. At real discount rates higher than 5\%, "poor" harvest practices are financially more attractive to landowners even if we assume higher growth rates on "good" tracts.

Another issue relevant to the comparison of "good" and "poor" harvest practices is their effect on length of time between harvests. Tracts subjected to "good" harvest practices could reasonably support a subsequent harvest after just 10 years. It is highly questionable whether tracts subjected to "poor" harvest practices could support another commercial harvest in 10 
years, due to low per-acre volumes, a high proportion of less valuable species, and the relative scarcity of quality timber, particularly timber in the larger diameter classes. These factors, coupled with the higher per-unit harvesting costs on these tracts, result in stands that are clearly financially unattractive to potential buyers. In a market with an adequate supply of average and better timber, it is hard to imagine such tracts garnering much, if any, serious interest from buyers. Even after 20 years, there is question as to whether these tracts could attract the interest of buyers in a normal market, unless the timber sold at a discount. This is consistent with the conclusions drawn by Reed at al (1986).

The inability to conduct a subsequent timber harvest 20 years after the initial harvest impacts the present values of these tracts. In this case, terminal timber value would need to be calculated at the earliest year in which a commercial harvest is feasible and the resulting value discounted for the longer time period. Although these calculations were not performed in this study (since there were no growth projections performed beyond Year 20), it is reasonable to assume that the present values of these future harvests would be quite low, due to the additional discounting. Under such a scenario, NPVs of the "good" tracts would likely exceed NPVs of the "poor" tracts at all discount rates below 5\% - 6\%, making them more financially attractive.

In addition, the reduced ability to conduct future harvests exposes these tracts to increased market risk (Ferguson 2006). Timber prices exhibit significant fluctuation, both in the long-term and the short-term, and sellers' ability to respond to these fluctuations is critical to maximizing financial returns. Landowners who engaged in "good" harvest practices (owners of Tracts $2 \mathrm{C} 3$ and $2 \mathrm{C} 4$ ) retained the ability to respond to favorable markets in 10 years by conducting another sale. Landowners who engaged in "poor" harvest practices (owners of Tracts 4I6 and 4N1) have forfeited this option by harvesting their timber so intensely with the initial harvest. They have, in effect, "put all their eggs in one basket" - the initial harvest. This behavior (the antithesis of diversification) incurs additional risk. Although these landowners are expected to realize higher rates of return than landowners who engaged in "good" harvesting practices, they should demand higher returns as a result of their greater exposure to market risk. Therefore, it is inappropriate to conclude that "poor" harvest practices are financially superior to "good" harvest practices simply because they resulted in higher rates of return. Unfortunately, 
since most NIPFs lack the knowledge or skills to adequately access market risk, let al.one access how their harvesting decisions affect their exposure to such risk, it is unlikely that they properly evaluate the financial consequences of their actions. In the absence of knowledge about relative risks, investors universally choose the option with the highest expected return. For landowners, this generally means engaging in poor harvest practices. 


\section{CHAPTER IV \\ Post-harvest Survey of Participating Landowners}

The final phase of the project was a printed survey mailed to all landowners who participated in the first phase of the project. The purpose of this survey was to illicit feedback from landowners regarding their level of satisfaction with the harvesting process and the postharvest condition of their property, and to access landowners' perceptions of problems with the harvest.

\section{Methodology}

\section{Data Collection}

Following completion of field work, a two-page survey was mailed to each landowner who participated in the project (Appendix D). The first part of the survey (10 questions) dealt with the landowners' level of satisfaction with various facets of the timber harvests on their properties (amount of timber harvested, condition of residual trees, etc.). Landowners were asked to respond to each issue as being either: a) completely satisfied, b) mostly satisfied, c) mostly unsatisfied, or d) completely unsatisfied. Responses were given a numerical score, ranging from $4=$ completely satisfied to $1=$ completely unsatisfied, to aid with statistical analysis.

The second part of the survey (10 questions) dealt with any problems or concerns encountered by landowners during or immediately after the harvests (damage to roads, damage to residual trees, etc.). Landowners were asked to respond to each issue as being either: a) not a problem, b) a minor problem, or c) a serious problem. Responses were given a numerical score, ranging from $1=$ not a problem to $3=$ a serious problem, to aid with statistical analysis. 
After 2 weeks, a follow-up letter was sent to landowners who had not responded to the survey, in an effort to improve the response rate. Completed surveys were received from 78 landowners (27 “consultant", 24 "industry" and 27 "non-forester"), representing $87 \%$ of the study participants.

\section{Data Analysis}

Using the numerical scores given to each survey question response, the Kruskal-Wallis one-way analysis of variance for ranked data was used to determine if average landowner responses to each survey question were different among the three forester types.

In order to examine the relationship, if any, between landowner satisfaction and actual physical stand conditions, Spearman's rank-order correlations were calculated for a number of residual stand attributes and landowner survey responses.

Responses to the following survey questions were deemed likely to be influenced by actual stand conditions:

- Satisfaction with amount of timber harvested (Question 2)

- Satisfaction with condition of residual trees (Question 4)

- Satisfaction with logger performance (Question 6)

- Satisfaction that harvest met objectives (Question 9)

- Overall satisfaction with harvest (Question 10)

- Problem with excessive trees cut (Question 15)

- Problem with trees left that should have been cut (Question 16)

- Problem with damage to residual trees (Question 17)

- Concern about future of the forest (Question 20) 
The following harvest and residual stand attributes were deemed likely to have influenced landowners' responses to the above survey questions:

- Percent of sawtimber basal area harvested

- Percent of residual basal area in dominant / co-dominant canopy position

- Percent of residual basal area damaged

- Percent of residual basal area severely damaged

- Percent reduction in quadratic mean diameter

- Species preference ratio (harvested value per $\mathrm{MBF} \div$ initial value per MBF)

- Residual stocking level

- Percent of residual basal area in best quality trees

- Percent of residual basal area in acceptable growing stock

- Percent of residual basal area in worst quality trees

- Overall harvest evaluation, as determined by criteria in Table 4

For each survey question listed above, correlations between the survey question response and the value of each of the harvest and stand attributes listed above were determined. 


\section{Results}

Summaries of survey responses and results from the Kruskal-Wallis test on response scores are shown in Tables 20 and 21. The Kruskal-Wallis test was not performed for Questions 7 and 8 due to the lack of a sufficient number of responses.

The reader is directed to Appendix D for a more complete description of the survey questions and response choices.

Table 20. Number of survey responses by satisfaction level and type of forester involved in the sale for various questions related to landowner satisfaction. CS = completely satisfied, $M S=$ mostly satisfied, $M U=$ mostly unsatisfied, and $C U=$ completely unsatisfied. "Score" is the average numerical score for each forester type (4 = completely satisfied to $1=$ completely unsatisfied). For each question, forester types followed by the same letter do not have significantly different scores $(\alpha=0.10)$.

\begin{tabular}{|c|c|c|c|c|c|c|c|c|c|c|c|c|c|}
\hline \multicolumn{7}{|c|}{ Question 1 - Price Received } & \multicolumn{7}{|c|}{ Question 6-Logger Performance } \\
\hline Forester & cS & MS & MU & $\mathrm{CU}$ & Score & & Forester & CS & MS & MU & $\mathrm{CU}$ & Score & \\
\hline Consultant & 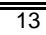 & 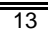 & 2 & 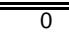 & 3.4 & a & Consultant & 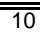 & 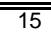 & 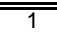 & 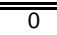 & 3.3 .3 & a \\
\hline Industry & 6 & 17 & 1 & 0 & 3.2 & $a b$ & Industry & 9 & 11 & 3 & 0 & 3.3 & $a$ \\
\hline None & 7 & 17 & 1 & 2 & 3.1 & b & None & 13 & 10 & 2 & 2 & 3.3 & $a$ \\
\hline \multicolumn{7}{|c|}{ Question 2 - Amount Harvested } & \multicolumn{7}{|c|}{ Question 7 -Industry Forester Performance } \\
\hline Forester & cS & MS & MU & $\mathrm{CU}$ & Score & & Forester & cS & MS & MU & $\mathrm{CU}$ & & \\
\hline Consultant & 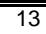 & 12 & 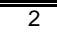 & $=1$ & 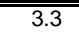 & a & Consultant & 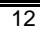 & 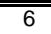 & 2 & $=1$ & & \\
\hline Industry & 4 & 18 & 1 & 0 & 3.1 & b & Industry & 13 & 8 & 0 & 0 & & \\
\hline None & 12 & 10 & 3 & 2 & 3.2 & ab & None & & & & & & \\
\hline \multicolumn{7}{|c|}{ Question 3 - Road Condition } & \multicolumn{7}{|c|}{ Question 8 - Consultant Performance } \\
\hline Forester & CS & MS & MU & $\mathrm{CU}$ & Score & & Forester & CS & MS & MU & $\mathrm{CU}$ & & \\
\hline Consultant & $\overline{5} 5$ & 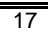 & 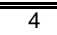 & 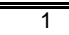 & 3.0 & $a$ & Consultant & $\overline{20}$ & 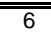 & 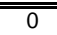 & 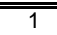 & & \\
\hline Industry & 4 & 17 & 1 & 0 & 3.1 & a & Industry & & & & & & \\
\hline None & 12 & 9 & 3 & 3 & 3.1 & a & None & & & & & & \\
\hline \multicolumn{7}{|c|}{ Question 4 - Tree Condition } & \multicolumn{7}{|c|}{ Question 9 - Met Objectives } \\
\hline Forester & $\mathrm{CS}$ & MS & MU & $\mathrm{CU}$ & Score & 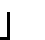 & Forester & $\mathrm{CS}$ & MS & MU & $\mathrm{CU}$ & L Score & \\
\hline$\overline{\text { Consultant }}$ & $=8$ & 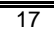 & $=2$ & $=0$ & 3.2 & $a$ & Consultant & 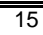 & 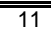 & 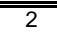 & 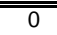 & 3.5 & $a$ \\
\hline Industry & 5 & 15 & 2 & 1 & 3.0 & $a$ & Industry & 6 & 16 & 1 & 0 & 3.2 & b \\
\hline None & 9 & 14 & 2 & 2 & 3.1 & a & |None & 11 & 12 & 1 & 2 & 3.2 & ab \\
\hline \multicolumn{7}{|c|}{ Question 5 - Time Required } & \multicolumn{7}{|c|}{ Question 10 - Overall } \\
\hline Forester & $\mathrm{CS}$ & MS & MU & $\mathrm{CU}$ & Score & $\downarrow$ & Forester & $\mathrm{CS}$ & MS & MU & $\mathrm{CU}$ & Score & \\
\hline$\overline{\text { Consultant }}$ & 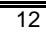 & 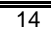 & 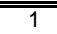 & 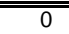 & 3.4 & $a$ & Consultant & 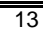 & 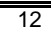 & $=2$ & 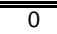 & $\begin{array}{c}3.4 \\
\end{array}$ & $a$ \\
\hline Industry & 8 & 11 & 3 & 1 & 3.1 & $a$ & Industry & 4 & 18 & 1 & 0 & 3.1 & b \\
\hline None & 13 & 9 & 2 & 3 & 3.2 & $\mathrm{a}$ & None & 10 & 14 & 1 & 2 & 3.2 & $a b$ \\
\hline
\end{tabular}


Table 21. Number of survey responses by severity of problem encountered and type of forester involved in the sale for various questions related to problems with the timber sale. None $=$ no problem, Minor = minor problem, and Serious = serious problem. "Score" is the average numerical score for each forester type $(1=$ no problem to $3=$ serious problem). For each question, forester types followed by the same letter do not have significantly different scores $(\alpha=0.10)$.

\begin{tabular}{|c|c|c|c|c|c|c|c|c|c|c|c|}
\hline \multicolumn{6}{|c|}{ Question 11 - Road Condition } & \multicolumn{6}{|c|}{ Question 16 - Excessive Trees Left } \\
\hline Forester & None & Minor & Serious & Score & & Forester & None & Minor & Serious & Score & \\
\hline Consultant & 14 & 11 & 2 & 1.6 & $a$ & Consultant & 18 & 9 & 0 & 1.3 & a \\
\hline Industry & 12 & 11 & 0 & 1.5 & a & Industry & 18 & 3 & 2 & 1.3 & a \\
\hline None & 16 & 7 & 4 & 1.6 & a & None & 22 & 3 & 2 & 1.3 & a \\
\hline \multicolumn{6}{|c|}{ Question 12 - Roads Impassable } & \multicolumn{6}{|c|}{ Question 17 - Tree Damage } \\
\hline Forester & None & Minor & Serious & Score & d & Forester & None & Minor & Serious & Score & \\
\hline Consultant & 15 & 7 & 4 & 1.6 & a & Consultant & 17 & 10 & 0 & 1.4 & $a$ \\
\hline Industry & 16 & 5 & 2 & 1.4 & $a$ & Industry & 11 & 9 & 3 & 1.7 & $a$ \\
\hline None & 19 & 4 & 3 & 1.4 & a & None & 15 & 10 & 2 & 1.5 & a \\
\hline \multicolumn{6}{|c|}{ Question 13 - Stream Crossing } & \multicolumn{6}{|c|}{$\underline{\text { Question } 18 \text { - Property Damage }}$} \\
\hline Forester & None & Minor & Serious & Score & 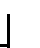 & Forester & None & Minor & Serious & Score & \\
\hline Consultant & 22 & 2 & 1 & 1.2 & a & Consultant & 20 & 6 & 0 & 1.2 & $a$ \\
\hline Industry & 18 & 3 & 0 & 1.1 & a & Industry & 21 & 2 & 0 & 1.1 & a \\
\hline None & 21 & 3 & 2 & 1.3 & a & None & 24 & 2 & 1 & 1.1 & a \\
\hline \multicolumn{6}{|c|}{ Question 14 - Seeding / Mulching } & \multicolumn{6}{|c|}{$\underline{\text { Question } 19 \text { - Paid for all Timber }}$} \\
\hline Forester & None & Minor & Serious & Score & | & Forester & None & Minor & Serious & Score & \\
\hline Consultant & 16 & 111 & 0 & 1.4 & $a$ & Consultant & 23 & 2 & 2 & 1.2 & $a$ \\
\hline Industry & 15 & 8 & 0 & 1.3 & a & Industry & 18 & 3 & 2 & 1.3 & $a$ \\
\hline None & 15 & 7 & 5 & 1.6 & a & None & 21 & 3 & 3 & 1.3 & a \\
\hline \multicolumn{6}{|c|}{ Question 15 - Excessive Trees Cut } & \multicolumn{6}{|c|}{ Question 20 - Future of Forest } \\
\hline Forester & None & Minor & Serious & Score & & Forester & None & Minor & Serious & Score & \\
\hline Consultant & 21 & 4 & 2 & 1.1 .3 & a & Consultant & 16 & 9 & 2 & 1.5 & $a$ \\
\hline Industry & 17 & 5 & 1 & 1.3 & $a$ & Industry & 14 & 5 & 4 & 1.6 & $a$ \\
\hline None & 20 & 5 & 2 & 1.3 & a & None & 19 & 4 & 4 & 1.4 & $a$ \\
\hline
\end{tabular}

Overall, the type of forester involved had little effect on landowners' level of satisfaction with the harvests on their properties (Questions $1-10$ ), with the following exceptions:

- Landowners who used a consulting forester were more satisfied with the price received for their timber than landowners who dealt directly with the logger (Question 1).

- Landowners who used a consulting forester were more satisfied with the amount of timber harvested than landowners who dealt with an industry forester (Question 2). 
- Landowners who used a consulting forester were more satisfied that the harvest met their objectives than landowners who dealt with an industry forester (Question 9).

- Landowners who used a consulting forester were more satisfied with the overall harvest than landowners who dealt with an industry forester (Question 10).

The vast majority (82\%) of landowner responses that indicted complete dissatisfaction with some aspect of the harvest came from landowners who had no contact with a professional forester (Table 20).

The type of forester involved had no effect on problems reported by landowners during or immediately after the harvest on their property (Questions $11-20$ ).

Results from Spearman's rank-order correlations between survey question responses and actual stand attributes are shown in Table 22. Absolute correlations of 0.20 or greater are underlined and displayed in bold type.

Table 22. Correlations between various survey question responses and physical stand attributes, using Spearman's rank-order correlation.

\begin{tabular}{|c|c|c|c|c|c|c|c|c|c|c|c|}
\hline \multirow[b]{2}{*}{ Survey Question } & \multicolumn{11}{|c|}{ Physical Stand Attributes } \\
\hline & $\begin{array}{l}\% \text { Sawtimber } \\
\text { BA Harvested }\end{array}$ & $\begin{array}{c}\% \text { BA } \\
\text { Dominant / } \\
\text { Codominant }\end{array}$ & $\begin{array}{c}\% \text { BA } \\
\text { Damaged }\end{array}$ & $\begin{array}{c}\% \text { BA } \\
\text { Severely } \\
\text { Damaged }\end{array}$ & $\begin{array}{c}\% \text { Change in } \\
\text { QMD }\end{array}$ & $\begin{array}{l}\text { Species } \\
\text { Preference } \\
\text { Ratio }\end{array}$ & Stocking Level & $\begin{array}{l}\text { \% BA Best } \\
\text { Quality }\end{array}$ & $\begin{array}{c}\% \text { BA } \\
\text { Acceptable } \\
\text { Growing } \\
\text { Stock } \\
\end{array}$ & $\begin{array}{l}\text { \% BA Worst } \\
\text { Quality }\end{array}$ & $\begin{array}{c}\text { Overall } \\
\text { Harvest } \\
\text { Evaluation }\end{array}$ \\
\hline \begin{tabular}{|l} 
Amount Harvested \\
(Question 2)
\end{tabular} & $\underline{-0.34}$ & 0.15 & $\underline{-0.26}$ & -0.17 & -0.19 & -0.17 & $\underline{0.28}$ & 0.19 & $\underline{0.28}$ & $\underline{-0.20}$ & $\underline{0.20}$ \\
\hline $\begin{array}{l}\text { Tree Condition } \\
\text { (Question 4) }\end{array}$ & $\underline{-0.26}$ & 0.11 & $\underline{-0.30}$ & $\underline{-0.26}$ & -0.15 & -0.10 & 0.19 & 0.02 & 0.09 & -0.13 & $\underline{0.22}$ \\
\hline \begin{tabular}{|l|} 
Logger Performance \\
(Question 6)
\end{tabular} & $\underline{-0.23}$ & 0.18 & $\underline{-0.25}$ & $\underline{-0.23}$ & -0.18 & $\underline{-0.20}$ & $\underline{0.21}$ & 0.00 & 0.03 & -0.08 & $\underline{0.23}$ \\
\hline $\begin{array}{l}\text { Met Objectives } \\
\text { (Question 9) }\end{array}$ & $\underline{-0.24}$ & 0.02 & -0.11 & -0.09 & -0.15 & -0.23 & 0.12 & 0.00 & 0.13 & -0.16 & 0.07 \\
\hline $\begin{array}{l}\text { Overall Satisfaction } \\
\text { (Question 10) }\end{array}$ & -0.16 & -0.06 & -0.18 & -0.13 & -0.02 & $\underline{-0.24}$ & 0.07 & 0.13 & $\underline{0.21}$ & $\underline{-0.26}$ & 0.19 \\
\hline $\begin{array}{l}\text { Excessive Trees Cut } \\
\text { (Question 15) }\end{array}$ & 0.19 & -0.02 & 0.16 & 0.10 & 0.15 & $\underline{0.21}$ & -0.10 & -0.07 & -0.07 & 0.10 & -0.09 \\
\hline \begin{tabular}{|l} 
Improper Trees Left \\
(Question 16)
\end{tabular} & -0.07 & 0.00 & 0.03 & -0.03 & -0.13 & 0.14 & 0.15 & -0.06 & -0.07 & 0.05 & 0.10 \\
\hline $\begin{array}{l}\text { Tree Damage } \\
\text { (Question 17) }\end{array}$ & $\underline{0.35}$ & -0.15 & $\underline{0.23}$ & $\underline{0.28}$ & $\underline{0.40}$ & $\underline{0.24}$ & -0.05 & 0.10 & 0.02 & 0.01 & $\underline{-0.24}$ \\
\hline $\begin{array}{l}\text { Future of Forest } \\
\text { (Question 20) }\end{array}$ & 0.19 & -0.10 & 0.15 & 0.14 & 0.09 & $\underline{0.25}$ & -0.09 & -0.14 & -0.16 & 0.18 & -0.16 \\
\hline
\end{tabular}


Although none of the correlations were particularly strong (absolute values of all correlations were less than 0.50), the results do provide some insight into the factors that influence landowner satisfaction with timber harvesting.

The three most important factors influencing landowners' satisfaction with the amount of timber harvested were: 1) the percentage of sawtimber basal area harvested, 2) residual stocking level, and 3) percentage of residual basal area in acceptable growing stock (Table 22). As the proportion of basal area harvested increased, landowner satisfaction decreased. As stocking level and acceptable growing stock increased, landowner satisfaction increased.

The most important factors influencing landowners' satisfaction with the condition of the residual trees were: 1) percentage of residual basal area damaged, 2) percentage of residual basal area severely damaged, and 3) percentage of basal area harvested. As damage to residual trees increased, landowner satisfaction decreased. Landowner satisfaction also decreased as harvesting intensity increased, likely due to its impact on damage to the residual stand.

The stand attributes having the most influence of landowners' satisfaction with logger performance were: 1) percentage of residual basal area damaged, 2) percentage of residual basal area severely damaged, 3) percentage of basal area removed, and 4) overall harvest evaluation (a combination of assessments of residual stocking level, acceptable growing stock, and tree damage). As damage to the residual stand and harvesting intensity increased, landowners' judgment of logger performance became less favorable. In general, landowners were more satisfied with logger performance on properties with higher overall harvest evaluations.

The most important factors determining whether or not the harvest met landowners' objectives were harvest intensity and species harvesting preference. As harvesting intensity increased, landowners were less likely to respond that the harvest met their objectives. When harvests tended to remove the more valuable species, determined by higher species preference ratios, landowners were less likely to believe that the harvest met their objectives. 
Overall satisfaction with the harvest was most influenced by: 1) percentage of the residual basal area in worst-quality trees, 2) species harvesting preference, and 3) percentage of the residual stand in acceptable growing stock. As the proportion of the residual stand occupied by very low-quality trees increased, landowner satisfaction decreased. Likewise, harvests that favored the removal of the more valuable species resulted in lower levels of landowner satisfaction. As the proportion of the residual stand rated as acceptable growing stock increased, so did landowner's overall satisfaction with the harvest.

The most important factor determining whether or not landowners perceived a problem with excessive trees being cut was the species preference ratio. Landowners were more likely to report a problem with excessive trees being harvested on those properties where harvests removed a higher proportion of valuable species.

None of the harvest or stand attributes examined in this study had a significant influence on whether or not landowners perceived a problem with trees being left that should have been harvested. This might be due to the difficultly in non-foresters evaluating whether or not a tree should be removed during harvesting.

The three factors that most influenced landowners' perceptions of problems with damage to residual trees were: 1) percentage change in quadratic mean diameter, 2) percentage of sawtimber basal area harvested, and 3) percentage of residual basal area severely damaged. Harvests that resulted in large decreases in QMD and removed high proportions of sawtimber basal area increased the probability that landowners reported a problem with damage to residual trees. This is likely due to the effect that both of these factors have on damage to the residual stand. Not surprisingly, as severe damage to the residual stand increased, so too did the incidence of landowners reporting problems with damage to the residual trees.

The harvest attribute most likely to cause landowners to voice concern about the future of their forest was the species preference ratio. Landowners were more concerned about the future of their forest when harvests favored the removal of the more valuable species from the property. 


\section{Discussion}

Landowners were generally satisfied with the harvests on their properties regardless of whether the harvest was conducted by a consulting forester, an industry forester, or a nonforester. However, landowners who used consulting foresters were more satisfied with the price received for their timber than landowners who dealt directly with loggers. Satisfaction with the price received was strongly correlated with overall satisfaction with the harvest. This is consistent with results from McGill et al. (2006) who found that West Virginia landowners were 38 times more likely to be satisfied with a timber harvest on their property if they were satisfied with the revenue generated from the sale.

Landowners who used consulting foresters were more satisfied with the amount of timber harvested, more satisfied with the overall harvest, and more likely to feel that the harvest met their objectives compared to landowners who dealt with industry foresters. Landowners who dealt directly with a logger (no forester involvement) were more than 4 times as likely to report that they were "completely unsatisfied" with some aspect of the harvest.

The relatively minor differences in landowner satisfaction among the three forester types could be a result of differences among the landowner population. Some landowners are likely to be very involved with their forest and very concerned about the impact of harvesting on their forest. Such landowners might have very high expectations for the harvest and be hard to please, even with a well-managed harvest. Other landowners are unlikely to know much or care much about their property and might be perfectly satisfied with even a poorly-conducted harvest. This might be especially true with absentee landowners. As long as these two landowner groups (and others that lie between these extremes) are evenly distributed among the forester types, there is no bias in our analysis. However, it is reasonable to assume that landowners with high expectations for their forest might be more apt to seek out the assistance of consulting and state service foresters before conducting a harvest. If that is the case, consulting foresters are more likely to be working with "hard to please" landowners than either industry foresters or loggers. This would tend to bias the results from this analysis and diminish the observed differences in landowner satisfaction between forester types. 
Relatively few serious problems with harvesting were reported by landowners and there were no differences in the incidence of harvest-related problems among the three forester types. The issues that concerned landowners the most were: 1) damage to residual trees, 2) the condition of roads after harvest, and 3) the future of their forest.

Landowners' satisfaction with timber harvesting was only weakly correlated with the actual physical attributes of the harvests and the residual stands, a phenomenon that has been noted previously (Egan and Jones 1993). This suggests that landowners are either not aware of the impact that harvesting has had on their property or lack the knowledge to discern "good" harvests from "poor" harvests. As Egan and Jones (1993) noted, "simply embracing a land ethic does not ensure responsible management." Clearly, landowners need knowledge and experience to properly evaluate harvesting practices or they need the assistance of professional foresters to perform these evaluations. Also, as mentioned before, a landowner's apathy towards their forest could cause a serious disconnect between the quality of the harvest and the landowner's level of satisfaction with the harvest. Nevertheless, a few insights from this study are noteworthy.

The species preference ratio was the harvest attribute most often associated with landowner satisfaction. When harvests favored the removal of the more valuable species, landowners became less satisfied with both logger performance and the overall harvest and were less likely to feel that the harvest met their objectives. They were also more likely to perceive problems with excessive trees being cut and damage to residual trees and were more likely to voice concerns about the future of their forest. This would tend to suggest that at least some portion of the landowner population is not only aware of the differences in value among species, but are aware that those species are being harvested disproportionately from their property and understand the potential negative long-term impacts.

Landowners also seemed perceptive with regards to damage to residual trees. As damage to residual trees increased, landowners were less satisfied with both logger performance and the condition of the residual stand and were more likely to report problems with damage to residual trees. This is not surprising, given that much logging damage is readily visible and is discernable 
even to non-professionals. By contrast, landowner satisfaction was not strongly influenced by residual tree quality, canopy position, or residual stocking level - attributes that require more knowledge and expertise than most landowners likely possess.

In summary, landowner satisfaction was mostly dependent on three factors: 1) preferential harvesting of valuable species, 2) damage to residual trees, and 3) harvesting intensity (percentage of sawtimber basal area removed). Items 2 and 3 are rather easily observed and can be at least somewhat effectively evaluated even by non-foresters. As for item 1, it is probably common knowledge among most forest landowners that oaks, cherry and hard maple are valuable species and it is not difficult to identify these species, particularly during the growing season. In addition, some landowners receive copies of mill receipts from the buyer as part of the sale contract terms. Therefore, it is reasonable to expect that at least some landowners would be aware if the more valuable species were being harvested from their forests. Since all three of these attributes are discernable to non-professionals, it is not surprising that landowners tended to base their level of satisfaction on these factors.

By contrast, stocking level, canopy position and the potential to produce quality sawtimber are all attributes that require specialized knowledge and expertise to evaluate effectively. Hence, most landowners do not consider these attributes when evaluating a harvest or formulating an opinion about its effectiveness. However, these are very important factors affecting sustainability for timber production and future timber quality and value. This underscores the importance of educating landowners about the need to engage professional foresters to assist with their timber harvests, rather than relying solely on their own limited knowledge and perceptions. 


\section{SUMMARY AND CONCLUSIONS}

This study reinforced what many practicing foresters believe and other researchers have discovered - most timber harvesting in West Virginia is performed without regard for silviculture and is dominated by diameter-limit cuts and high-grading. Furthermore, this study confirmed the conclusions drawn by others that, in general, the participation of a professional forester in the timber harvesting process has little effect on the harvest practices employed. However, this study clearly demonstrates that the type of forester involved in the harvest is much more important than whether or not a forester is involved at all. It would not be much of a stretch to suggest that a non-professional acting in the landowner's best interest might be better than a professional forester acting in the buyer's interest.

Very few $(<10 \%)$ timber harvests in the state are likely to be regarded as "good" from the standpoint of silviculture or sustainability. Overwhelmingly, these harvests are conducted by private consulting foresters and state service foresters. However, the overall performance by consulting foresters can only be considered "fair" at best. Just as many consultant harvests received "poor" evaluations as received "good" evaluations and over half were judged "fair". Consultants were just as likely to leave a severely under-stocked residual stand as they were to leave a fully-stocked residual stand. The fact that such mediocre performance stood out as clearly superior to harvests conducted on the majority of the sites says volumes about the sad state of forestry in the state.

To be fair to consultants, and the forestry profession in general, they are fighting an uphill battle. The first obstacles to be overcome are landowner indifference and/or objectives that run contrary to good silviculture. An example from this study will illustrate this point.

The very last harvest investigated for this study was a sale handled by a consultant in the southeastern part of the state. By chance, I had an opportunity to visit with the landowner before and after performing the field work. The sale came about when a forest products company made an unsolicited offer to purchase all the timber $\geq 14$ " DBH on his property. The landowner was 
not particularly interested in selling, but told the company he would consider their offer. Two months later, they made a second offer, substantially higher than the first. At this point, the landowner become very interested in selling, but also realized he really had no idea what the timber was worth. On the advice of the local state service forester, he retained the services of a private forestry consultant. His instructions to the consultant were to "market al.1 the timber on my property $\geq 14$ " DBH to maximize sale income." That is precisely what the consultant did, and the resulting harvest was one of the worst we examined in the entire study, in terms of residual stocking, acceptable growing stock and tree damage. My conversations with the landowner led me to believe he was happy with sale, except for some concerns about a few culverts being too small. He did not appear to be particularly interested in long-term management, at least as it related to timber production. He seemed more interested in what effects the harvest would have on the size and number of deer on the property and what he was going to do with the income he had received. He indicated he was very pleased with the price the consultant got for his timber - the company that made the original offer ended up being the high bidder, but at a substantially higher price than their second offer.

Did the consultant attempt to persuade the landowner to alter his harvest plans to something more sustainable? Perhaps he did, but the landowner was unconvinced (my perception is that this would have been a difficult task). Maybe the consultant could have tried harder. Perhaps, he made no effort whatsoever and simply went along with the landowner's decision. Regardless, there are going to be situations where the forester's influence on the harvest is going to be completely negated by the landowner's wishes. How often this is the case is anyone's guess. My personal experience (from this study and my consulting work) is that this scenario is not uncommon.

Perhaps a more substantial obstacle is that imposed by economics and market constraints. There is a very weak and limited market for poor-quality timber in Appalachia, particularly for the smaller diameter classes. Since this material has no stumpage value (the cost of harvesting and transporting it is greater than the delivered price at the mill), its removal must be subsidized by accepting a lower price for the marketable timber. If the marketable timber is itself of marginal value and/or a substantial quantity of unmarketable timber is marked for removal, the 
sale becomes economically unattractive and will not garner the interest of buyers. A much more likely scenario is that the inclusion of unmarketable timber makes the overall price offered by buyers so low that the landowner refuses to sell. Every private consultant is keenly aware of the dangers of "polluting" a sale with too much unmarketable timber. With many landowners seemingly willing to allow high-grading on their property, it is easy to see why a sale with substantial unmarketable timber marked for harvest would receive a very cool reception from timber buyers.

Certain species are so undesirable that buyers will not buy them and loggers will not cut them unless contractually obligated to do so. This again entails subsidizing the removal of these species by accepting lower prices on the desirable species. In this study, very little hickory or beech and virtually no sweet birch was harvested on the sales conducted by industry foresters and non-professionals. Even though consultants were often successful in getting beech and some birch harvested, even they shied away from marking hickory and very low-value species such as blackgum. Consultants were more apt to harvest smaller-diameters trees - presumably in an effort to improve the stand by removing trees of poor quality and less desirable species - but their efforts were limited. As one procurement forester put it to me, "a 12-inch diameter tree has no value". Enough said.

When market constraints are coupled with landowner indifference or a strong desire for immediate income, it is actually surprising that consultants are able to practice even "fair" silviculture. It is one thing to have a genuine desire to practice silviculture and implement good harvest practices. It is an altogether different thing to actually do it on private land.

The obstacles facing industry/procurement foresters are no less daunting, and possibly even more so. Industry foresters cannot reasonably hope to reap the benefits of practicing silviculture on private lands. This would entail forgoing some benefit now (harvesting less timber and/or the less valuable timber) in return for increased benefits later. But those future benefits are just as likely to be captured by a competing mill or lost altogether through land use conversion or ownership transfer to a landowner disinclined to sell timber. Given the state of the industry, I think it is fair to assume that many mills are wondering if they will even be in 
business 10 to 20 years from now and it is hard to imagine that an individual procurement forester is going to give serious thought to where he's going to find timber 20 years from now.

Suggesting that mills "invest" in private landowners' properties in the remote hope that the mill will benefit at some future date is wishful thinking, at best. The lesson is clear - it is in the industry forester's best interest to maximize immediate sale income. The fact that some industry foresters actually did employee good harvest practices is, in my opinion, nothing short of amazing. These foresters/mills are banking on the ability to maintain a close relationship with the landowner until the next harvest. Whether this is a calculated risk or pure folly is unclear. What is certain, however, is that this sort of behavior by buyers is rare, and understandably so.

Industry foresters might also be more apt to be dealing with apathetic landowners and/or those who are seeking maximum immediate financial gain. Although not every landowner who seeks out the services of a consulting forester is interested in management (as noted earlier), a fairly large percentage probably are, which is why they sought out professional assistance. The same probably cannot be said about landowners who approach, or are approached by, procurement foresters. Many are likely to be interested only in maximizing sale income and are not concerned with whether or not they are getting sound management advice - that is why they eschew professional assistance. In a case study of six Pennsylvania landowners, only three thought that it would be worthwhile to hire a professional forester to assist with a timber sale and all three thought that the forester's fees would exceed any extra timber value they might realize from the sale (Brubaker et al. 2006). If industry foresters are more likely to be working with landowners disinterested in management, and it is in the forester's economic interest to engage in poor harvest practices, what chance is there that silviculture will be implemented?

Invariably, some landowners probably assume that if a professional forester is involved, they are getting professional advice on how to manage/harvest their timber. Thus, a landowner interested in long-term management might still succumb to high-grading because it was recommended by the procurement forester. The fact that some landowners are clearly confused about the difference between a procurement forester and a consulting forester (or even between a logger and a forester!) makes this issue particularly troublesome. Has our profession done all it 
can to make landowners aware of the different types of foresters in our profession and the roles each plays in the timber sale process? What obligations do procurement foresters have when dealing with "unsuspecting" landowners who look to them for management advice? What if the landowner does not clearly articulate to the procurement forester their desire to practice management because they assume they are receiving sound advice ... after all, they are dealing with a professional. A procurement forester's primary responsibility is to secure timber for their mill at reasonable cost. Should they also be expected to manage the landowner's property? Should landowners expect to receive advice on how to manage their property from someone whose objective is simply to purchase an asset from them? When I go to the farmers' market to purchase produce, I do not offer advice to the farmer about how to grow better tomatoes for me to purchase next year, nor does she expect to receive such advice from me. No one confuses buying tomatoes with growing tomatoes, but many landowners seem to confuse buying/selling timber with growing/managing timber and our profession has done a very poor job of clearing up the confusion.

Our society looks upon "professionals" as being beneficial to society and holds them in high regard. What is usually left unspoken is the reality that professionals also pose a serious potential threat to society. By definition, professionals possess knowledge about a particular field well beyond that possessed by the general public. This creates the possibility that professionals can use their expert knowledge and considerable experience for personal gain, at the expense of the non-professional members of society. Most professions attempt to address this issue by holding those members who deal directly with the public to a higher standard of conduct. Having professional foresters negotiating directly with unsuspecting, naïve, illinformed, and inexperienced laypeople creates an environment ripe for professional misconduct. Whether such misconduct occurs, and to what extent, is really beside the point. The appearance of a conflict of interest is a conflict of interest. Our profession can do better.

The ethical dilemma posed by diameter-limit cutting has not gone unnoticed (Ford 2006), but this study confirms that little has changed in the forest over the past two decades or more. Landowners, the forestry profession, and the economic realities of the free-market system each shoulder some of the blame. 
While mills and loggers have a vested interest in the long-term availability of quality timber within their market, there is very little incentive for them to invest in management on a particular property that they do not control (the "tragedy of the commons"). Landowners would seem to be the entities most likely to benefit from sound management, but rarely behave accordingly. There are several possible explanations for this. As has been noted earlier, many landowners have non-timber reasons for owning forestland and this is not surprising given that $70 \%$ of the state's NIPFs own 20 acres or less. Even if these landowners expressed an interest in timber production, it would likely be uneconomical to do so. Fortunately, these landowners account for only $15 \%$ of the state's forestland. More important is the behavior of those landowners with significant forestland acreage (50 acres or more). These owners control more than two-thirds of the forest resource and seem to be much more interested in timber production than the general NIPF population.

This is significant since the landowners in this study who sold 50 acres or more were twice as likely to have had a professional forester involved with the sale as those who sold less than 50 acres. This would seem to support the assumption that larger NIPFs are more inclined to consider timber production important and worthy of professional assistance. Another possible explanation is that professional foresters shy away from smaller harvests since they possess less of an economy of scale (e.g. a procurement forester many expend the same effort to purchase 40 acres as he/she spends to purchase 120 acres, but receives only 1/3 as much timber; smaller harvests mean a smaller sales commission for a consultant). However, consulting foresters were involved in $23 \%$ of the harvests less than 50 acres in size and $29 \%$ of the harvests 100 acres or larger, so that does not seem to entirely explain the difference.

Harvests 50 acres or larger were nearly three times as likely to receive a "good" evaluation as smaller harvests. This could be the result of the lower involvement by professional foresters with the smaller sales or it could be the result of more interest in proper forest management by owners of larger properties. Evidence supporting the latter assumption can be found by analyzing the performance of consulting foresters when working on different size harvests. Forty-three percent of the consultant harvests 100 acres or larger received a "good" evaluation, compared to $13 \%$ of their harvests between $50-99$ acres and 14\% of their harvests 
less than 50 acres. A compelling explanation is that owners of larger properties were more interested in long-term forest management which made it much easier for consultants to implement silviculture on these properties. Also noteworthy is the fact that all industry harvests that received "good" evaluations occurred on harvests larger than 75 acres. This would be consistent with nationwide trends which clearly show that owners of larger forested properties are more likely to conduct commercial timber harvests, more likely to seek professional assistance, and more likely to have a written management plan (Butler 2008). The relationship between ownership/harvest size and harvest practices certainly warrants further investigation.

A significant obstacle to implementing good harvest practices is the apparent financial disincentive to do so. The short-term gain realized by immediately harvesting all the good timber overshadows the future benefits that could have been received by practicing silviculture during the harvest. The long time periods between harvests and high market discount rates play a role, but foresters are powerless to do much about either factor, especially the latter. Besides, neither factor makes high-grading inevitable, so long as the market pays an adequate premium for quality timber. With high premiums for better quality timber and larger tree sizes, the future gains resulting from good harvest practices could easily compensate for the effects of discounting these gains for long time periods, even at high discount rates. Unfortunately, the premiums currently existing in the market appear inadequate to induce landowners to produce larger, better quality timber. As a consequence, virtually every study that has compared silvicultural harvests to diameter-limit harvests, including this study, have concluded that diameter-limit harvests are at least as financially rewarding to landowners as silvicultural harvests, under most circumstances.

Short ownership tenure is another factor that discourages landowners from thinking longterm and implementing sound forest management. It is difficult to persuade landowners to investment in forest management (either directly through fertilization, etc. or indirectly by implementing good harvest practices) when they feel they will not be around to reap the benefits. Nationwide, $60 \%$ of "family forest" owners have owned their land for less than 25 years (Butler 2008). With an aging NIPF population and an increasing number of new NIPFs, we can expect to see continued ownership transfers and this is certain to have a profound effect on the 
attractiveness of long-term investments in forestry. If landowners believed that they would be adequately compensated for their silvicultural investments when they sold their property, this would help alleviate this concern. However, future buyers of NIPF properties are likely to be people interested in non-timber amenities and therefore unwilling to pay for possible future timber benefits. Even if the future buyer was interested in timber production, estimating the expected future benefits of past management practices is extremely difficult, reducing the probability of the seller being adequately compensated. In the eastern hardwood region, investments in silviculture are unlikely to be financially beneficial unless the owner will have possession of the property long enough to capture the benefits in a future timber harvest. Although larger landowners are more likely to have longer ownership tenure (Butler 2008), long ownership tenure is becoming an unlikely scenario for an increasing number of NIPFs.

In short, the NIPF ownership structure is ill-suited for long-term forest management. Sound timber management requires, at a minimum, the following four conditions: 1) long and certain ownership tenure, 2) sufficient knowledge of forestry to make sound decisions, 3) either a sufficient market premium as a reward for producing quality timber or manufacturing facilities that capture the value of quality timber, and 4) ownership objectives which place at a least moderately high priority on timber production. In an increasing number of instances, NIPF ownership fails to meet Condition \#1. In the majority of cases, Condition \#2 is not being met (few landowners take advantage of professional assistance). Condition \#3 is probably not being met due to a combination of inadequate premiums and the nature of NIPFs (lack of knowledge about how to capture premiums if they exist and no manufacturing facilities). Condition \#4 might hold true for larger NIPFs, although this is not clear.

Two other ownership structures appear to offer much better opportunities for practicing forest management. The first is direct ownership by forest products companies. This structure meets all four of the conditions listed above. Unfortunately, forest industry has been selling vast acreages over the past two decades and the trend is continuing, albeit at a somewhat slower pace. Whether or not this trend will reverse in the future is unclear, but seems unlikely. 
A second ownership structure conducive to long-term management is the real estate investment trust (REIT). Unlike timberland investment management organizations that have finite investment horizons (similar to NIPF ownership tenures), REITs are "at will" entities that operate under the assumption of perpetuity. They also utilize professional forest management, both in the form of direct employment of foresters and contracted consulting services. This structure clearly fulfills Conditions \#1, \#2, and \#4. Condition \#3 is still an issue, but one that could be addressed. REITs, being knowledgeable about forestry and marketing timber, are wellsuited to capture market premiums for timber, if they exist. To the extent that large NIPFs can mimic the behavior of REITs, this ownership structure could also be conducive to long-term forest management.

A more troubling possibility is that adequate market premiums for quality timber do not exist now and will not exist in the future (or may disappear in the future, even if they exist currently). While this might be viewed as a market failure, it actually indicates a signal from the market that quality timber is not in high demand. While this may seem improbable, given that hardwood sawmills invariably harvest the best quality timber at every opportunity, we might very well see a shift towards commodity hardwood lumber production, similar to the softwood dimension lumber market. Manufacturers have historically demonstrated amazing creativity in adapting to the available resource. As the availability of quality timber has diminished, manufacturers have found ways to utilize poorer-quality timber - oriented strand board replacing plywood (which is itself a replacement for large dimension boards once sawn from old-growth timber), laminated veneer lumber replacing large timber beams, wood and vinyl veneer over particleboard replacing solid lumber, flooring mills that utilize only poor grades of lumber (\#2 or worse). It is possible that the mills themselves are not particularly concerned with the future availability of high-quality timber or the species composition of the future forest. When asked what kind of timber landowners should be growing for the future, a former forest industry executive replied, "We'll find a way to make something useful out of whatever resource is available." If this scenario is currently being played out, and I'm not necessary suggesting that it is, we should not expect the market to pay substantial premiums to landowners as an inducement to grow better timber. 
If, on the other hand, quality timber is expected to be in demand in the future, the market should respond appropriately by inducing landowners to produce such timber through stumpage price premiums. This is commonly observed with premiums/discounts applied to various hardwood species. Oak lumber is in higher demand than poplar lumber and the stumpage prices for white oak and yellow-poplar reflect this.

Unfortunately, it is difficult for landowners to properly read these market signals. Rather than responding to higher stumpage prices by growing more timber, they respond by selling more timber. Higher prices for oak stumpage simply induce landowners to harvest more oak. They do not seem to induce landowners to grow more oak. Part of the problem stems from the focus on short-term price fluctuations, rather than expected long-term price trends. Professional foresters are just as guilty of this behavior as landowners.

Even if the market responds to a decreasing supply of quality timber by offering a higher premium for quality timber (which is far from certain), it will likely induce landowners to harvest their quality timber more intensely, rather than implement silvicultural harvests that will produce more quality timber in the future. This clearly indicates a market failure, due in part to landowners' lack of knowledge about forestry, timber markets, etc. and due in part to their propensity to think short-term. The REIT structure - with its ability to correctly interpret market signals and its long-term outlook which allows it to respond to these signals by growing more quality timber - at least provides the possibility of practicing sound forest management, provided the market provides the proper incentives. If the market does not provide such incentives, we must accept the possibility that quality timber may be passé in the future, as unpleasant as that prospect may seem. This would paint a very dim picture for the future of hardwood silviculture, at least as it relates to timber production. 


\section{BIBLIOGRAPHY}

Atmadja, S.S. and Sills, E.O. 2009. Discount rates of limited resource woodland owners in North Carolina and Virginia. Pp. 232-242 in: Siry, J., B. Izlar, P. Bettinger, T. Harris, T. Tye, S. Baldwin, and K. Merry, editors. Proceedings of the 2008 Southern Forest Economics Workers Annual Meeting, March 9-11, 2008. Savannah, GA. Univ. of Ga. Center for Business Publication No. 30.

Brubaker, R.D., Finley, J.C., and McDill, M.E. 2006. The effect of timber value information on Pennsylvania's private forest landowner: a case study. NJAF 23(4):234-240.

Bullard, S.H., Gunter, J.E., Doolittle, M.L., and Arano, K.G. 2002. Discount rates for nonindustrial private forest landowners in Mississippi: how high a hurdle rate? SJAF 26(1):26-32.

Bullard, S.H. and Moulton, R.J. 1989. An economic analysis of state forestry assistance in Mississippi. Technical Bulletin 147, Mississippi Agriculture and Forestry Experiment Station, Mississippi State University, Starkville, MS.

Butler, B.J. 2008. Family forest owners of the United States, 2006. USDA For. Serv. Northern Exp. Sta. Gen. Tech. Rep. NRS-27. 72 p.

Cubbage, F.W., Skinner, T.M., and Risbrudt, C.D. 1985. An economic evaluation of the Georgia Rural Forestry Assistance Program. Research Bulletin 322, University of Georgia College of Agriculture Experiment Station, Athens, GA.

Cubbage, F.W., Risbrudt, C.D., and Skinner, T.M. 1988. Trends in funding state forestry programs. J. For. 86(12):19-25.

Cubbage, F.W., Greene, W.D., and Lyon, J.P. 1989. Tree size and species, stand volume, and tract size: effects on southern harvesting costs. SJAF 13:145-152.

Dixon, G.E. 2003. Essential FVS: A User's Guide to the Forest Vegetation Simulator. Internal Rep. Fort Collins, CO: USDA For. Serv. Forest Management Service Center. 193p.

Egan, A.F. 1993. Forest stewardship: the relationship between the articulations and actions of NIPF owners. PhD diss., The Pennsylvania State University, University Park.

Egan, A.F. 1997. From timber to forests and people: a view of nonindustrial private forest research. NJAF 14(4):189-193.

Egan, A.F. and Jones, S.B. 1993. Do landowner practices reflect beliefs? J. For. 91:39-45. 
Egan, A.F. and Jones, S.B. 1997. Determining forest harvest impact assessment criteria using expert opinion: a Delphi study. NJAF 14(1):20-25.

Egan, A.F., Rowe, J., Peterson, D., and Philippi, G. 1997. West Virginia Tree Farmers and consulting foresters: a comparison of views on timber harvesting. NJAF 14(1):16-19.

Egan, A.F., Whipkey, R.D., and Rowe, J.P. 1998. Compliance with forestry best management practices in West Virginia. NJAF 15(4):211-215.

Egan, A.F. and Baumgras, J.E. 2003. Ground skidding and harvested stand attributes in Appalachian hardwood stands in West Virginia. For. Prod. J. 53(9):59-63.

Fajvan, M.A., Grushecky, S.T., and Hassler, C.C. 1998. The effects of harvesting practices on West Virginia's wood supply. J. For. 96(5):33-39.

Ferguson, K. 2006. Economics, markets, and diameter-limit cutting. Pp. 39-40 in: Kenefic, L.S. and Nyland, R.D., editors, Proceedings of the Conference on Diameter-Limit Cutting in Northeastern Forests. USDA For. Serv. Northeastern Res. Sta. Gen. Tech. Rep. NE-342.

Ford, V. 2006. Ethical considerations with diameter-limit cutting. Pp. 43-46 in: Kenefic, L.S. and Nyland, R.D., editors, Proceedings of the Conference on Diameter-Limit Cutting in Northeastern Forests. USDA For. Serv. Northeastern Res. Sta. Gen. Tech. Rep. NE-342.

Fraser, R. and Magill, D. 2000. Training and assistance needs of forestland owners in West Virginia. Pp. 125-134 in: Proceedings of the Forest Fragmentation 2000 Conference, Lester DeCoster and R. Neil Sampson, editors, September 17-20, 2000, Annapolis, MD. Sampson Group, Inc.

Gingrich, S.F. 1967. Measuring and evaluating stocking and stand density in upland hardwood forests in the central states. For. Sci. 13:38-53.

Hanks, L.F. 1976. Hardwood tree grades for factory lumber. USDA For. Serv. Northeastern For. Exp. Sta. Res. Pap. NE-333. 92 p.

Hassler, C.C., Grushecky, S.T., and Fajvan, M.A. 1999. An assessment of stand damage following timber harvests in West Virginia. NJAF 16(4):191-196.

Hodge, S.S. and Southard, L. 1992. A profile of Virginia NIPF landowners: results of a 1991 survey. Virginia Forests 47(4):7-9.

Hodges, D.G. and Cubbage, F.W. 1990. Nonindustrial private forest management in the South: assistance foresters' activities and perceptions. SJAF 14(1):44-48.

Johnson, J.S., Cowan, M. and Caldwell, D., editors. 2007. Hardwood Market Report. Volume 85, Nos. 22-26. Memphis, TN. 
Joshi, S. 2007. Nonindustrial private landowner's characteristics and their forest management decisions. MS thesis, West Virginia University, Morgantown.

Jones, S.B., Luloff, A.E., and Finley, J.C. 1995. Another look at NIPFs: facing our "myths". J. For. 93(9):41-44.

Kronrad, G.D. and de Steiguer, J.E. 1983. Relationships between discount rates and investment lengths among nonindustrial private landowners. Small Woodland R\&D Program, North Carolina St. Univ. Res. Notes Series No. 19.

Lamson, N.I. and Smith, H.C. 1988. Effect of logging wounds on diameter growth of sawlogsize Appalachian hardwood crop trees. USDA For. Serv. Northeastern For. Exp. Sta. Res. Paper NE-616.

Lamson, N.I., Smith, H.C., and Miller, G.W. 1985. Logging damage using an individual-tree selection practice in Appalachian hardwood stands. North. J. Appl. For. 2:117-120.

Li, X., Wang, J., Miller, G., and McNeel, J. 2006. Production economics of harvesting smalldiameter hardwood stands in central Appalachia. For. Prod. J. 56(3):81-86.

Luppold, W.G., Prestemon, J.P., and Baumgras, J.E. 1998. An examination of the relationships between hardwood lumber and stumpage prices in Ohio. Wood and Fiber Science. 30(3):281-292.

Luppold, W.G. and Bumgardner, M.S. 2009. Timber value issues resulting from harvest activity in Appalachian forests. Pp. 116-122 in: Siry, J., B. Izlar, P. Bettinger, T. Harris, T. Tye, S. Baldwin, and K. Merry, editors. Proceedings of the 2008 Southern Forest Economics Workers Annual Meeting, March 9-11, 2008. Savannah, GA. Univ. of Ga. Center for Business Publication No. 30.

Marquis, D.A. and Ernst, R.L. 1991. The effects of stand structure after thinning on the growth of an Allegheny hardwood stand. For. Sci. 37(4):1182-1200.

McCauley, O.D. and Trimble, Jr., G.R. 1972. Forest returns evaluated for uneven-aged management in two Appalachian woodlots. USDA For. Serv. Northeastern For. Exp. Sta. Res. Pap. NE-244. 12 p.

McGill, D.W., Pierskalla, C.D., Jennings, B.M., Grushecky, S.T., and Lilly, D. 2006. Landowner satisfaction with timber harvesting on West Virginia Forest Stewardship Program properties. NJAF 23(1):6-10.

Miller, G.W. 1993. Financial aspects of partial cutting practices in central Appalachian hardwoods. USDA For. Serv. Northeastern Exp. Sta. Res. Pap. NE-673. 9 p.

Miller, G.W., Hanks, L.F., and Wiant, H.V. 1986. A key for the Forest Service hardwood tree grades. NJAF 3:19-22. 
Miller, G.W. and Smith, H.C. 1991. Comparing partial cutting practices in central Appalachian hardwoods. Pp. 105-119 in McCormick, L.H. and K.W. Gottschalk, eds. Proceedings, $8^{\text {th }}$ Central Hardwood Forest Conference. USDA For. Serv. Northeastern For. Exp. Sta. Gen. Tech. Rep. NE-148.

Munn, I.A. 1996. Public, private, expert, layman: who's selling makes a difference. Pp. 386-393 in: Proceedings of the Symposium on Nonindustrial Private Forests: Learning from the Past, Prospects for the Future, February 18-20, 1996, Washington, DC.

Nyland, R.D. 1992. Exploitation and greed in eastern hardwood forests. J. For. 90(1):33-37.

Nyland, R.D. 2001. Forestry and silviculture in the northeast - past, present, and the probable future. Pp. 319-325 in Proceedings of the Society of American Foresters 2000 National Convention, November 16-20, 2000, Washington, DC.

Nyland, R.D. 2006. Diameter-limit cutting and silviculture in northern hardwoods. Pp. 16-23 in: Kenefic, L.S. and Nyland, R.D., editors, Proceedings of the Conference on DiameterLimit Cutting in Northeastern Forests. USDA For. Serv. Northeastern Res. Sta. Gen. Tech. Rep. NE-342.

Nyland, R.D. and Gabriel, W.J. 1971. Logging damage to partially cut hardwood stands in New York State. State Univ., Coll. of For., Syracuse Univ. AFRI Res. Pap. 5.38 p.

Ohman, J.H. 1970. Value loss from skidding wounds in sugar maple and yellow birch. J. For. 68:226-230.

Olson, D.D. 1979. Realities of nonindustrial private forest ownership in northern Michigan. J. For. 77(1):17-18.

Pelkki, M.H. and Gracey, E. 1998. NIPF management in Kentucky: is the primacy of timber management really passé? Pp. 5-9 in: Proceedings of the Southern Forest Economics Workgroup Annual Meeting, Kluender, R., M. Corrigan, and N. Smith, editors, March 19-21, 1997, Little Rock, AR.

Pell, J.A. 1998. Variables characterizing timber resource sustainability of recently harvested tracts across Pennsylvania. M.S. thesis. The Pennsylvania State University, University Park.

Reed, D.D., Holmes, M.J., and Johnson, J.A. 1986. A 22-year study of stand development and financial return in northern hardwoods. NJAF 3:35-38.

Schuler, T.M. and Gillespie, A.R. 2000. Temporal patterns of woody species diversity in a central Appalachian forest from 1856 to 1997. J. Torrey Bot. Soc. 127:149-161. 
Smith, H.C., Trimble, Jr., G.R., and DeBald, P.S. 1979. Raise cutting diameters for increased returns. USDA For. Serv. Northeastern For. Exp. Sta. Res. Pap. NE-445. 7 p.

Smith, H.C. and Miller, G.W. 1987. Managing Appalachian hardwood stands using four regeneration practices: 34 year results. NJAF 4:180-185.

Smith, H.C., Miller, G.W., and Schuler, T.M. 1994. Closure of logging wounds after 10 years. USDA For. Serv. Northeastern For. Exp. Sta. Res. Pap. NE-692.

Teck, R.M. and Hilt, D.E. 1991. Individual-tree diameter growth model for the northeastern United States. USDA Forest Service Northeastern Forest Exp. Sta. Res. Pap. NE-649.

Trimble, Jr., G.R. 1969. Diameter growth of individual hardwood trees. USDA For. Serv. Northeastern For. Exp. Sta. Res. Pap. NE-145. 25 p.

Vicary, B.P. 2006. Discount rates and timberland investments. Timberland Report Vol. 8 No. 3. James W. Sewell Company. Old Town, ME.

Wang, J. and LeDoux, C.B. 2003. Estimating and validating ground-based timber harvesting production through computer simulation. For. Sci. 49(1):64-76.

Wang, J., Long, C., McNeel, J., and Baumgras, J. 2004. Productivity and cost of manual felling and cable skidding in central Appalachian hardwood forests. For. Prod. J. 54(12):45-51.

Wang, J. Spong, B., and McNeel, J. 2007. Timber harvesting production and cost analysis workshop. West Virginia University Division of Forestry \& Natural Resources, Morgantown, WV. June 1, 2007.

Wang, J. and Spong, B. 2010. Personal communications, October 2010.

Wiant, H.V. 1989. Local volume tables for West Virginia species. The Consultant 4:79-80.

Widmann, R.H., Butler, B.J., and Cook, G.W. 2010. West Virginia's forest resources, 2008. USDA For. Serv. Northern Res. Sta. Res. Note NRS-61. 4 p. 


\section{APPENDIX A}

Regression Equations to Predict DBH from Stump Diameter 


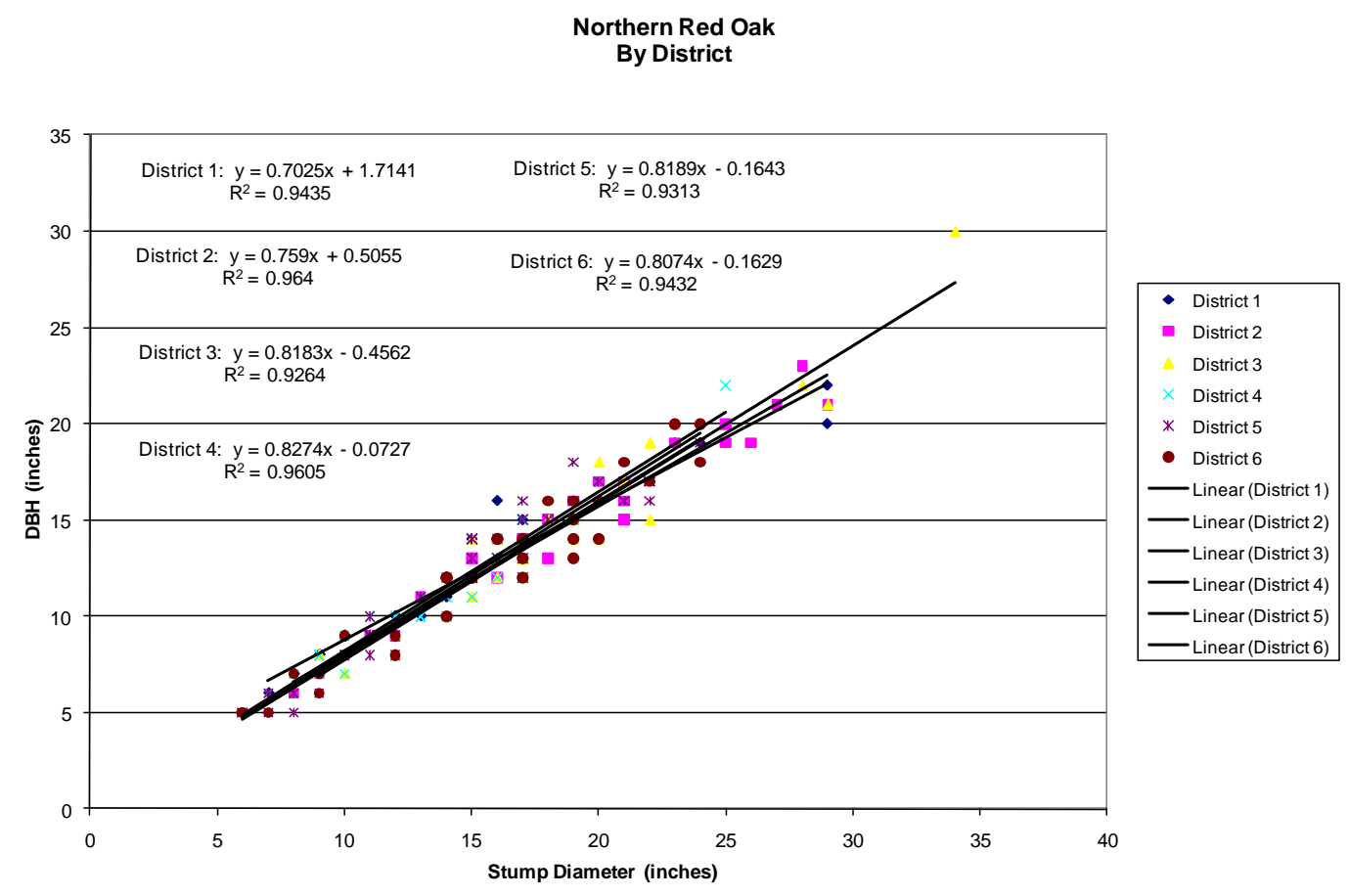

Figure A-1. Linear regression equations to predict DBH from stump diameter for northern red oak for each of the six WVDOF districts in West Virginia.

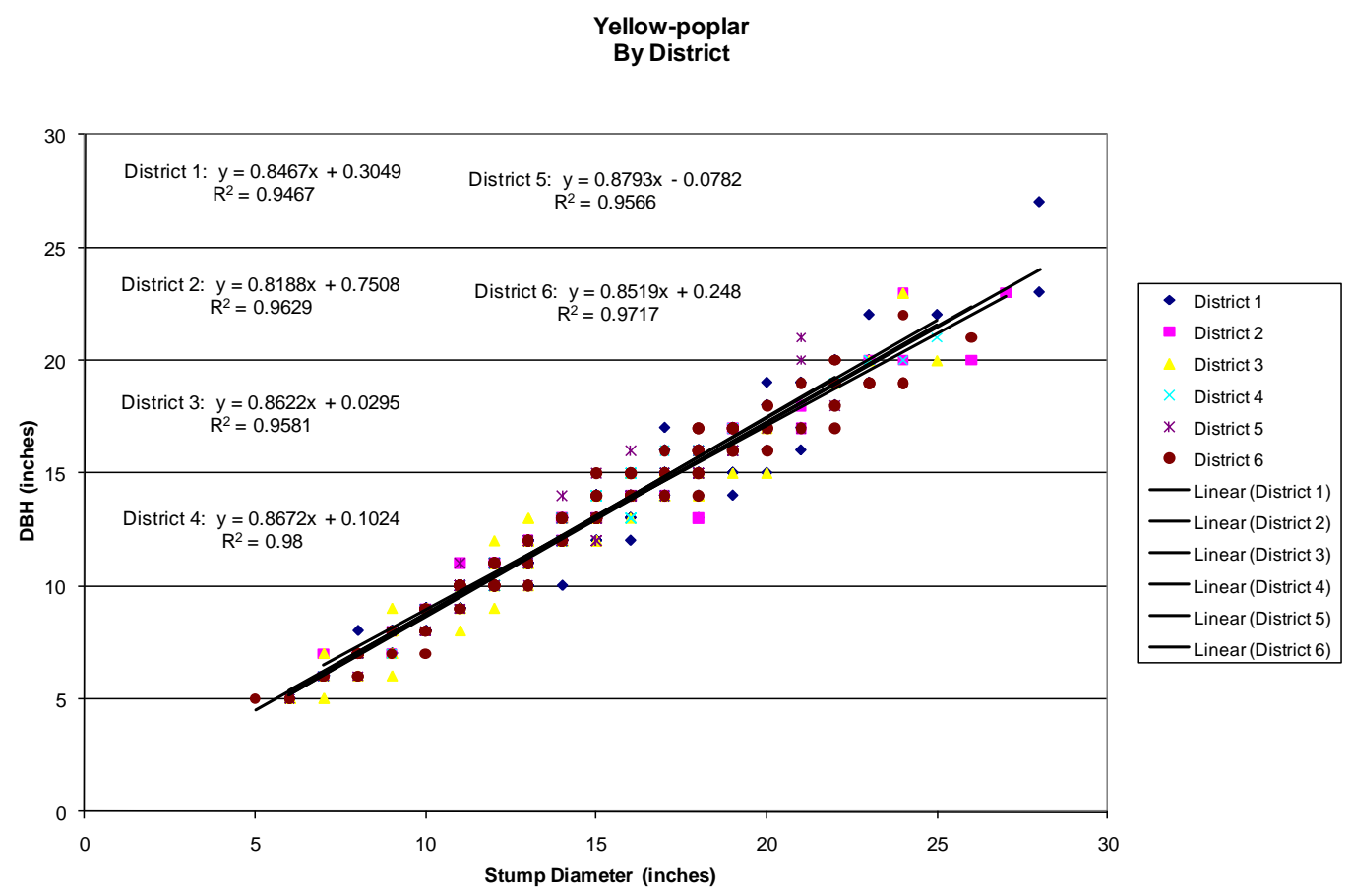

Figure A-2. Linear regression equations to predict DBH from stump diameter for yellow-poplar for each of the six WVDOF districts in West Virginia. 


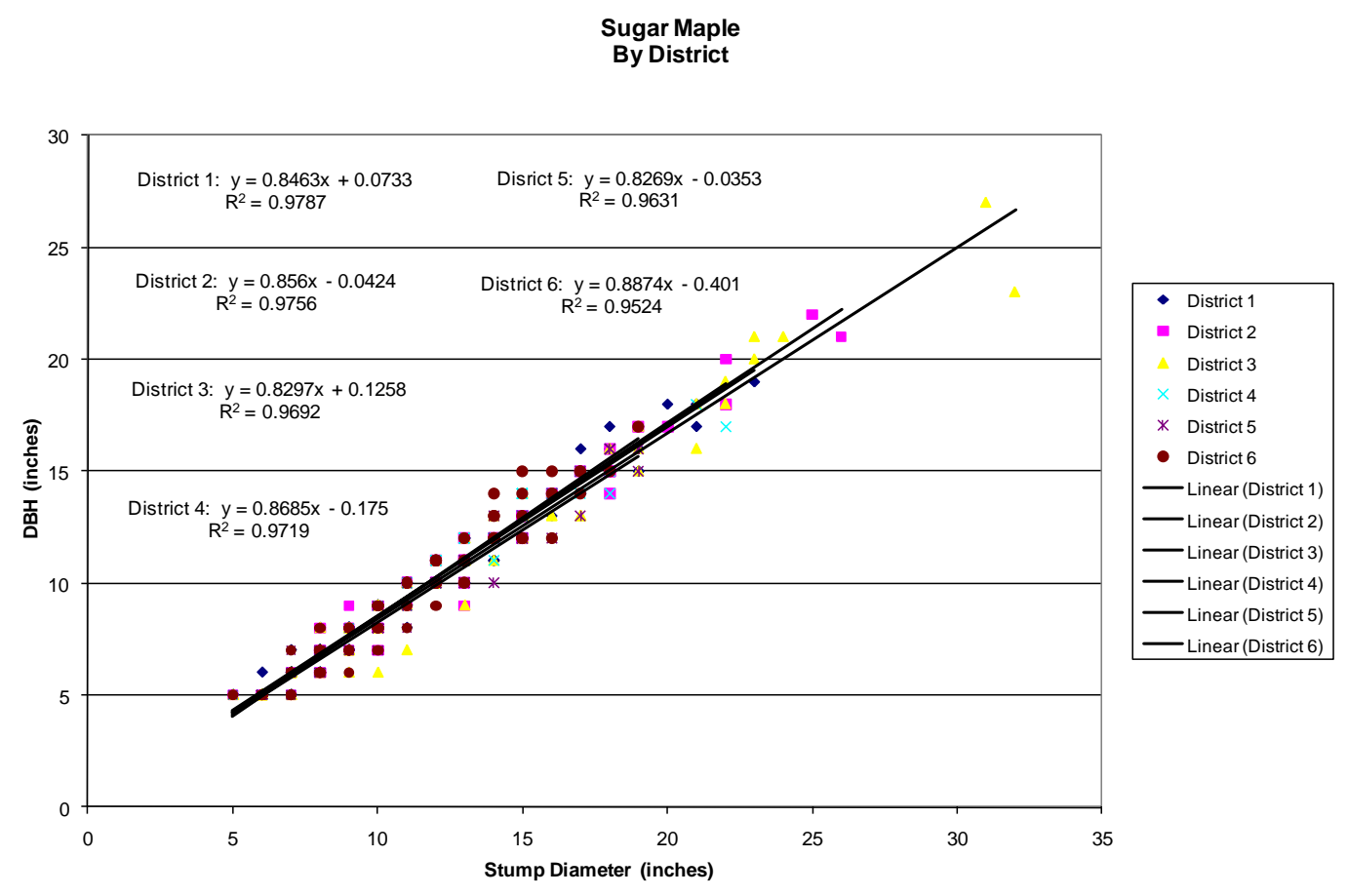

Figure A-3. Linear regression equations to predict DBH from stump diameter for sugar maple for each of the six WVDOF districts in West Virginia.

Table A-1. Linear regression equations to predict DBH from stump diameter for various species in West Virginia.

\begin{tabular}{|l|c|c|}
\hline Species & Prediction Equation & $\mathrm{R}^{2}$ \\
\hline \hline American Beech & $\mathrm{D}=0.8260^{*} \mathrm{~S}+0.0910$ & 0.97 \\
\hline Ash spp. & $\mathrm{D}=0.8128^{*} \mathrm{~S}+0.4281$ & 0.96 \\
\hline Basswood & $\mathrm{D}=0.8574^{*} \mathrm{~S}+0.2039$ & 0.97 \\
\hline Black Cherry & $\mathrm{D}=0.8875^{*} \mathrm{~S}-0.0771$ & 0.98 \\
\hline Black Locust & $\mathrm{D}=0.8799^{*} \mathrm{~S}-0.0223$ & 0.96 \\
\hline Black Oak & $\mathrm{D}=0.7913^{*} \mathrm{~S}+0.4345$ & 0.93 \\
\hline Blackgum & $\mathrm{D}=0.8588^{*} \mathrm{~S}-0.3739$ & 0.95 \\
\hline Chestnut Oak & $\mathrm{D}=0.7838^{*} \mathrm{~S}+0.5273$ & 0.93 \\
\hline Cucumbertree & $\mathrm{D}=0.8252^{*} \mathrm{~S}+0.4696$ & 0.95 \\
\hline Eastern Hemlock & $\mathrm{D}=0.8210^{*} \mathrm{~S}+0.0359$ & 0.98 \\
\hline Eastern White Pine & $\mathrm{D}=0.8395^{*} \mathrm{~S}-0.1942$ & 0.98 \\
\hline Hickory spp. & $\mathrm{D}=0.8242^{*} \mathrm{~S}-0.1274$ & 0.95 \\
\hline Northern Red Oak & $\mathrm{D}=0.7782^{*} \mathrm{~S}+0.3796$ & 0.95 \\
\hline Other Hardwoods & $\mathrm{D}=0.8560^{*} \mathrm{~S}-0.0326$ & 0.94 \\
\hline Red Maple & $\mathrm{D}=0.8629^{*} \mathrm{~S}-0.0035$ & 0.97 \\
\hline Scarlet Oak & $\mathrm{D}=0.8100^{*} \mathrm{~S}-0.1767$ & 0.92 \\
\hline Sugar Maple & $\mathrm{D}=0.8508^{*} \mathrm{~S}-0.0501$ & 0.97 \\
\hline Sweet Birch & $\mathrm{D}=0.8023^{*} \mathrm{~S}+0.4224$ & 0.96 \\
\hline White Oak & $\mathrm{D}=0.7804^{*} \mathrm{~S}-0.0271$ & 0.93 \\
\hline Yellow Pine spp. & $\mathrm{D}=0.8866^{*} \mathrm{~S}-0.6555$ & 0.96 \\
\hline Yellow-poplar & $\mathrm{D}=0.8543^{*} \mathrm{~S}+0.2083$ & 0.96 \\
\hline
\end{tabular}

$D=$ predicted diameter at breast height $(D B H)$ in inches

$S=$ average stump diameter in inches 


\section{APPENDIX B}

Indicated Stumpage Prices by Species, Tree Grade and DBH 


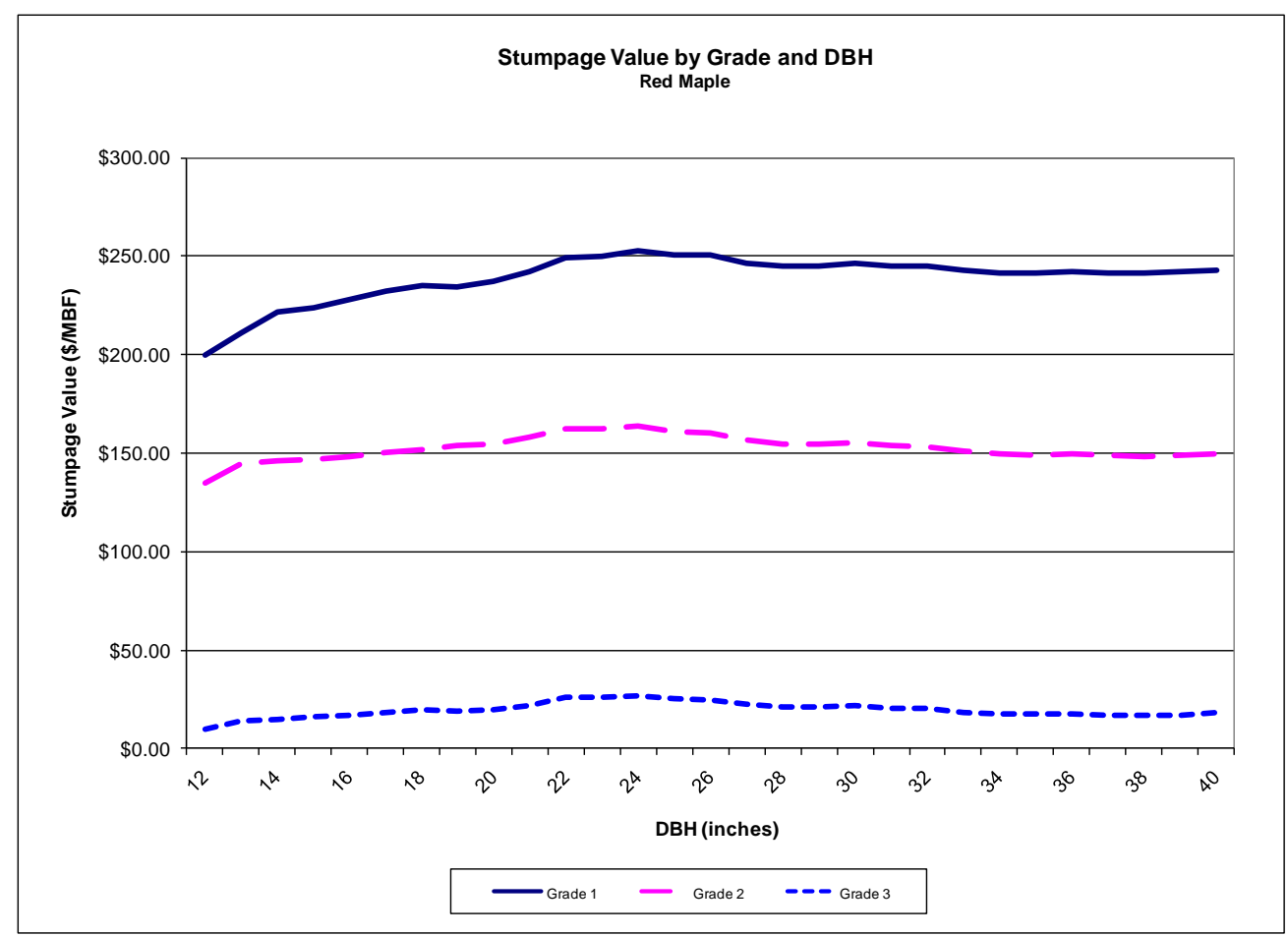

Figure B-1. Indicated stumpage value by tree DBH and Forest Service tree grade for red maple in West Virginia during the summer of 2007.

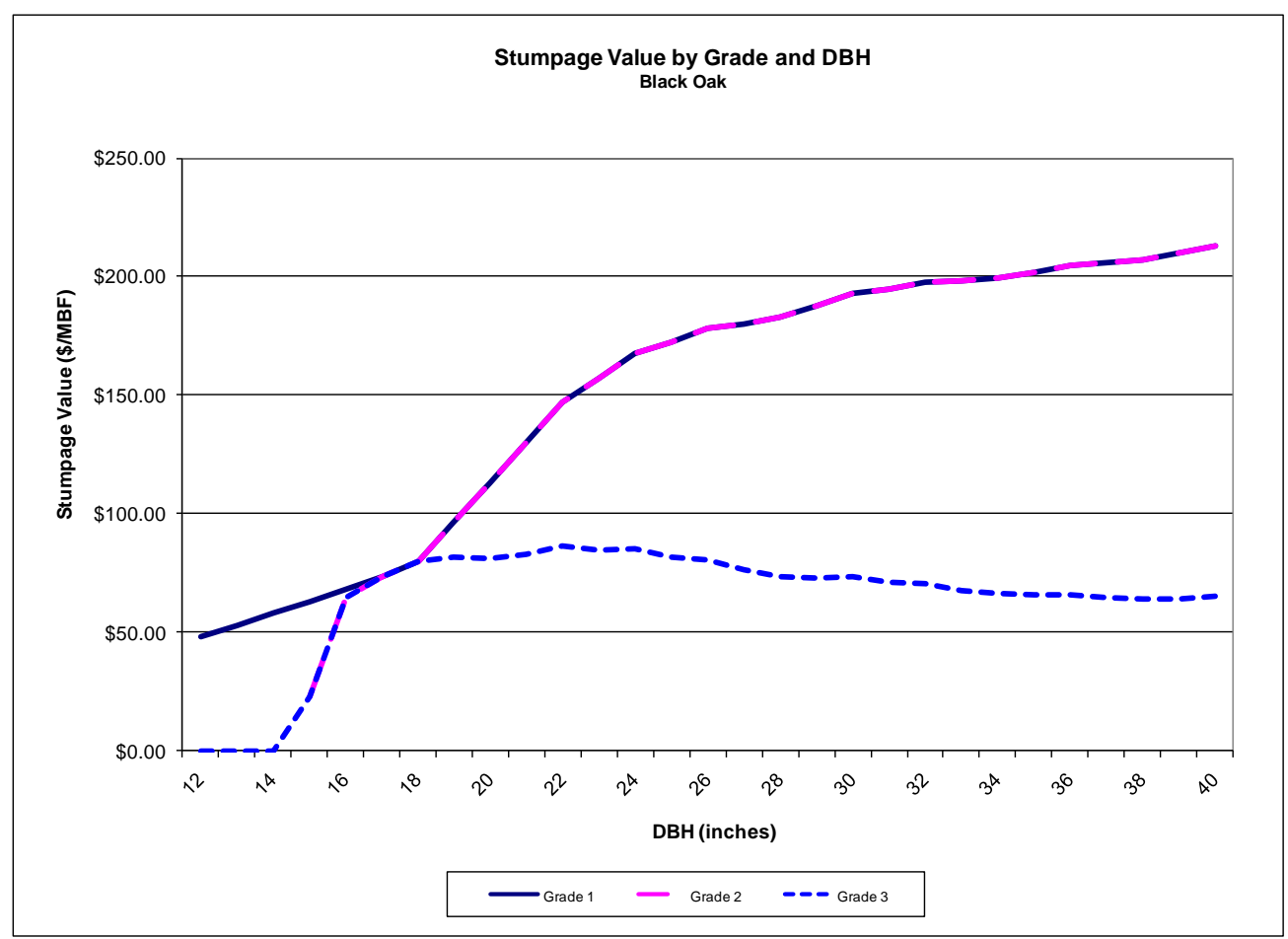

Figure B-2. Indicated stumpage value by tree DBH and Forest Service tree grade for black oak in West Virginia during the summer of 2007. 


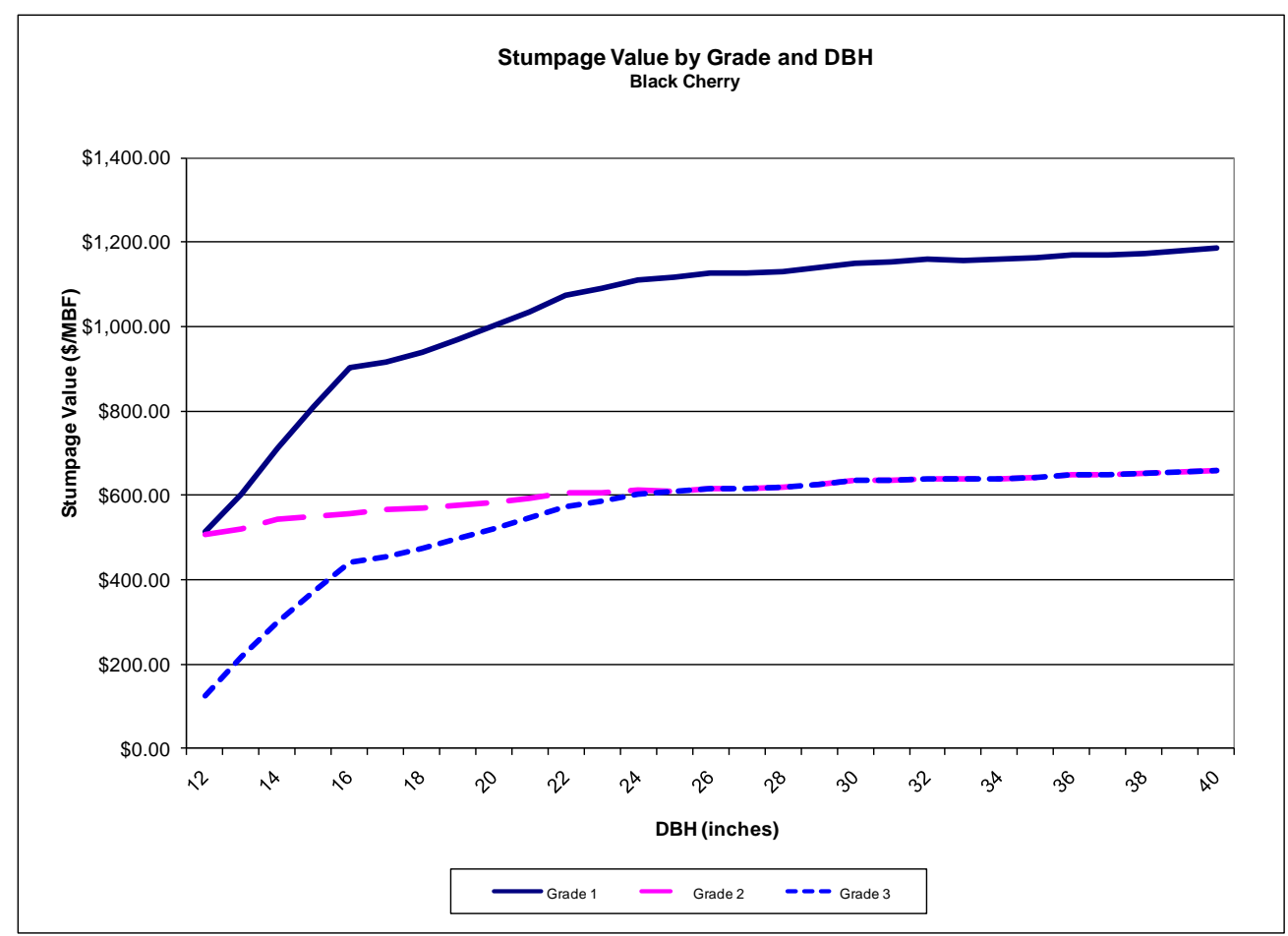

Figure B-3. Indicated stumpage value by tree DBH and Forest Service tree grade for black cherry in West Virginia during the summer of 2007.

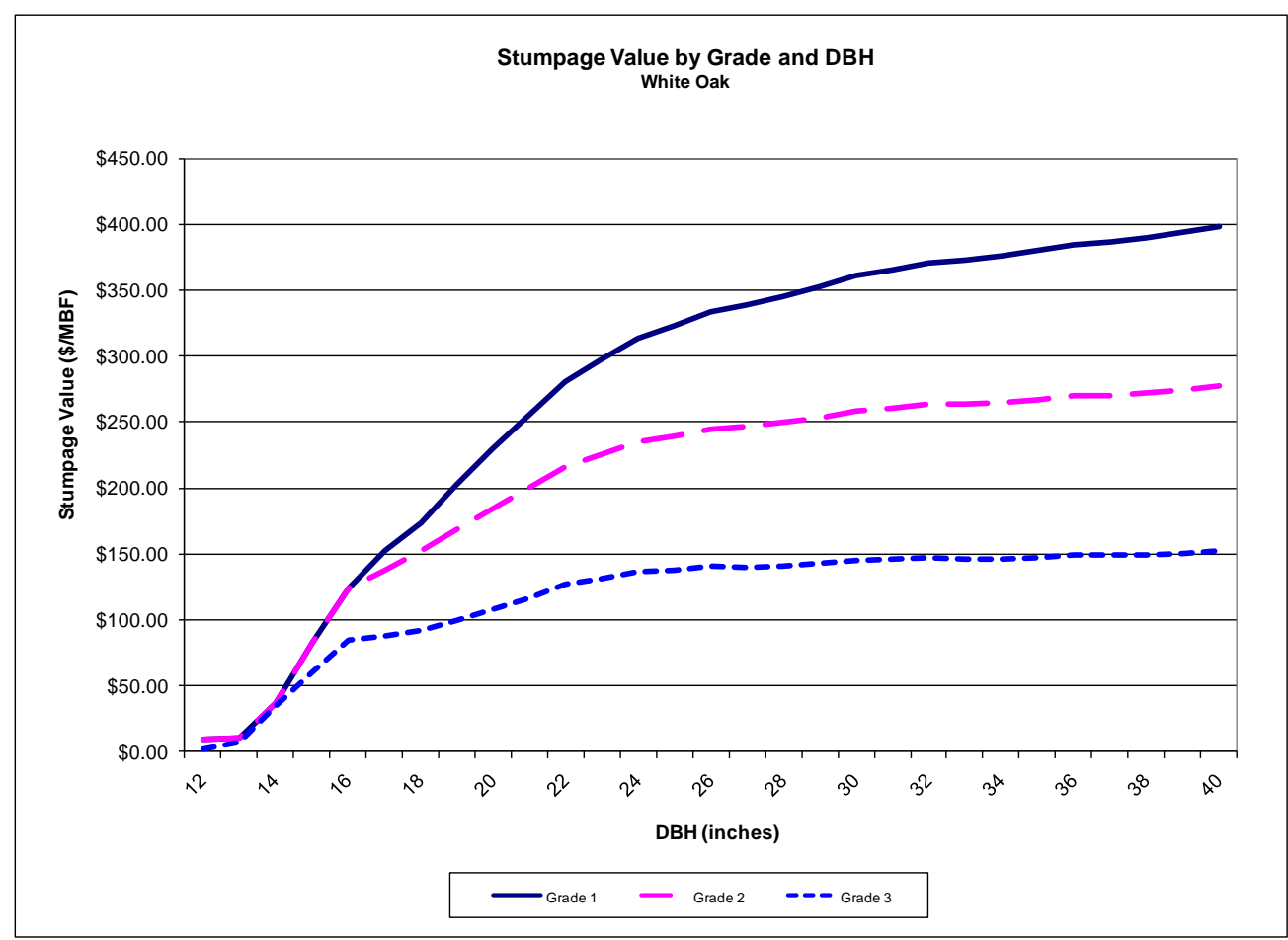

Figure B-4. Indicated stumpage value by tree DBH and Forest Service tree grade for white oak in West Virginia during the summer of 2007. 


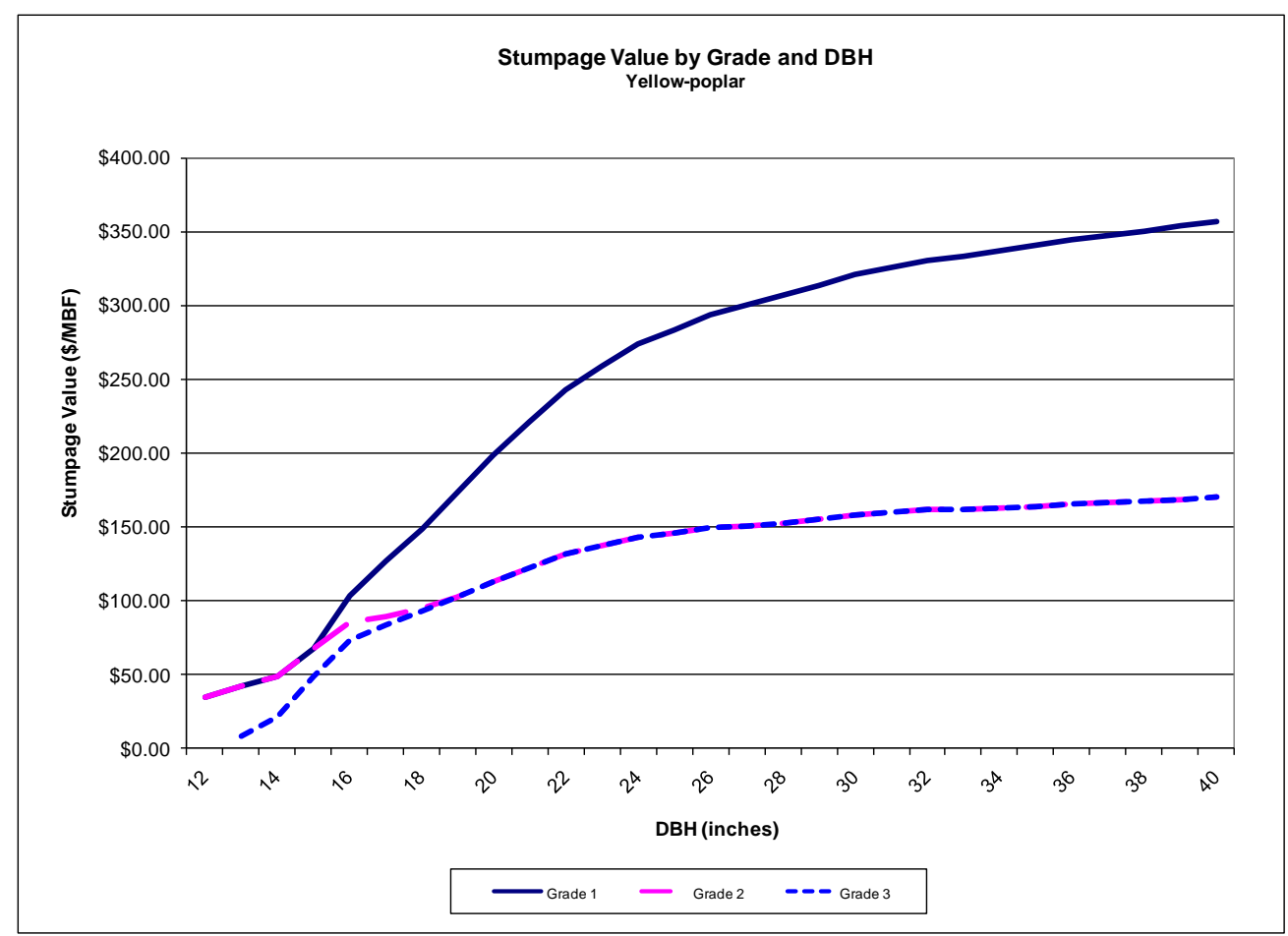

Figure B-5. Indicated stumpage value by tree DBH and Forest Service tree grade for yellow-poplar in West Virginia during the summer of 2007.

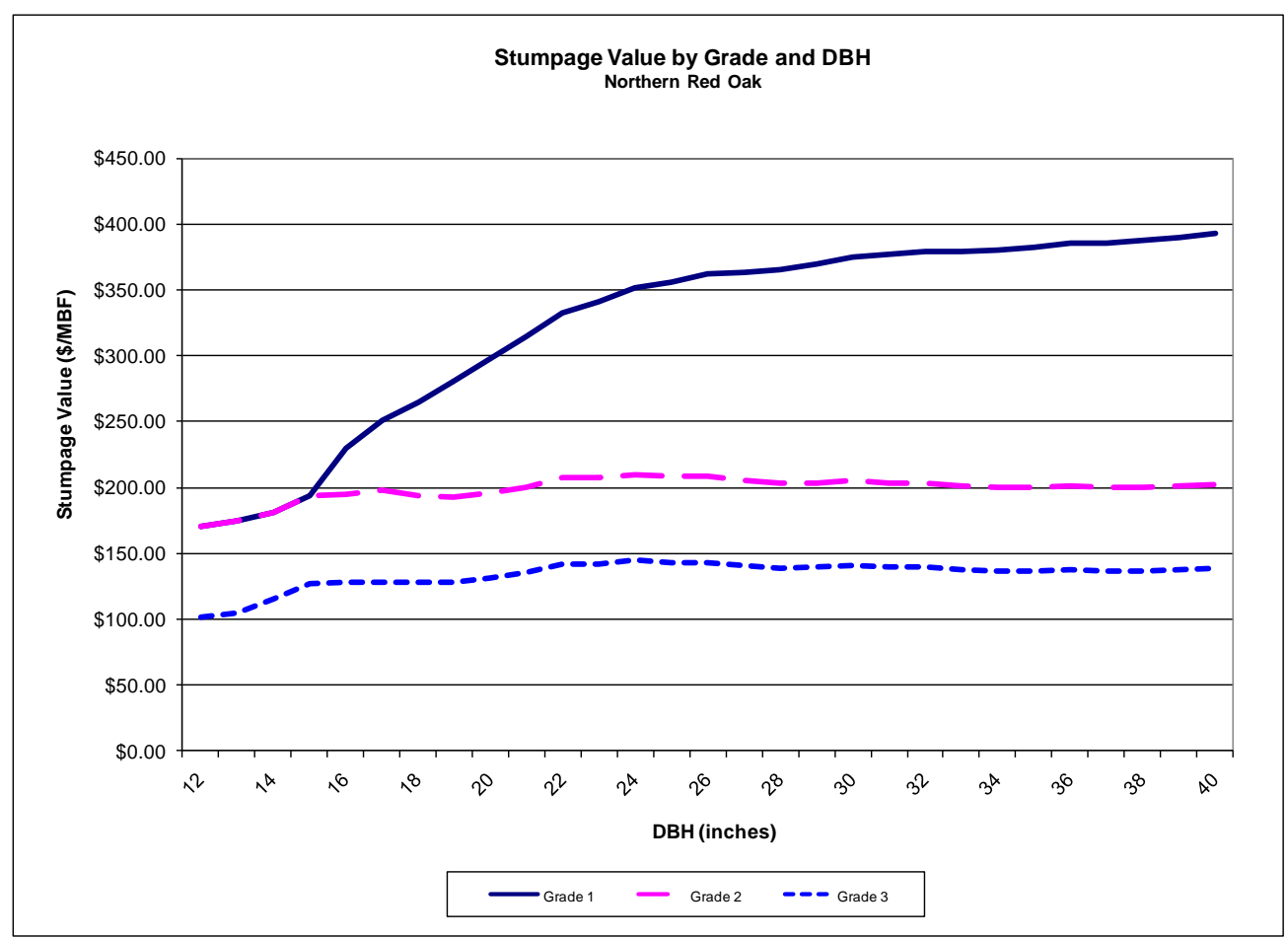

Figure B-6. Indicated stumpage value by tree DBH and Forest Service tree grade for northern red oak in West Virginia during the summer of 2007. 


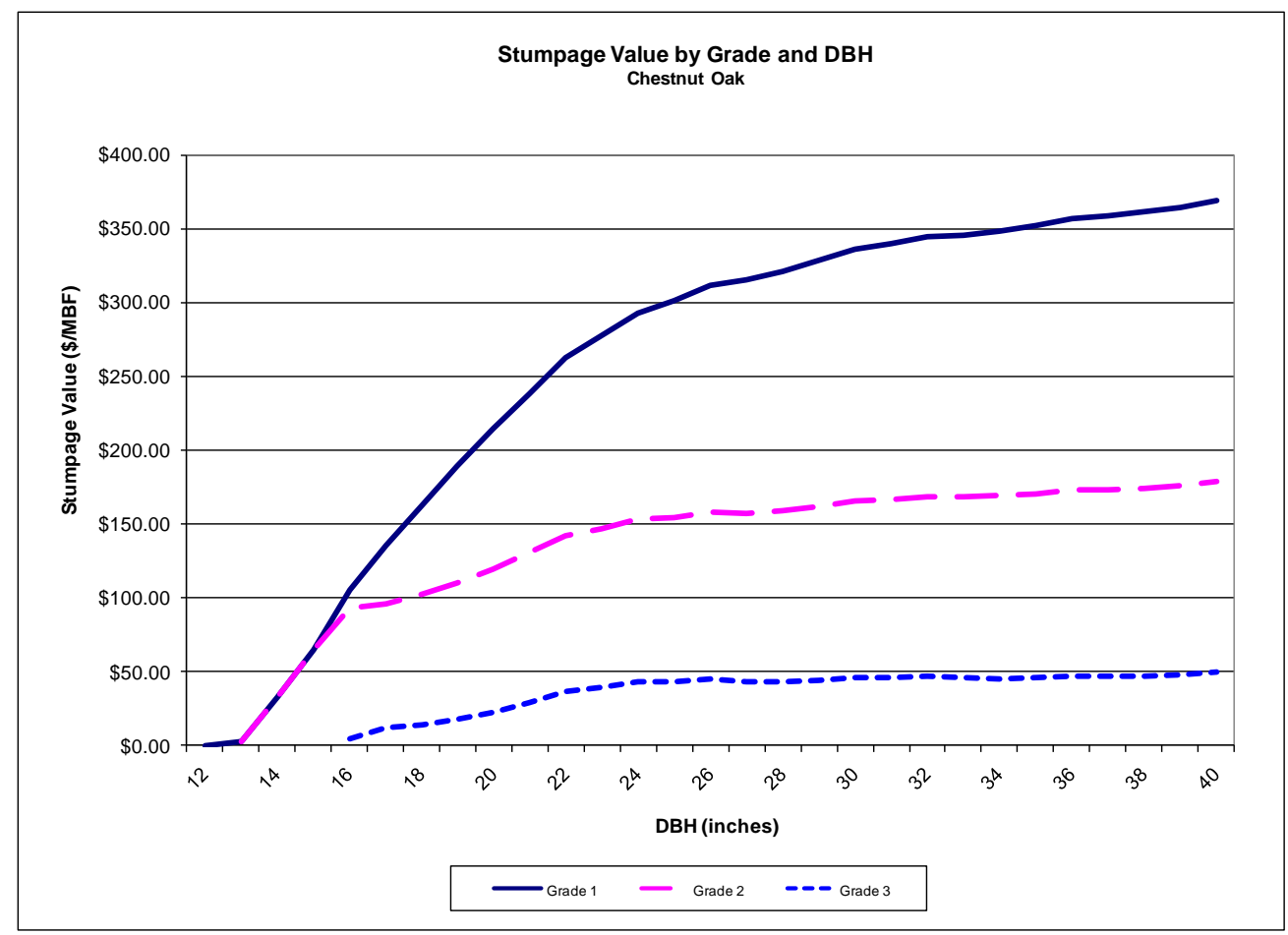

Figure B-7. Indicated stumpage value by tree DBH and Forest Service tree grade for chestnut oak in West Virginia during the summer of 2007.

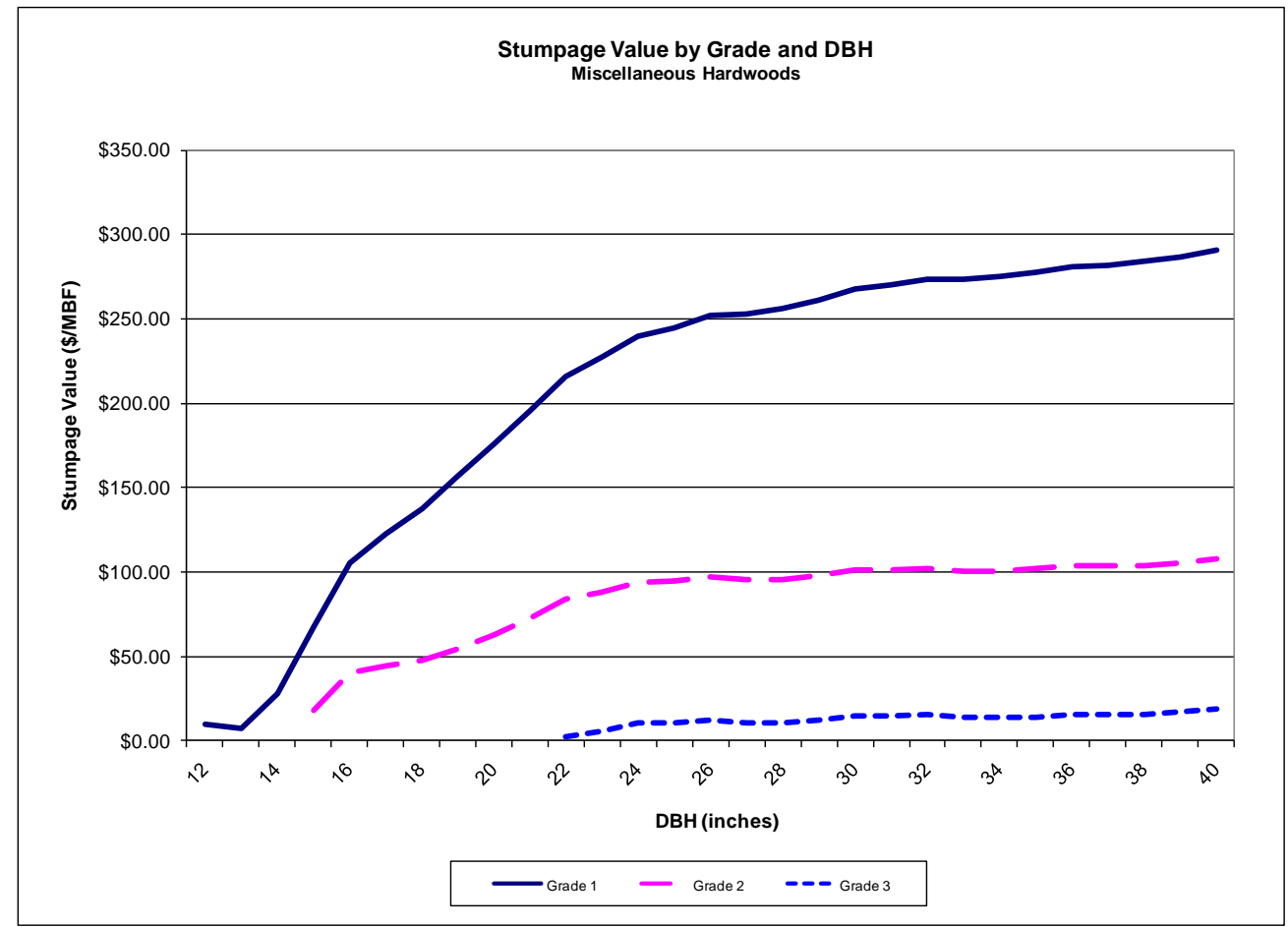

Figure B-8. Indicated stumpage value by tree DBH and Forest Service tree grade for miscellaneous hardwoods in West Virginia during the summer of 2007. 


\section{APPENDIX C}

Sample Screen for the Central Appalachian Harvesting Analyzer 


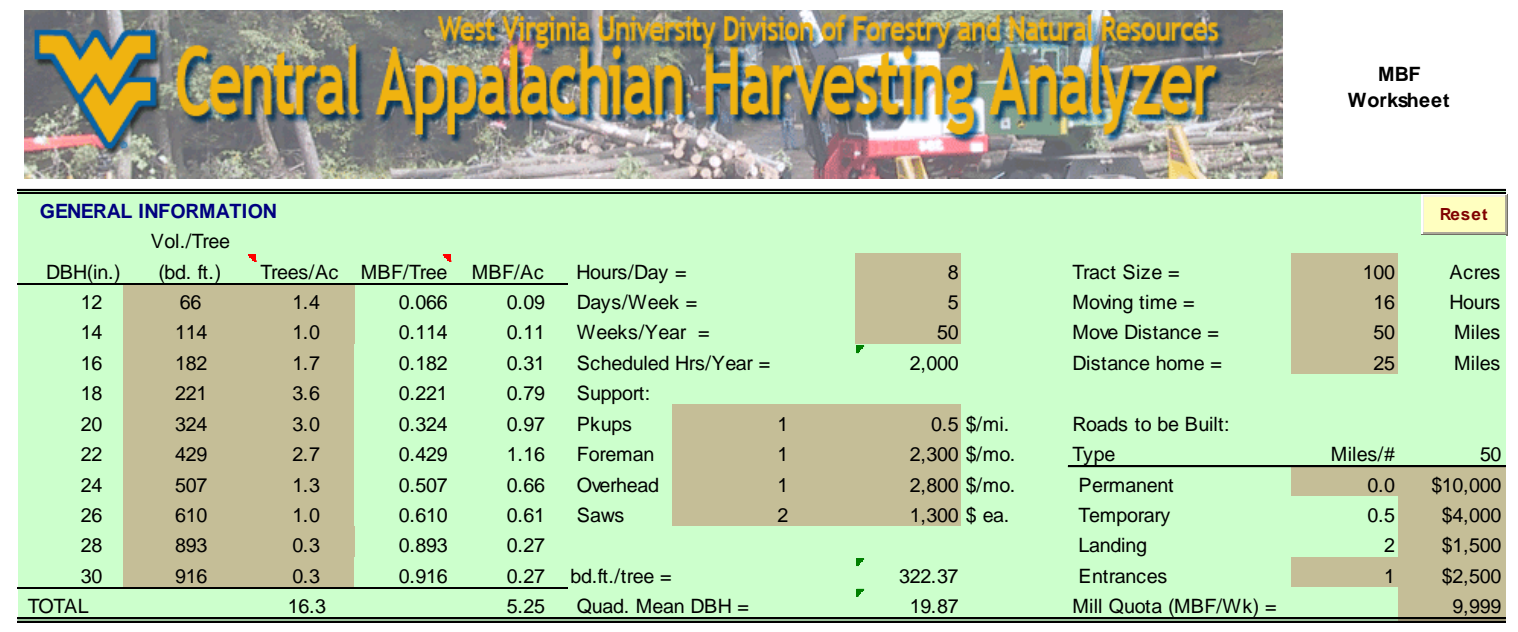

\begin{tabular}{|c|c|c|c|c|c|c|c|c|c|c|c|c|}
\hline \multicolumn{13}{|c|}{ MACHINES } \\
\hline \multirow[t]{2}{*}{ Felling } & Chainsaw & $\mp$ & & Extraction & Cable sk & 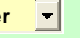 & Loading & Loader & $\nabla$ & Hauling & Long log tru & ck \\
\hline & & & \multicolumn{7}{|c|}{ Machine Productivity } & \multicolumn{3}{|r|}{ Reset } \\
\hline dist/tree, $f t=$ & MHT & Min/Tree & \multicolumn{3}{|c|}{$\begin{array}{l}\text { Avg Extraction Dist } \\
\text { (feet) }=\end{array}$} & 1,000 & \multicolumn{2}{|c|}{$\begin{array}{l}\text { Prep. Time = } \\
\text { Product Type = }\end{array}$} & $\begin{array}{r}11.83 \\
\text { Sawlogs } \\
24.71\end{array}$ & \multicolumn{2}{|c|}{$\begin{array}{l}\text { Haul Distance } \\
(\text { miles })=\end{array}$} & 40 \\
\hline 12 & 66.4 & 0.35 & 0.01 & \multirow{3}{*}{\multicolumn{2}{|c|}{$(\mathrm{MBF})=$}} & 0.60 & & & 6.31 & \multicolumn{2}{|c|}{$\begin{array}{c}\text { Average Speed } \\
(\mathrm{mph})=\end{array}$} & 40 \\
\hline 14 & 114.1 & 1.29 & 0.02 & & & & & & & \multicolumn{2}{|c|}{ Load Size } & \\
\hline 16 & 182.4 & 2.23 & 0.06 & & & & & & & \multirow{2}{*}{\multicolumn{2}{|c|}{$\begin{array}{c}(\mathrm{MBF})= \\
\text { Unloading Time }\end{array}$}} & 2.60 \\
\hline 18 & 220.5 & 3.16 & 0.19 & \multirow{3}{*}{\multicolumn{2}{|c|}{$\begin{array}{c}\text { Time per Turn } \\
\text { (minutes) }=\end{array}$}} & & \multirow{2}{*}{\multicolumn{2}{|c|}{ Time per Load }} & & & & \\
\hline 20 & 324.2 & 4.10 & 0.21 & & & & & & & \multicolumn{2}{|c|}{ (minutes) $=$} & 30.00 \\
\hline 22 & 429.4 & 5.04 & 0.23 & & & 17.17 & $(\min$ & utes) $=$ & 18.14 & Loading & g Time & \\
\hline 24 & 506.7 & 5.98 & 0.13 & & & & & & & $(\min u$ & utes) $=$ & 18.14 \\
\hline 26 & 610.4 & 6.92 & 0.12 & & & & & & & & & \\
\hline 28 & 892.7 & 7.85 & 0.04 & & & & & & & & & \\
\hline 30 & 915.7 & 8.79 & 0.04 & & & & & & & Round & Trip Time & \\
\hline TOTAL & & & 1.04 & & & & & & & & (rs) $=$ & 2.80 \\
\hline $\mathrm{MBF} / \mathrm{PMH}$ & & & 5.04 & & & 2.10 & & & 8.60 & & & 0.93 \\
\hline Oper Effy & & & 0.8 & & & 0.8 & & & 0.8 & & & 1.0 \\
\hline & & & & & & chine Co & & & & & & \\
\hline & & & Felling cost & & & ion cost & & & Loading cost & & System Balance & Reset \\
\hline Depreciati & $\operatorname{tion}(\$ / S M H)=$ & & $\$ 0.26$ & & & $\$ 10.40$ & & & $\$ 9.94$ & Haul $\mathrm{R}$ & & \\
\hline Interest in & nsur.\&taxes $(\$ / S$ & $M H)=$ & $\$ 0.06$ & & & $\$ 8.94$ & & & $\$ 6.83$ & & nile $)=$ & $\$ 4.00$ \\
\hline Total Fix & xed Cost $(\$ / S M r$ & & $\$ 0.32$ & & & $\$ 19.34$ & & & $\$ 16.77$ & & & \\
\hline Fuel\&Lube & oe $(\$ / P M H)=$ & & $\$ 0.90$ & & & $\$ 13.40$ & & & $\$ 1.39$ & & & \\
\hline Maint.\&Re & Repair $(\$ / P M H)=$ & & $\$ 0.51$ & & & $\$ 14.40$ & & & $\$ 16.26$ & & & \\
\hline Total Var & Iriable cost $(\$ / S$ & MH) & $\$ 0.92$ & & & $\$ 19.18$ & & & $\$ 15.00$ & & & \\
\hline Labor $(\$ / S I$ & $S M H)=$ & & $\$ 12.00$ & & & $\$ 12.00$ & & & $\$ 12.00$ & & & \\
\hline Labor fring & ge $(\%)=$ & & $40 \%$ & & & $40 \%$ & & & $40 \%$ & & & \\
\hline Mechanic & cal Availability $\%$ & & $65 \%$ & & & $69 \%$ & & & $85 \%$ & & & $90 \%$ \\
\hline No. of $\mathrm{mac}$ & achine $=$ & & 1 & & & 2 & & & 1 & & & \\
\hline SYSTEM & & & & & & & & & & & & \\
\hline Function & & & MBF/PMH & Mech & & & Utiliz & & Cost per SM & & & Cost \\
\hline & & & & Avail\% & One & All & & Fixe & Ope & Labor & Total & $\$ / M B F$ \\
\hline Felling & & & 4.03 & $65 \%$ & 2.62 & 2.62 & $57 \%$ & 0.3 & 0.81 & 16.80 & 17.93 & 7.75 \\
\hline Extraction & & & 1.68 & $69 \%$ & 1.16 & 2.31 & $69 \%$ & 38.6 & 38.36 & 33.60 & 110.64 & 47.81 \\
\hline Loading & & & 6.88 & $85 \%$ & 5.85 & 5.85 & $34 \%$ & 16.7 & 5.94 & 16.80 & 39.51 & 17.07 \\
\hline Hauling & & & 0.93 & $90 \%$ & 0.84 & & & & & & & 61.54 \\
\hline Support & & & Pickups, $\mathrm{C}$ & Chainsaws, & oreman, an & erhead & & & & & & 15.14 \\
\hline Road Wor & & & & & & & & & & & & 14.27 \\
\hline Moving & & & $16.00 \mathrm{r}$ & hours spent & moving men & quipment & & & & & & 5.27 \\
\hline System R & Rate (MBF/SMH & & & 2.31 & & & & & Onboard Co & st/MBF: & $\$ 107$ & \\
\hline $\begin{array}{l}\text { Daily prod } \\
\text { Days requ }\end{array}$ & duction (MBF, tr & uck loads) & & 18.5 & $(\mathrm{MBF})=$ & & k loads) & & & & & \\
\hline Days requ & fuired to harvest & ract $=$ & & 29 & & & & & Cut $\&$ haul & ost/MBF: & $\$ 169$ & \\
\hline
\end{tabular}




\section{APPENDIX D}

\section{Landowner Post-Harvest Survey}


Please indicate your level of satisfaction with each of the following items by marking the appropriate box:

1) Price received for your timber:

Completely Satisfied

Mostly Satisfied

Mostly Unsatisfied

Completely Unsatisfied

2) Amount of timber harvested (too much? too little?):

Completely Satisfied

Mostly Satisfied

Mostly Unsatisfied

Completely Unsatisfied

3) Condition of roads following harvest:

Completely Satisfied

Mostly Satisfied

Mostly Unsatisfied

Completely Unsatisfied

4) Condition of trees remaining after harvest (quality, damage, etc.):

Completely Satisfied

Mostly Satisfied

Mostly Unsatisfied

Completely Unsatisfied

5) Time it took to complete the harvest and reclamation:

Completely Satisfied

Mostly Satisfied

Mostly Unsatisfied

Completely Unsatisfied

6) Professionalism of logger:

Completely Satisfied

Mostly Satisfied

Mostly Unsatisfied

Completely Unsatisfied

7) Professionalism of forester working for the buyer, if applicable:

Completely Satisfied

Mostly Satisfied

Mostly Unsatisfied

Completely Unsatisfied

8) Professionalism and quality of service provided by the consulting forester working for you, if applicable:

Completely Satisfied

Mostly Satisfied

Mostly Unsatisfied

Completely Unsatisfied

9) How well the harvest met your objectives:

Completely Satisfied

Mostly Satisfied

Mostly Unsatisfied

Completely Unsatisfied

10) Overall level of satisfaction with the harvest:

Completely Satisfied

Mostly Satisfied

Mostly Unsatisfied

Completely Unsatisfied 
Please indicate if you experienced any of the following problems or concerns, and their severity, by marking the appropriate box:

11) Roads were left in poor condition (inadequate drainage, rutting, etc.):
Not a problem
Minor problem
Serious problem

12) Roads are impassable due to improper water bar installation (too high):
Not a problem
Minor problem
Serious problem

13) Improper stream crossing or culvert installation:
Not a problem
Minor problem
Serious problem

14) Inadequate seeding and mulching of roads and landings:
Not a problem
Minor problem
Serious problem

15) Trees were cut that should have been left:
Not a problem
Minor problem
Serious problem

16) Trees were left that should have been cut:

Not a problem $\quad$ Minor problem $\quad$ Serious problem

17) Excessive damage to trees remaining after harvest:

Not a problem $\quad$ Minor problem $\quad$ Serious problem

18) Other damage to property, excluding roads and timber (e.g. gates, fences, etc.):

Not a problem Minor problem $\quad$ Serious problem

19) Concern about being paid for all the timber that was harvested:

Not a concern Minor concern Serious concern

20) Concern about the future of my forest (e.g. growth, quality) as a consequence of harvesting:

Not a concern Minor concern Serious concern

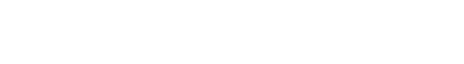

ou=Acquisitions Department 